\title{
Albania: Report on the Observance of Standards and Codes-Data Module, Response by the Authorities, and Detailed Assessments Using the Data Quality Assessment Framework
}

This Report on the Observance of Standard and Codes on Data Module for Albania was prepared by a staff team of the International Monetary Fund as background documentation for the periodic consultation with the member country. It is based on the information available at the time it was completed on October 20, 2006. The views expressed in this document are those of the staff team and do not necessarily reflect the views of the government of Albania or the Executive Board of the IMF.

The Response by the Authorities to this report, and the Detailed Assessments Using the Data Quality Assessment Framework (DQAF) are also included.

The policy of publication of staff reports and other documents by the IMF allows for the deletion of market-sensitive information.

To assist the IMF in evaluating the publication policy, reader comments are invited and may be sent by e-mail to publicationpolicy@imf.org.

Copies of this report are available to the public from

International Monetary Fund • Publication Services

$70019^{\text {th }}$ Street, N.W. • Washington, D.C. 20431

Telephone: (202) 623-7430 • Telefax: (202) 623-7201

E-mail: publications@imf.org • Internet: http://www.imf.org

Price: $\$ 18.00$ a copy

\section{International Monetary Fund} Washington, D.C. 

INTERNATIONAL MONETARY FUND

\author{
ALBANIA \\ Report on the Observance of Standards and Codes (ROSC)—Data Module \\ Prepared by the Statistics Department \\ Approved by Robert W. Edwards and Michael Deppler
}

October 20, 2006

The Report on the Observance of Standards and Codes (ROSC) data module provides an assessment of Albania's macroeconomic statistics against the recommendations of the General Data Dissemination System (GDDS) complemented by an assessment of data quality based on the IMF's Data Quality Assessment Framework (DQAF July 2003). The DQAF lays out internationally accepted practices in statistics, ranging from good governance in data-producing agencies to practices specific to datasets.

The datasets covered in this report are national accounts, consumer and producer price indices, and government finance, monetary, and balance of payments statistics. The agencies that compile the datasets assessed in this report are the Institute of Statistics, Ministry of Finance, and the Bank of Albania.

The datasets to which this report pertains can be accessed in print and on the Internet:

Institute of Statistics http://www.instat.gov.al

Ministry of Finance http://www.minfin.gov.al

Bank of Albania http://www.bankofalbania.org

This report is based on information provided prior to and during a staff mission from March 8-22, 2006 and publicly available information. The mission team was headed by Mrs. Armida San Jose, and also comprised Messrs. Gary Jones and René Piché, Mmes. Wipada Soonthornsima and Florina Tanase (all STA), Messrs. David Hughes and John Karlik (Experts), and Mrs. Heather A. Tzanninis (STA-Administrative Assistant). 
Contents

Page

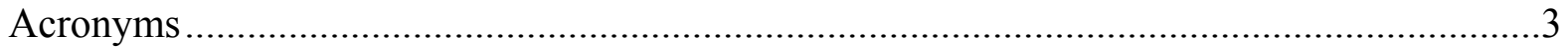

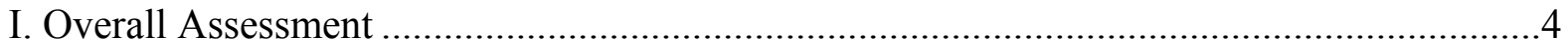

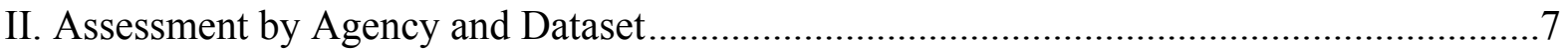

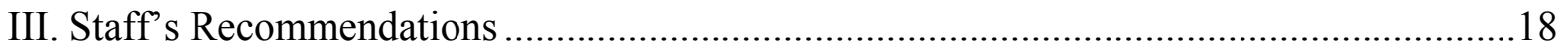

Tables

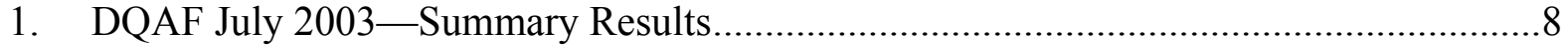

2a. Albania: Assessment of Data Quality-Dimensions 0 and 1-Institute of Statistics .......9

2b. Albania: Assessment of Data Quality-Dimensions 0 and 1-Ministry of Finance ......10

2c. Albania: Assessment of Data Quality_Dimensions 0 and 1-Bank of Albania............11

3a. Assessment of Data Quality-Dimensions 2 to 5-National Accounts.........................12

3b. Assessment of Data Quality-Dimensions 2 to 5-Consumer Price Index...................13

3c. Assessment of Data Quality-Dimensions 2 to 5-Producer Price Index.....................14

3d. Assessment of Data Quality-Dimensions 2 to 5-Government Finance Statistics ......15

3e. Assessment of Data Quality-Dimensions 2 to 5-Monetary Statistics........................16

3f. Assessment of Data Quality-Dimensions 2 to 5-Balance of Payments Statistics ......17

Appendix Table

Albania: Practices Compared to the GDDS Coverage Periodicity, and ...............................21 


\section{ACRONYMS}

1995 ESA

1993 SNA

ASYCUDA

BoA

BPM5

COFOG

COICOP

CPA

CPI

DQAF July 2003

DSBB

GDDS

GDP

GFS

GFSM 1986

GFSM 2001

HBS

IMF

INSTAT

ISWGNA

MFSM

$\mathrm{MoF}$

NACE

NAS

OBL

PPI

ROSC

SDDS

SLAs

STA

VAT
European System of Accounts 1995

System of National Accounts 1993

Automated Information System for Customs Data

Bank of Albania

Balance of Payments Statistics Manual, fifth edition

Classification of Functions of Government

Classification of Individual Consumption by Purpose

Classification of Products by Activity

Consumer Price Index

Data Quality Assessment Framework, July 2003 version

Dissemination Standards Bulletin Board

General Data Dissemination System

Gross Domestic Product

Government Finance Statistics

A Manual of Government Finance Statistics, 1986

Government Financial Statistics Manual 2001

Household Budget Survey

International Monetary Fund

Institute of Statistics

Intersecretariat Working Group on National Accounts

Monetary and Financial Statistics Manual

Ministry of Finance

Statistical Classification of Economic Activities in the European

Communities

National Accounts Section (INSTAT)

Organic Budget Law

Producer Price Index

Report on the Observance of Standards and Codes

Special Data Dissemination Standard

Savings and Loans Associations

IMF Statistics Department

Value Added Tax 


\section{Overall ASSESSMent}

1. Albania was among the first countries to participate in the General Data Dissemination System (GDDS), posting its metadata on the Dissemination Standards Bulletin Board (DSBB) on May 22, 2000. Its metadata have been used as a model by other countries participating in the GDDS. Albania meets all of the GDDS recommendations for coverage, periodicity, and timeliness, with the exception of the timeliness of national accounts statistics and the producer price index (PPI). In a number of data categories (consumer price index (CPI), general and central government operations, analytical accounts of the central bank, and balance of payments), the coverage, periodicity, and timeliness have reached the requirements of the Special Data Dissemination Standard (SDDS). Appendix I provides an overview of Albania's dissemination practices compared to the GDDS.

2. Albania was also one of the first countries to participate in piloting the data module for the Report on the Observance of Standards and Codes (ROSC)-prepared in 1999 and posted on the IMF website in May 2000. This March 2006 ROSC is a reassessment based on the subsequently developed Data Quality Assessment Framework (DQAF), dating from July 2003, which is the IMF's instrument for assessing national statistical systems. This data module (reassessment) ROSC contains the following main conclusions. Albania's statistical system has made significant progress in adopting international statistical standards despite acute resource constraints. The statistical agencies covered in this report - the Institute of Statistics (INSTAT), the Ministry of Finance (MoF), and the Bank of Albania (BoA) - have availed themselves of substantial technical assistance and staff training provided by numerous donors, including the IMF. Albania's official statistical agencies demonstrate strong and sustained commitment to pursuing plans and programs to further upgrade statistics in response to greater challenges posed by a rapidly evolving economy and the desire of the Albanian authorities to (i) subscribe to the SDDS; ii) adopt an inflation targeting regime; and iii) advance national aspirations to join the European Union. In several areas, Albania's macroeconomic statistics are adequate to conduct effective surveillance. Exceptions are national accounts, initiated only in 2000, and to a certain extent balance of payments statistics.

3. Owing to severe resource constraints at INSTAT, the improvement in the national accounts has been slower relative to other datasets and has barely kept pace with the increasing data needs for policymaking. INSTAT generally has made effective use of its limited resources but needs adequate and sustained financing to develop and maintain a pool of qualified staff and to undertake data collection programs vital for the compilation of methodologically sound, accurate, and timely national accounts statistics.

4. In applying the IMF's DQAF, the remainder of this section presents the mission's main conclusions at the level of the DQAF's quality dimensions, by agency for the first two dimensions and across datasets for the remaining four. Section II provides a summary assessment by agency and dataset based on a four-part scale. This is followed by staff recommendations in Section III. The authorities' response to this report and a volume of detailed assessments are presented in separate documents. 
5. Prerequisites of quality and Assurances of integrity. Institutional responsibility for the compilation and dissemination of the datasets covered in this report is clearly defined by the legal framework and established practices under which INSTAT, the MoF, and the BoA operate. These agencies-within their respective resource envelopes-endeavor to consult with data users and are active in organizing and/or participating in statistical meetings and seminars held in Albania and abroad. All agencies demonstrate notably high levels of data quality awareness, professionalism, transparency, and ethical standards.

- $\quad$ The legal framework for INSTAT as an independent government agency under the Council of Ministers has recently been strengthened with the adoption in 2004 of the Law On Official Statistics, which contains key elements of the United Nations' Fundamental Principles of Official Statistics. The law redefines the role of the Statistics Council as INSTAT's governing body; previously it only had an advisory function. The composition and selection of its members, and of the Director General of INSTAT, are specified in separate decisions of the Council of Ministers of 2005 and 2003, respectively. These provisions governed the recent appointments of the members of the Statistics Council and the new Director General for INSTAT. Weaknesses in data sharing and coordination are expected to be addressed with the signing of memorandums of understanding with other major data-producing agencies. Confidentiality of respondents' data is protected in the law and in practice. INSTAT's staff, working facilities, information technology, and financing resources are grossly inadequate to undertake its mandate. INSTAT encourages staff to focus on the efficient use of resources.

- $\quad$ The Organic Budget Law and the Guidelines on State Budget Performance clearly mandate the responsibility of the MoF for compiling and disseminating government finance statistics (GFS). These require compliance with reporting requirements and data confidentiality. Resources are inadequate to undertake current and planned statistical programs needed to improve monitoring of fiscal policy. The internal reorganization of functions at the MoF in November 2005 should be closely monitored to ensure that expected outputs and efficiencies in discharging duties are actually achieved.

- $\quad$ The BoA is, by tradition and by virtue of its authority to supervise the banking system, responsible for compiling and disseminating monetary statistics, although the BoA law does not specifically spell out this statistical mandate. The BoA has a statutory mandate for compiling balance of payments statistics, but effectiveness in this area is constrained because it has enforcement authority only over banks. Nonbank reporters of data are not subject to fines or other enforcement sanctions. Confidentiality of individual data is rigorously observed by the BoA in practice and through the BoA law, the Code of Ethics of the Bank of Albania, and the Regulation for Transparency and Confidentiality in the Bank of Albania. However, a provision in the BoA law (Article 58 (2)), stating that it may disclose individual reporters' data to tax authorities, should be reviewed and clarified so as not to cast doubt among data reporters and users on the BoA's strict adherence to data confidentiality. Staff resources are not adequate for balance of payments statistics. Staff resources for 
monetary statistics are adequate for current responsibilities but insufficient for the compilation of other financial statistics included in the BoA's short-term plans for improvement. Additional resources are needed for information technology support and integrated database development to further enhance the efficiency of statistical processes at the BoA.

6. Methodological soundness. Albanian macroeconomic statistics follow internationally accepted standards and guidelines on concepts and definitions. Although a formal "migration path" to the GFSM 2001 has not been formally articulated, several coordinated technical actions at the MoF-including the design and implementation of an accrual-compatible database infrastructure - are well advanced. Improvements could be made in expanding the scope of national accounts statistics and of the CPI. All datasets use adequate classification and sectorization. The basis for recording is appropriate for the PPI and for the GFS vis-à-vis the Government Finance Statistics Manual 1986 (GFSM 1986), but international standards are not fully applied in the other datasets.

7. Accuracy and reliability. Except for monetary statistics, source data have shortcomings in the datasets; they are particularly weak for national accounts and balance of payments statistics, which rely on both administrative records and surveys. Assessment of source data for both the CPI and PPI, as well as monetary statistics, could be strengthened. Deficiencies in statistical techniques were observed in all datasets except GFS. The accuracy of estimates for national accounts is undermined by unusually weak assumptions and limited cross-checks of various data sources, which cast doubt on the plausibility of the revised national accounts data released in November 2005. Estimation of construction activity of the nonobserved economy is based too heavily on very narrow labor input source data without sufficient cross-checking with other data inputs on construction to assess reasonableness of the estimates. National accounts and PPI are not validated against other statistics, and errors have been overlooked in the data validation process for balance of payments. The CPI, GFS, and monetary statistics have sound procedures for the assessment and validation of intermediate data and statistical outputs. Revision studies for national accounts statistics should be developed further.

8. Serviceability. The periodicity and timeliness of disseminated statistics, except for national accounts and the PPI, meet GDDS recommendations. All datasets rated favorably in terms of consistency, except for national accounts, where the absence of independent estimates for the expenditure approach prevents consistency check with the production approach estimates. Information on the revision policy and practice for GFS should be made known to the public. The revision policy for national accounts should be consistently applied, and the status of the data clearly indicated on all releases.

9. Accessibility. All datasets, except for national accounts, are readily accessible — an observation that is confirmed by the results of a survey of users of Albanian statistics. Metadata accessibility for the CPI and PPI could be enhanced by the dissemination of updated methodological guides in Albanian and English. Users are not clearly informed on where and how to access the latest data on national accounts. 


\section{Assessment by Agency And Dataset}

Assessments of the quality of six macroeconomic datasets - national accounts, CPI, PPI, government finance, monetary, and balance of payments statistics - were conducted using the DQAF. In this section, the results are presented at the level of the DQAF elements and using a four-point rating scale (Table 1). Assessments of the prerequisites of data quality and the assurances of integrity (Dimensions " 0 " and " 1 " of the DQAF) are presented in Tables $2 \mathrm{a}-\mathrm{c}$. For each dataset, the assessment of methodological soundness, accuracy and reliability, serviceability, and accessibility (Dimensions " 2 " to " 5 " of the DQAF) are shown in Tables 3a-f. 


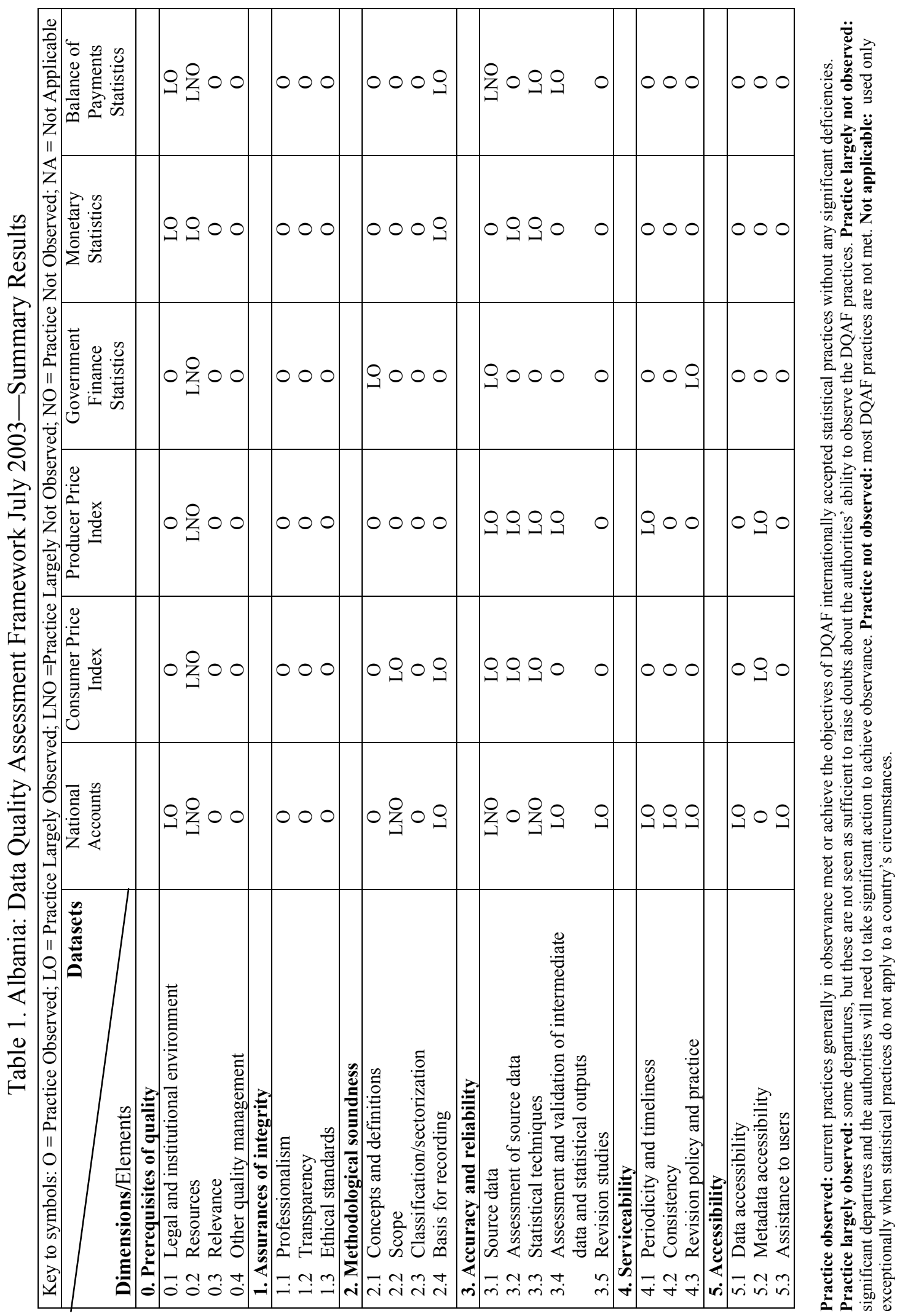




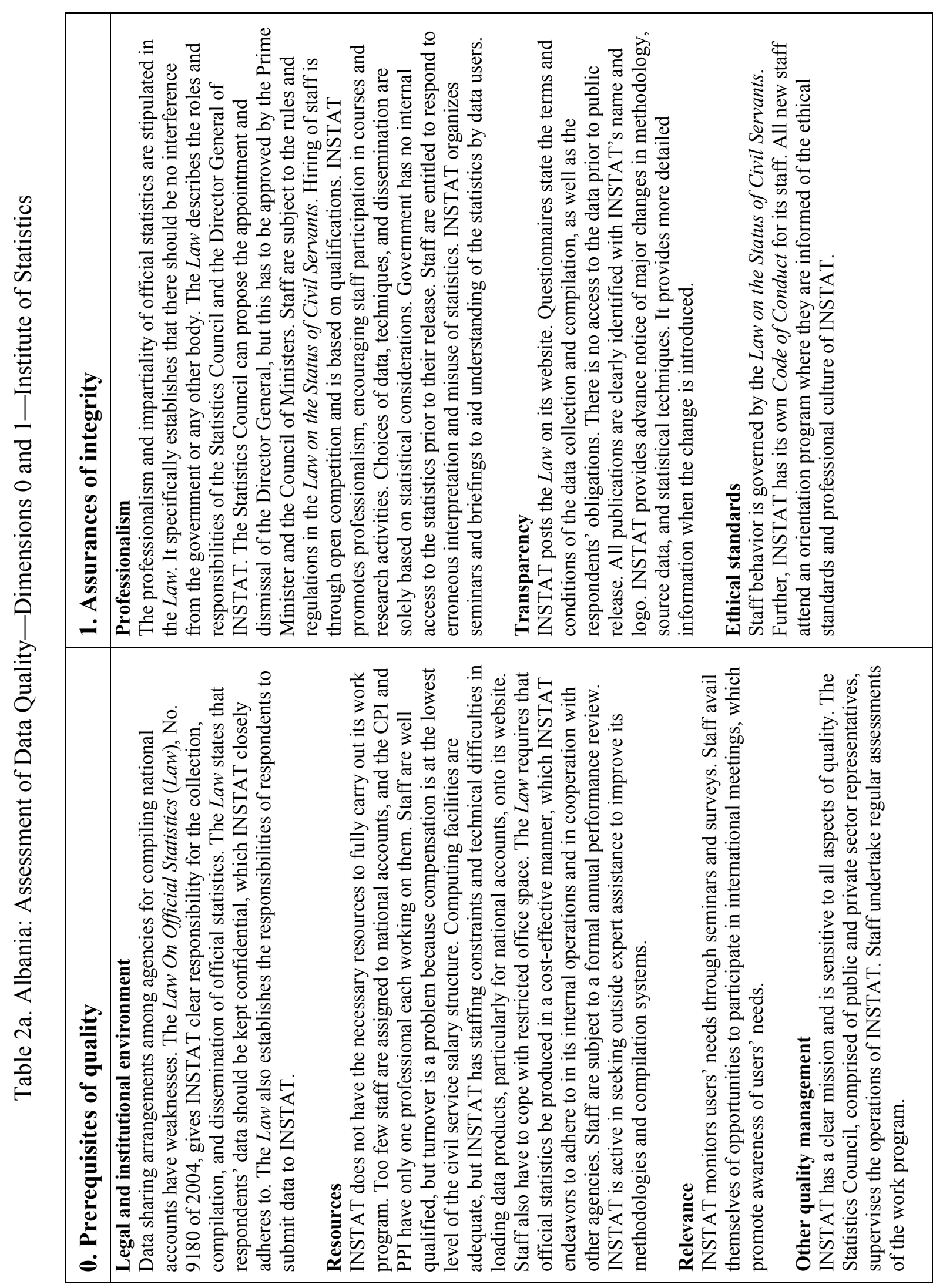




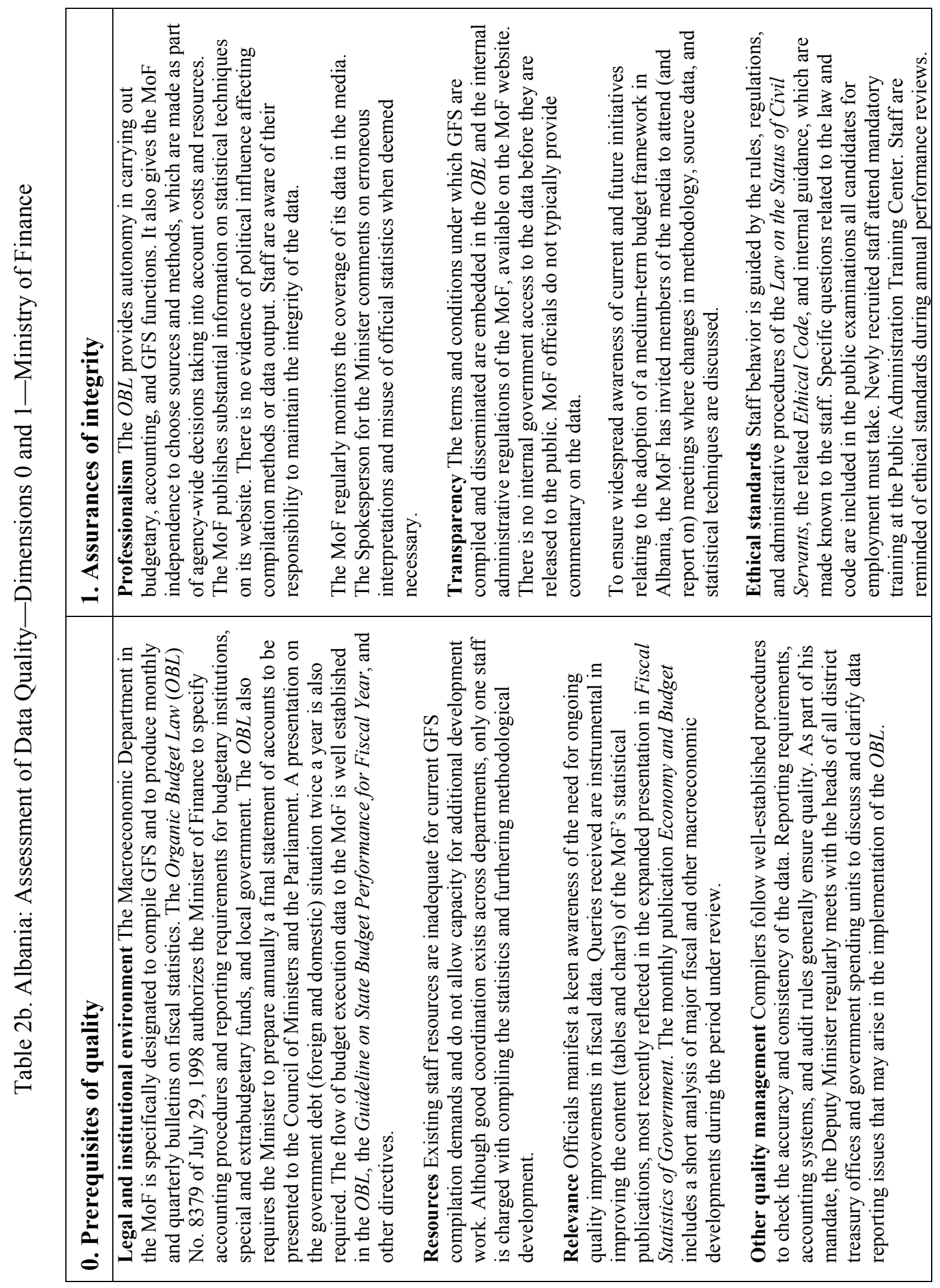




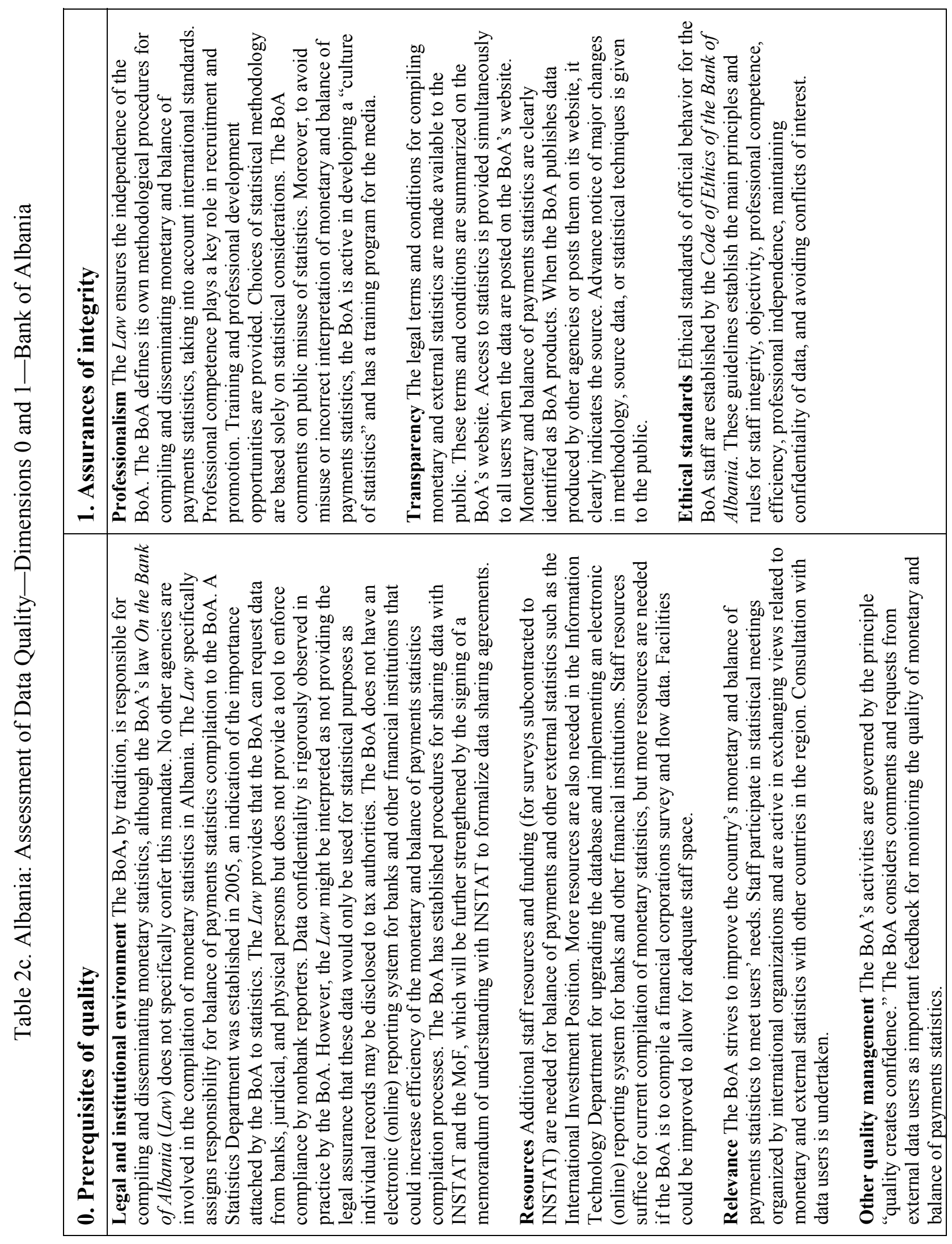









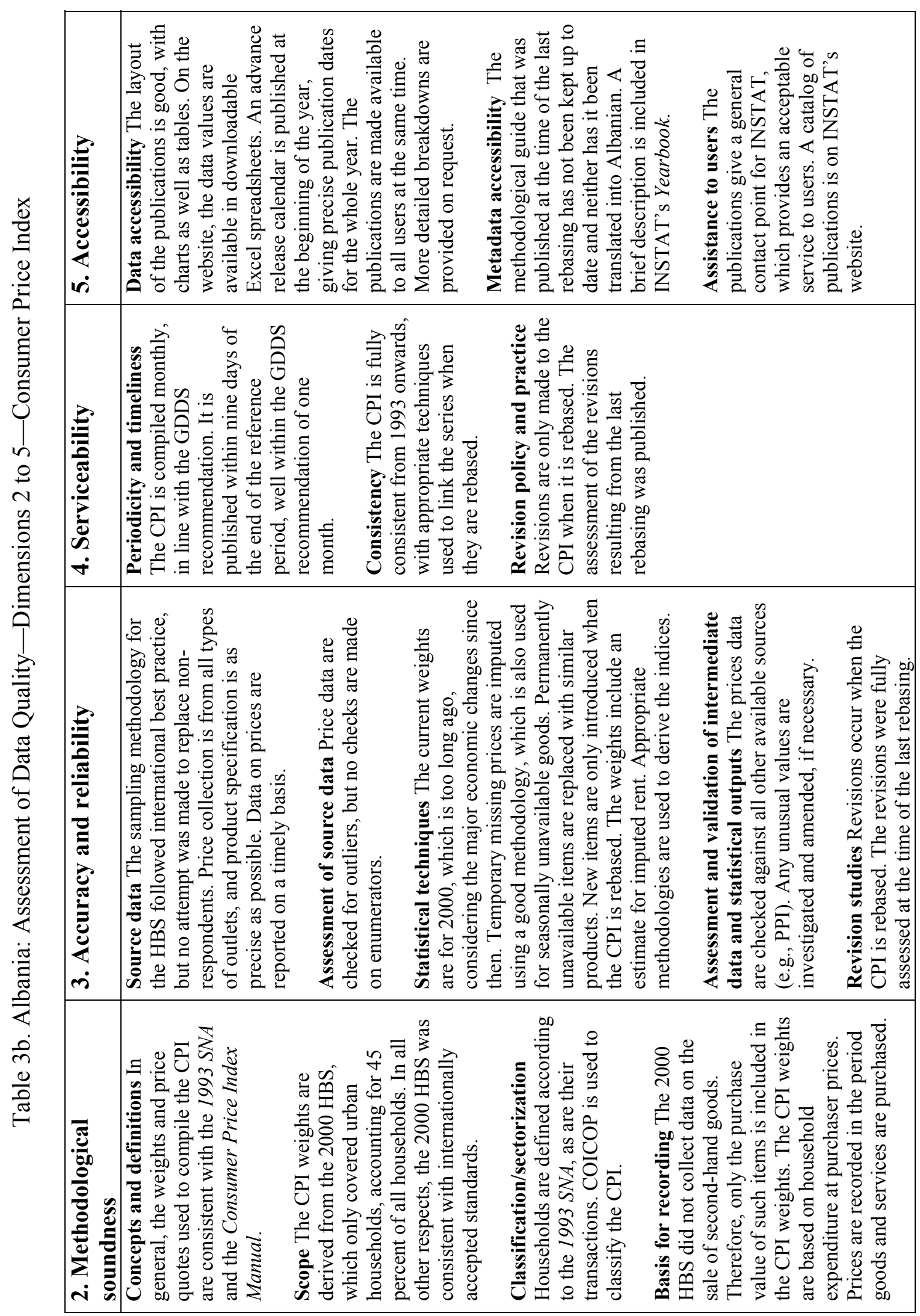




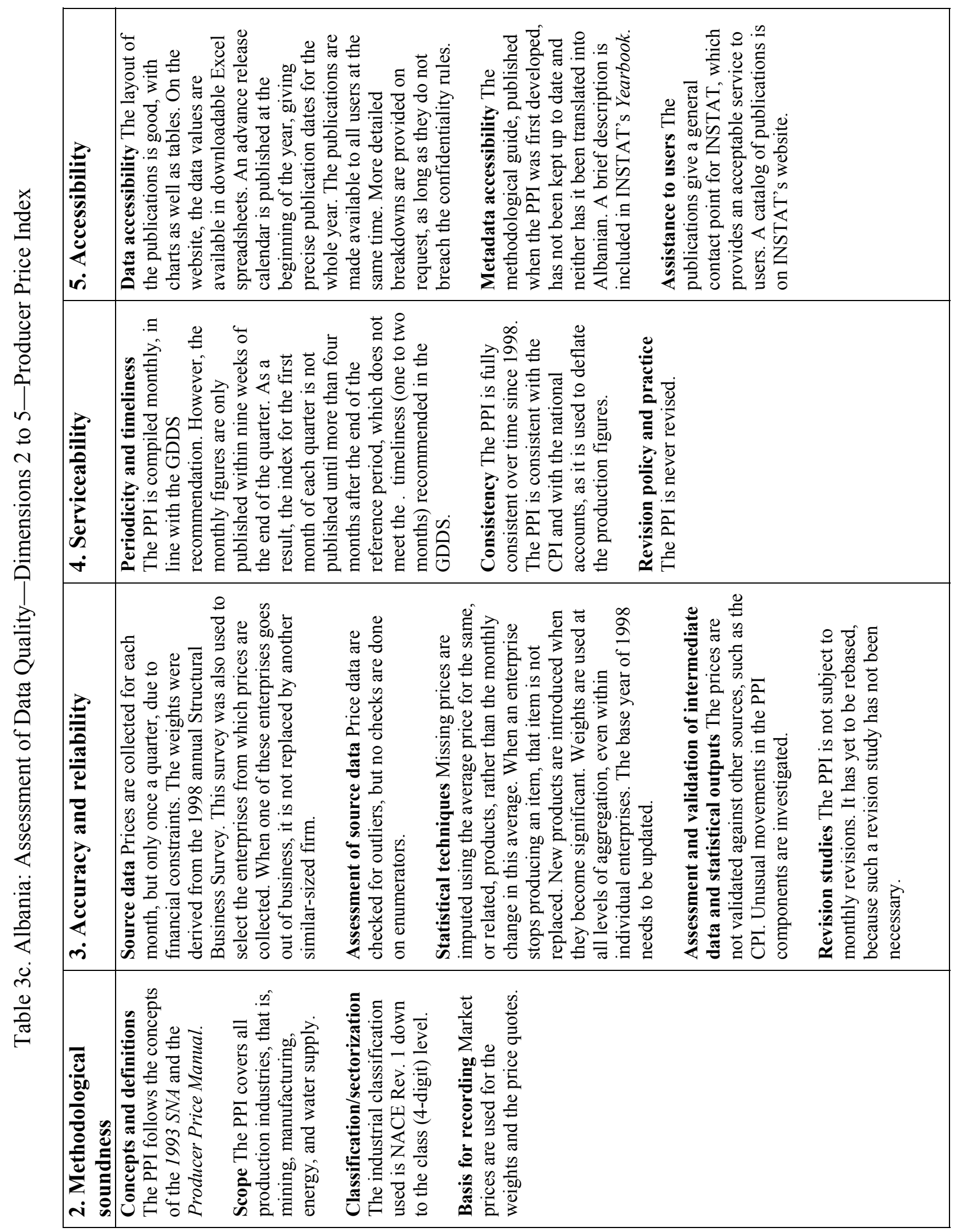




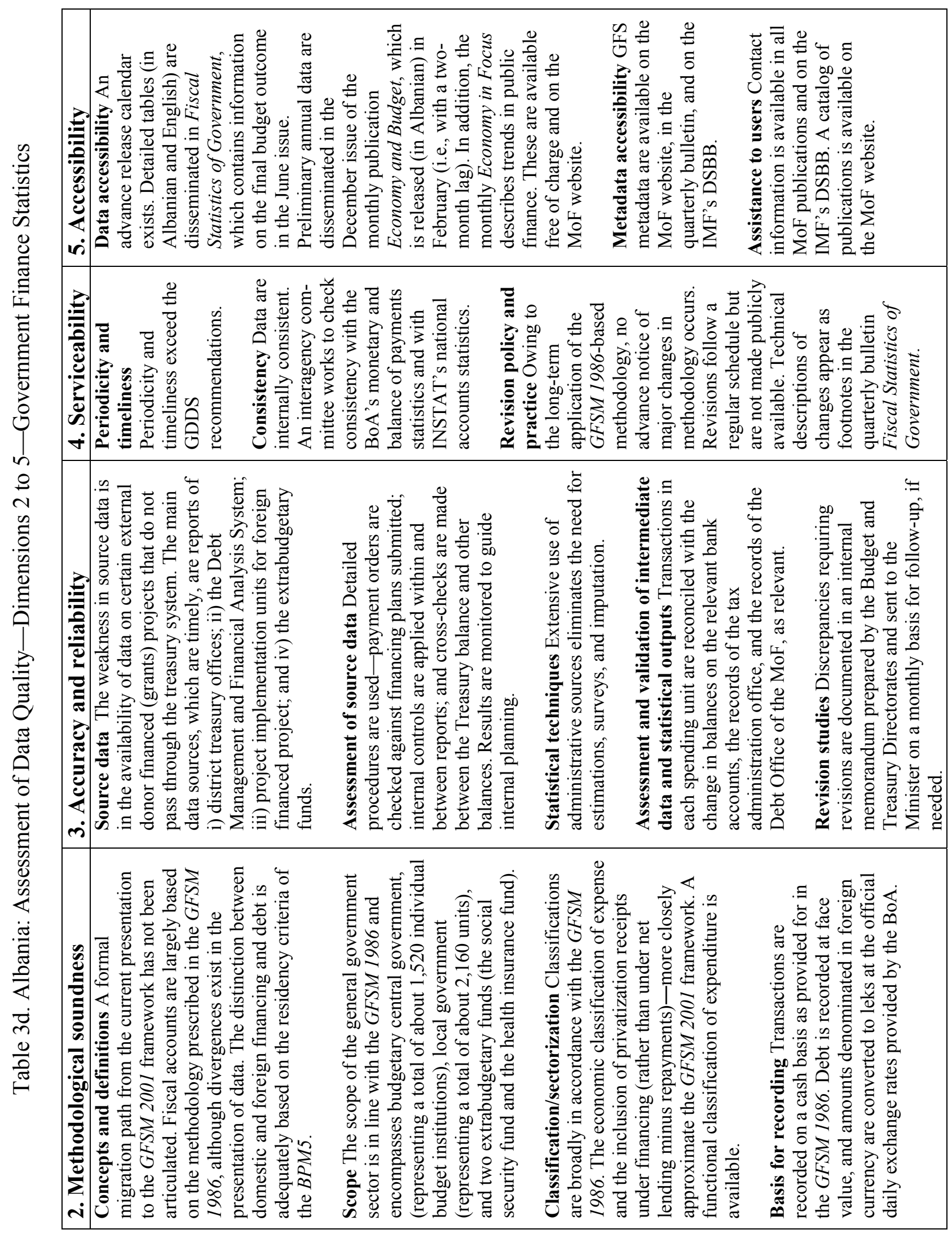




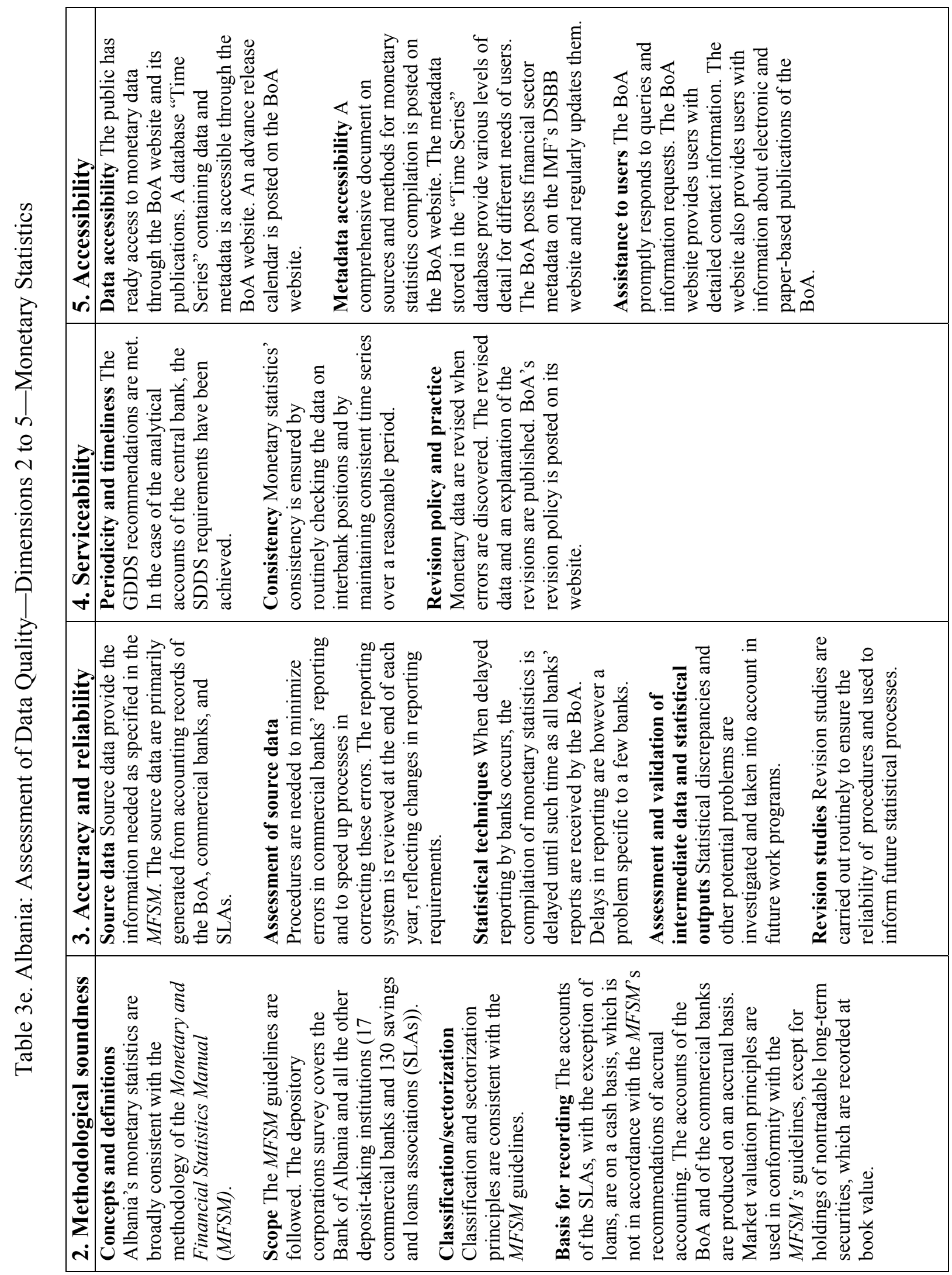




\begin{tabular}{|c|c|c|c|c|c|c|c|c|c|c|}
\hline & \multicolumn{4}{|c|}{ 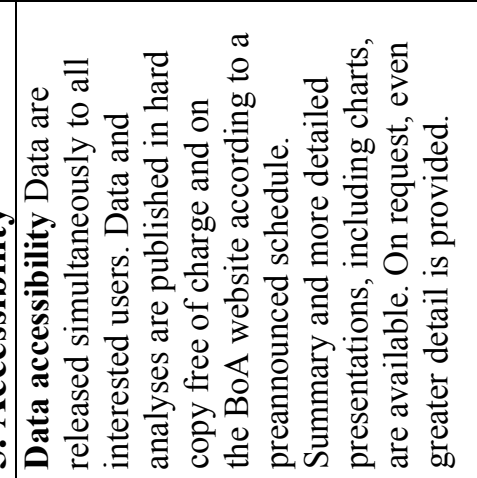 } & \multicolumn{3}{|c|}{ 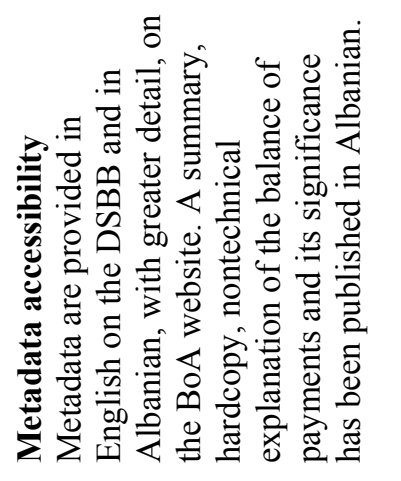 } & \multicolumn{3}{|c|}{ 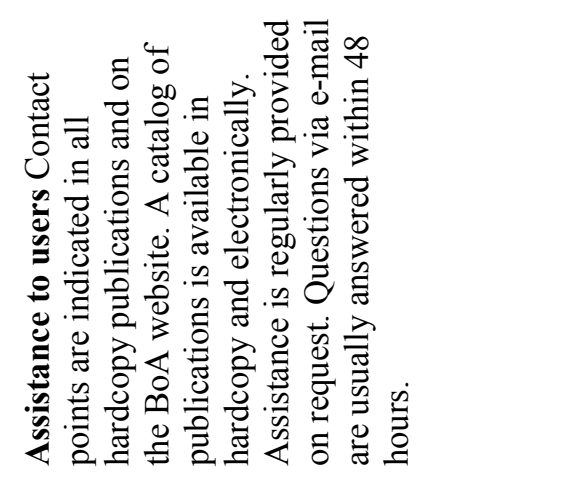 } \\
\hline & \multicolumn{10}{|c|}{ 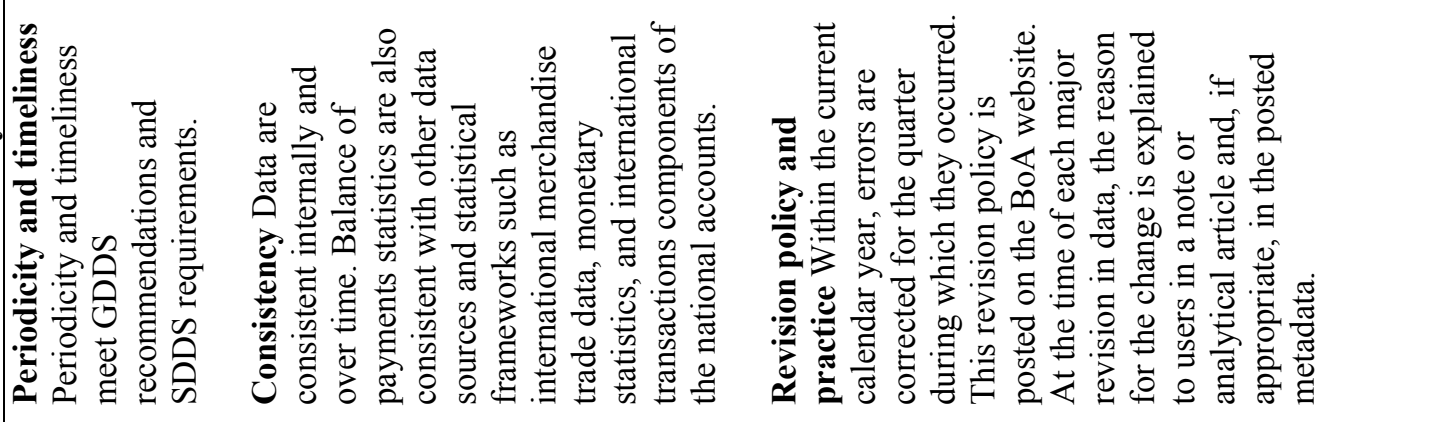 } \\
\hline & 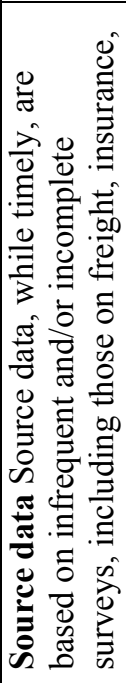 & 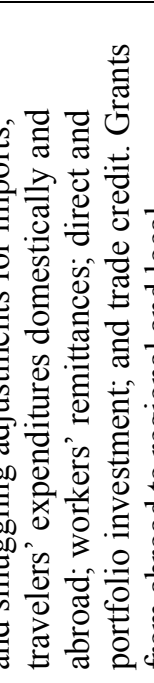 & & & 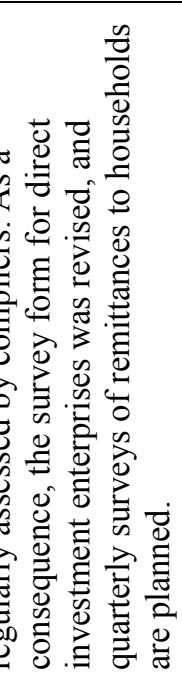 & & 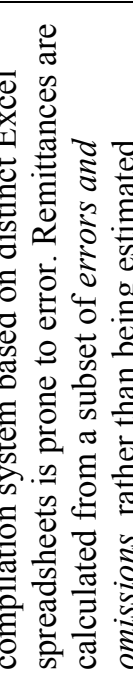 & 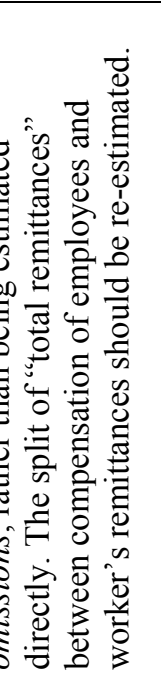 & 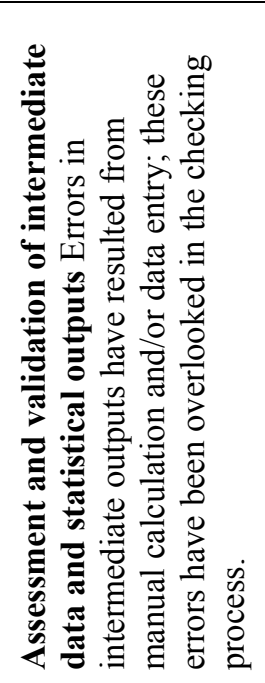 & 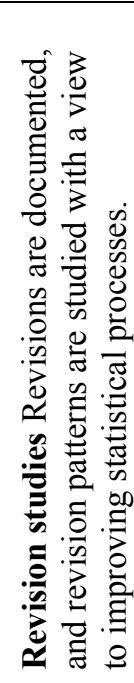 \\
\hline & 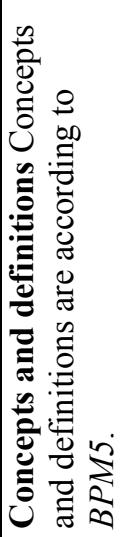 & 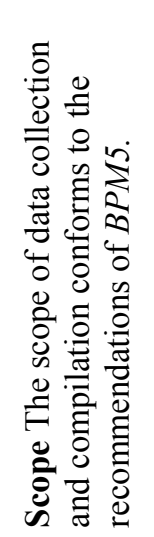 & & & 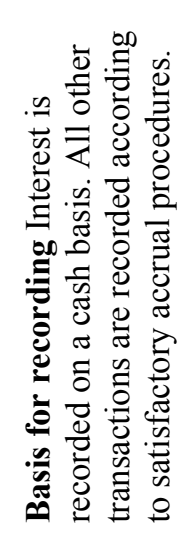 & & 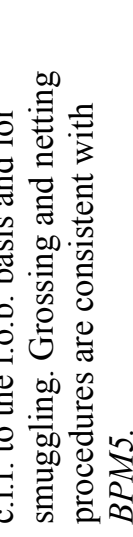 & & & \\
\hline
\end{tabular}




\section{STAFF's RECOMMENDATIONS}

10. Based on the review of Albania's statistical practices, discussions with the dataproducing agencies, and responses from data users (see Appendix III of the Detailed Assessments volume), the mission has a set of recommendations. They are designed to increase further Albania's adherence to internationally accepted statistical practices and would, in the mission's view, enhance the analytical usefulness of Albania's statistics. Some additional technical suggestions are included in the Detailed Assessments volume.

\section{Cross-cutting Recommendations}

- $\quad$ Allocate additional staff resources for the current and planned macroeconomic statistics compilation and dissemination programs, including for information technology support.

- $\quad$ Maintain a stable complement of trained professional staff through, among other methods, upgrading the status of INSTAT staff in the hierarchy of the government civil service and upgrading office facilities in all the data-producing agencies. Continue emphasizing staff training and development.

- Increase financial resources for improving source data, prioritizing the adequate capture of the nonobserved economy and remittances, which are particularly important in the Albanian economy. ${ }^{2}$

- $\quad$ Sign and implement the memorandums of understanding between data-producing agencies on the modalities of data sharing (e.g., identification of data to be shared, timetable, responsible unit within the agency, etc.).

- Implement an electronic (online) reporting system for banks and other financial institutions to enhance the efficiency of monetary and balance of payments statistics compilation processes. Introduce a database-driven compilation system for monetary and balance of payments statistics.

\section{National Accounts}

- $\quad$ Expand and improve surveys, e.g., labor force survey and country-wide HBS.

- $\quad$ Expand the scope of annual national accounts to include the income account, the capital account, and the rest of the world accounts as intended in INSTAT's Strategic Plan.

- $\quad$ For the expenditure approach, rationalize the statistical technique to maximize the use of existing source data. For years when household final consumption cannot be separately estimated, derive a single balancing item on the expenditure side combining household final consumption, changes in inventories, and the statistical discrepancies.

\footnotetext{
${ }^{2}$ In the Albanian context, remittances refer to the BPM5's compensation of employees and workers remittances.
} 
- Use more extensive data sources to cross-check validity of intermediate data. Estimates of construction activity (currently based on limited labor input data) should be assessed for consistency with other construction input and productivity estimates.

- Include nondeductible VAT in the valuation of intermediate consumption to conform to the 1993 SNA's concept of purchasers' price.

- $\quad$ Apply the revision policy consistently. Identify status of disseminated GDP (e.g., preliminary, revised, and final) in all releases.

- Update the advance release calendar to reflect the recently adopted revision policy.

- Identify clearly where users can obtain the official national accounts data (e.g., name of publication or a dedicated page on the INSTAT website).

- Improve the timeliness of the data through greater use of the INSTAT website for the first dissemination of the data.

\section{Consumer and Producer Price Indices}

- Update the weights as soon as possible.

- $\quad$ Publish the PPI every month.

- Introduce checks on the prices reported by enumerators.

- $\quad$ Replace nonrespondents to the HBS with similar households (CPI); replace enterprises that go out of business (PPI).

- $\quad$ Include new items into the CPI as they become significant.

- When an enterprise stops producing an item in the PPI, replace it with another product.

- $\quad$ Deduct sales from purchases of secondhand goods when deriving the CPI weights.

- $\quad$ Impute missing prices using the change in the average price for related products (PPI).

- Validate the PPI results against all other available price data.

- $\quad$ Update the methodological guides and publish them in Albanian and English.

\section{Government Finance Statistics}

- $\quad$ Accelerate work aimed at formally adopting the GFSM 2001-based reporting format, including high-frequency data (monthly cash flow and quarterly government operations data) as well as quarterly nonfinancial public sector debt.

- Improve source data coverage for external donor financed projects. 
- In the context of the development and implementation of the new Oracle-based IT infrastructure, construct and document as soon as feasible a national chart of accounts for all general government subsectors aligned with GFSM 2001 classifications.

- $\quad$ Publicize revisions (within or outside any revision cycle) in, for instance, Fiscal Statistics of Government or the freely accessible database maintained on the MoF website.

\section{Monetary Statistics}

- $\quad$ Apply fully the MFSM's recommendations on market valuation and accrual accounting (e.g., use market prices to value securities held by banks for investment; adopt accrual accounting for the SLAs).

- Implement measures to minimize errors in commercial banks' reporting and to speed up processes in addressing these errors.

- When delayed reporting by commercial banks occurs, carry forward the balance sheet for the previous month of the late reporting bank and make users aware of this technique. These data should be denoted as provisional.

\section{Balance of Payments Statistics}

- $\quad$ Conduct more frequent (e.g., quarterly) surveys on remittances; survey freight charges; and survey tourist expenditures biannually.

- Re-estimate the split of total "remittances" between compensation of employees and workers' remittances and explore the use of other data sources (e.g., Living Standard Measurement Survey) to check the plausibility of the estimates.

- Tighten procedures on data quality control and cross-checks, particularly in the estimation of remittances.

- $\quad$ Strengthen the BoA law to provide for the sanctions-including fines-needed to mandate survey responses from nonbank reporters, to inspect the financial accounts of firms, and to prohibit the provision of individual reporters' data to tax authorities.

- Implement the revised reporting form for insurance services.

- $\quad$ Obtain the public debt service schedule from the MoF and record interest on an accrual basis.

- $\quad$ Require quarterly reporting by significant firms of transactions in direct investment equity, debt, and reinvested earnings; in portfolio equity and debt; and in trade credit.

- $\quad$ Estimate purchases of land and construction financed by unidentified foreign exchange inflows. 


\section{Albania: Practices Compared to the GDDS Coverage Periodicity, and Timeliness of Data}



* Indicates that the coverage, periodicity, and timeliness currently meet SDDS requirements.

Italics indicate encouraged categories.

1/ Dissemination as part of a high-frequency (e.g. monthly) publication. 


\title{
INTERNATIONAL MONETARY FUND
}

\author{
ALBANIA \\ Report on the Observance of Standards and Codes (ROSC)—Data Module \\ Response by the Authorities
}

October 20, 2006

Contents

Page

I. General Remarks .23

II. Response to Cross-Cutting Recommendations .........................................................23

III. Response to Sectoral Recommendations ..............................................................24

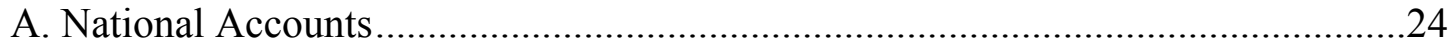

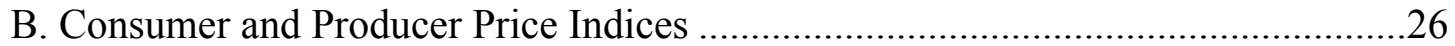

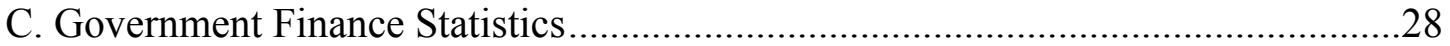

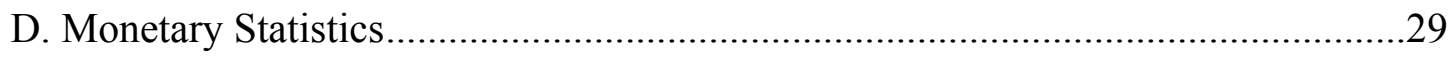

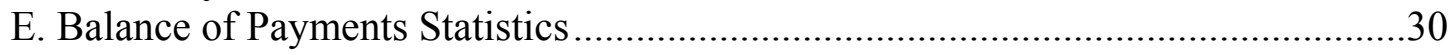




\section{GENERAL REMARKS}

Bank of Albania (Bank of Albania), Ministry of Finance (MoF) and Institute of Statistics (INSTAT) found that ROSC mission assessment of the Albanian's macroeconomic statistical data confirm our intention to harmonize the standards and methodologies towards achieving good quality of the statistical data.

Appreciating the experience of using the DQAF for assessing quality of the statistical data, we share the view that achieving the good statistical practices are the most important for transition economies. Albanian's main goal is to become a member country of EU and in this context we are working to improve our statistics as a part of reform in our policies to meet many requirements for EU accession.

As participant in GDDS, Albanian authorities pay much attention to produce higher quality of the macroeconomic data as well as to improve the transparency in dissemination of statistics to meet user's needs.

Reacting to the summary and detailed assessment of macroeconomic data as result of the ROSC mission, Albanian authorities share their general agreement with the Fund's findings.

A description of the mission's main recommendations and the authorities' implementation plans are detailed below.

\section{RESPONSE TO CROSS-CUTTING RECOMMENDATIONS}

11. Allocate additional staff resources for the current and planned macroeconomic statistics compilation and dissemination programs, including for information technology support

The structure of the, Department of Statistics, Bank of Albania will be reviewed until the first quarter of 2007, and will be expanded to include among other things, the compilation of flows data, IIP and External Debt statistics.

12. Maintain a stable complement of trained professional staff through, among others, the upgrading of status of INSTAT staff in the hierarchy of the government civil service and the upgrading of office facilities in all the data producing agencies. Continue the emphasis on staff training and development.

The development of human resources in INSTAT has recently benefited from a raise in salaries of its staff. In the view of the Bank of Albania's commitment to launch Inflation targeting and a greater involvement of real and fiscal sector indicators in the formulation of monetary policy, the staff working in the Statistics Department, Bank of Albania, has been recently trained to comprehend the statistical information produced by the other institutions. 
13. Increase financial resources for improving source data. Attach priority to improving source data to adequately capture the non observed economy and remittances, which are particularly important in the Albanian economy.

INSTAT and Bank of Albania will work on exploring the structure and quantitative estimates of the informal economy in Albania. A better understanding of the structure and type of the transactions will develop the estimation methods of remittances.

14. Sign and implement the Memorandums of Understanding between data producing agencies on the modalities of data sharing (e.g., identification of data to be shared, timetable, responsible unit within the agency, etc.).

Both institutions (INSTAT and Bank of Albania) are in the process of drafting the Memorandums of Understanding on the modalities of data sharing. Other data producing agencies are as well interested on a better collaboration in the future.

15. Implement an electronic (online) reporting system for banks and other financial institutions to enhance the efficiency of monetary and balance of payments statistics compilation processes. Introduce a database driven compilation system for monetary and balance of payments statistics.

The BoA has included this recommendation in its strategy plan as a medium-term plan. It is already defined that the duty to be fulfilled on 2007.

\section{RESPONSE TO SECTORAL RECOMMENDATIONS}

\section{A. National Accounts}

16. Expand and improve surveys e.g., labour force survey and country-wide HBS.

It is important to stress once more that INSTAT must expand source data and improve survey coverage to provide adequate basis for compilation of more reliable national accounts estimates. More specifically, INSTAT will conduct a labour force survey (beginning in 2007) as well as a country-wide household budget survey (already started on October $1^{\text {st }}$, 2007). Improving labour data should be a matter of priority in the context of using a labour input based methodology so as to ensure the reliability of the national accounts estimates; We fully agree that to improve the Albanian national accounts it is necessary to increase the human, technical and financial resources.

17. Expand the scope of annual national accounts to include the income account, the capital account, and the rest of the world accounts as intended in INSTAT Strategic Plan. 
In the framework of the EU funded Twinning project is created a strategic plan to define the possibilities to include the respective accounts recommended here. Sequence of development of national accounts depends on many different factors, where the predominant are data sources, etc.

In this case is important to develop a methodology to estimate the generation of income account starting from the estimate of wages and salaries;

18. For the expenditure approach, rationalize statistical technique to maximize the use of existing source data. For years when household final consumption cannot be separately estimated, derive a single balancing item on the expenditure side combining household final consumption, changes in inventories, and the statistical discrepancies.

INSTAT is using the "Commodity Flow" method in order to improve the methodology of calculation of GDP from expenditures side.

19. Use more extensive data sources to cross-check validity of intermediate data. Estimates of construction activity (currently based on limited labour input data) should be assessed for consistency with other construction input and productivity estimates.

From a methodological point of view it is possible that the output due to ordinary maintenance has been included in investments rather than in the household consumption. For this reason, INSTAT will start very soon an investigation of LSMS data 2003-2004 in order to verify whether it is possible to define a new estimate.

In the same time NA sector, will start also the investigation of the SBS data of the construction sector in order to estimate separately secondary activities from main activity of the construction sector. This exercise will contribute to a better estimation of the GFCF (construction component).

20. Include non-deductible VAT in the valuation of intermediate consumption to conform to the 1993 SNA's concept of purchasers' price.

We have started to make the preliminary estimation of non-deductible VAT based on the limited data in disposition for this purposes. In the future it is necessity to make a proposal for a new special survey, addressed to all units of Public Administration, etc, to know all other variables (depreciation, etc) in collaboration with the Ministry of Finance.

21. Apply the revision policy consistently. Identify status of disseminated GDP (e.g., preliminary, revised, and final) in all releases.

National Account sector has recently adopted the revision policy and it has already disseminated the information on the timeliness of national accounts data to the public and also the status of data is indicated on the last publications of INSTAT 
22. Update the advance release calendar to reflect the recently adopted revision policy.

INSTAT already updated the released calendar.

23. Identify clearly where users can obtain the official national accounts data (e.g., name of publication or a dedicated page on the INSTAT website).

The recommendation is implemented already.

24. Improve the timeliness of the data through greater use of the INSTAT website for the first dissemination of the data.

The recommendation is implemented already.

\section{B. Consumer and Producer Price Indices}

25. Update the weights as soon as possible.

Update of weights for the CPI will be after we will have the result of the Household Budget survey $(H B S) 2006$.

The current version of PPI, called a fix-base-year, imposes many practical problems.

INSTAT intend to replace this approach with the chain index one.

When using a "chain-index", new weights could be assigned each year if felt necessary. In this chain-index, each transaction will be compared with its previous year December price. These price relatives (ex. 1) will be weighted together to give index number for each product group, and so on to give index numbers for the total PPI.

Renovation of product list, establishment was done using the results of Business Structural Survey of 2004. New questionnaire, to compile the data of new PPI, is prepared. Creation of authentic data entry, in collaboration with IT staff, is in process.

26. Publish the PPI every month.

The publishing of PPI every month requests the collection of the data on monthly basis. So far, because of usage of enumerators, INSTAT visit the enterprises quarterly and collect their data on monthly basis. The recommendation will take place on medium term.

27. Introduce checks on the prices reported by enumerators

With the renovation of CPI and PPI the new data entry will have an automatic check of price reported. 
28. Replace non-respondents to the HBS with similar households (CPI); replace enterprises that go out of business (PPI).

In the methodology of the HBS it is not foreseen the replacement of the non-respondents with the similar household.

In the new PPI indices the replacement of enterprises will be once a year, in December.

29. Include new items into the CPI as they become significant.

INSTAT already analyze the new items when they are significant for the CPI, calculated their weights when possible.

30. When an enterprise stops producing an item in the PPI, replace it with another product.

In the new PPI it is foreseen the substitution of the item during the year. The item substitutions imply that the base price (previous December price) must be adjusted.

31. Deduct sales from purchases of second hand goods when deriving the CPI weights.

In the HBS we will deduct sales from purchases of second hand goods, so we will take in consideration when driving the CPI weights.

32. Impute missing prices using the change in the average price for related products (PPI).

The recommendation is already applied.

33. Validate the PPI results against all other available price data.

INSTAT will work on validating the PPI results, in line with other sources, such as exportimport data, short-term statistics CPI etc.

34. Update the methodological guides and publish them in Albanian and English

The update of methodological guide is in process. 


\section{Government Finance Statistics}

35. Accelerate work aimed at formally adopting the GFSM 2001-based reporting format, including for high-frequency data (monthly cash flow and quarterly government operations data) as well as quarterly non financial public sector debt.

Albanian Ministry of Finance Treasury System (AMoFTS) (oracle financials application parameterized and customized on the Albanian public financial system) is on phase of testing, training and getting used of the system (November-December 2006).

MoF plan to go- live with the system on the beginning of January 2007.

By using the Albanian integrated centralized computerized treasury system we are going to implement accrual accounting as it is required and provide reports in cash and modified accrual basis in the same time.

36. Improve source data coverage for external donor financed projects

In this context MoF has undertaken some steps for stregthening the public investment management, in the programming process as well as in the implementation platform (reports, entered in the AmoFTS etc..)

Responsibility transfer from the METE to the MoF, where is established the new Public Investment Management Directory under General Budget Department is a step ahead for improving the process of programming the Domestic and Foreign investments. Recently MoF has passed the State Debt Law in Parliament and expected in the future to cover all of the main issues specific to public debt issuance and managment.

37. In the context of the development and implementation of the new Oracle-based IT infrastructure, construct and document as soon as feasible, a national chart of accounts for all general government sub sectors aligned with GFSM 2001 classifications.

On 2007 we will implement the detailed (7 digits) chart of accounts for the general government (central, local, extra budgetary funds -SSI, HII) approximately with GFSM 2001 classifications.

38. Publicize revisions (within or outside any revision cycle) through, for instance, in the publication Fiscal Statistics of Government or in the freely accessible database maintained on the MoF website.

Ministry of Finance supports this recommendation of the mission to publish the revised data in the publication Fiscal Statistics of Government and in the freely accessible database 
maintained on the MoF website.(for the reason of the reconciliations with the banking system and budgetary units after the deadline of the fiscal indicators reporting)

\section{Monetary Statistics}

39. Strengthen the BoA law to provide full legal assurances that individual reporters' data may be used only for statistical purposes.

The BoA's Legal Department is drafting a new law on the Bank of Albania, expected to pass by end 2009, which will also strengthen the legal support for the dissemination of monetary and financial statistics by including an explicit role for the Bank of Albania to compile and disseminate these statistics. It will also ensure confidentiality of individual data and use of these for statistical purposes only.

40. Implement an electronic (online) reporting system for commercial banks and other financial institutions to enhance efficiency of monetary compilation.

The BoA has included this recommendation in its strategy plan as a medium-term plan. It is already defined that the duty to be fulfilled on 2007.

41. Although current staff resources suffice for monetary statistics compilation, additional resources are needed in the Information Technology Department to (1) design the SARS database for a better performance including the generation of monetary data and (2) implement an electronic (online) reporting system for commercial banks and other financial institutions. More resources are needed in the SD to expand monetary statistics to cover also other financial corporations and to compile and present flow data for the financial sector, as recommended by the Monetary and Financial Statistics Manual (MFSM).

The structure of the Department of Statistics will be reviewed until the first quarter of 2007, and will be expanded to include among other things, the compilation of flows data. The Sector of Monetary and Financial Statistics is currently working on a draft structure.

42. It would be desirable that further work in the area of monetary statistics include compilation of flow data.

The compilation of flows data in monetary statistics would require additional information from bank's reporting as regards securities holdings, in order to separately identify changes in values and transactions. The BoA plans to draft this requirement by the end of 2006. On the other hand data on changes in value due to changes in the exchange rate for main categories could be identified from the existing reports.

43. Revalue long-term securities for investment and available for trading held by the banking sector using estimated fair value. 
The BoA will consider obtaining estimates of long term securities issued by nonresidents in special tables of the regular reporting system by commercial banks. The necessary data for a revision of the series for the Central Bank's accounts are currently available.

44. Adopt accrual accounting for SLAs so as to apply fully the MFSM guidelines on accrual accounting.

For the moment the BoA considers that the SLA's accrual assets and liabilities are not enough materially significant such as to justify an increase in the reporting burden. The total assets of such institutions represent only 0.4 percent of the total assets of Other Depository Corporations.

45. Implement measures to minimize errors in commercial banks' reporting and to speed up processes in addressing these errors.

The BoA has shortened the time lag for reporting by banks from 20 days to 15 days. It will be further shortened to 10 days starting from March 2007. This currently allows more time for the reports to be checked for errors.

46. When delayed reporting by commercial banks occurs, carry forward the balance sheet for the previous month of the late reporting bank and make users aware of this technique. The data should be denoted as provisional.

The BoA has already adopted such practice.

\section{E. Balance of Payments Statistics}

47. Conduct more frequent (e.g., quarterly) surveys on remittances; survey freight charges; and survey tourist expenditures biannually.

Particularly because remittances are a predominant item in the Albanian balance of payments, several surveys will be conducted to the households who receipt money from their family abroad in quarterly basis. This recommendation will be applied on year 2007.

It will be analyzed whether new coefficients need to be applied on freight and smuggled goods and new survey will be conducted on the big importing companies.

The new system ASYCUDA which is still implemented will facilitate the estimation of freight. Its implementation in all the system offices may take time. Bank of Albania is still applying the coefficients recommended by the last IMF technical assistance mission, 2006).

Bank of Albania is conducting the travel survey on quarterly basis because of the seasonality of the expenditures during the summer and the winter vacations. This practice will be continued in order to maintain the time series on the coefficients of travel for further 
estimations. Bank of Albania will start carrying out the travel surveys at minor borders to improve the benchmark data (IMF technical assistance mission, 2006)

48. Re-estimate the split of total "remittances" between compensation of employees and workers' remittances and explore the use of other data sources (e.g., Living Standard Measurement Survey) to check the plausibility of the estimates.

Recently INSTAT is conducting a Household Budget Survey. The results of this survey will be used by Bank of Albania in order to check the plausibility of the estimates done by Bank of Albania on remittances.

49. Tighten procedures on data quality control and cross-checks, particularly in the estimation of remittances.

The Bank of Albania is working on revising the estimation of remittances checking the quality of the data provided by the sources and cross-checking the calculation of the estimation of remittances.

50. Because "remittances" are an important item in the Albanian balance of payments, a new survey should be conducted to re-estimate the division of unidentified inflows of foreign exchange between compensation of employees and workers' remittances. This survey could be either among banks and foreign exchange bureaus or among households, whichever the BoP division considers to be more feasible and cost-effective.

The recommendation will take place on year 2007.

51. Strengthen the Bank of Albania law to provide for the sanctions including fines needed to mandate survey responses from non-bank reporters, to inspect the financial accounts of firms, and to prohibit the provision of individual reporters' data to tax authorities.

Bank of Albania will revise the legal status regarding to the statistics in order to establish its right to data needed for fulfilling its mandate (including BoP statistics compilation),

providing the tool for enforcing this right including new legal provisions. This issue is part of the Bank of Albania medium term strategy.

52. Implement the revised reporting form for insurance services.

Bank of Albania has already implemented the new reporting form for insurance companies (last recommendation of IMF technical assistance mission, 2006).

53. Obtain the public debt service schedule from the MoF and record interest on an accrual basis. 
The DMFAS actually used by MoF for monitoring of external debt in the form of loans does not calculate the accrued interest. With the implementation of the new version DMFAS 5.3 the calculation of accrual interest is previewed. Consequently in the balance of payments the interest will be recorded on accrual basis.

54. Require quarterly reporting by significant firms of transactions in direct investment equity, debt, and reinvested earnings; in portfolio equity and debt; and in trade credit.

The annual survey of Bank of Albania in cooperation with INSTAT is actually taking place as the Bank of Albania law doesn't force the firms to have a direct reporting. The recommendation will be applied in line with the improvement of the Bank of Albania legal framework.

55. Estimate purchases of land and construction financed by unidentified foreign exchange inflows.

Bank of Albania is actually conducting a survey on construction companies and real estate agencies to find what portion of the current housing boom is being financed by unreported transactions between residents and nonresidents. This is the very first survey of this kind. The results will be analyzed in order understand the structure and the type of transactions necessary to develop estimation methods of the BoP statistics.

56. BoP division should strive to improve further coordination with INSTAT with respect to survey design, execution, and follow-up to non-response.

Bank of Albania's Statistics department has a productive relationship with INSTAT. The both institutions are making efforts on further improvement on the quality of the surveys starting with the designation of the questionnaire and the improvement of the response rate.

57. IT support should be provided to the BoP division to set up an automated database system that will preclude the need for manual data entry and could accommodate fully electronic reporting by banks, including an ITRS if this option is selected.

This is a medium -term plan in the Bank of Albania strategy plan.

58. During the interim before a database-driven compilation system can be introduced, the spreadsheets currently in use for intermediate compilation of different portions of the balance of payments should be linked by introduction of relevant formulas.

BoP division has already reorganized the excel files linked by relevant formulas to one BoP spreadsheet. 


\title{
INTERNATIONAL MONETARY FUND
}

\author{
ALBANIA \\ Detailed Assessments Using the Data Quality Assessment Framework (DQAF) \\ Prepared by the Statistics Department \\ Approved by Robert W. Edwards and Michael Deppler
}

October 20, 2006

This document contains a detailed assessment by dataset of the elements and indicators that underlie the data quality dimensions discussed in Albania's Report on the Observance of Standards and Codes (ROSC)—Data Module. It also includes as appendices the DQAF generic framework and the results of the users' survey. 


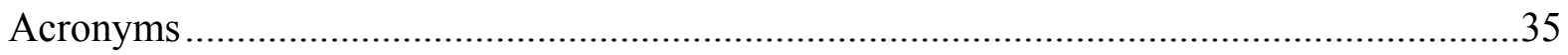

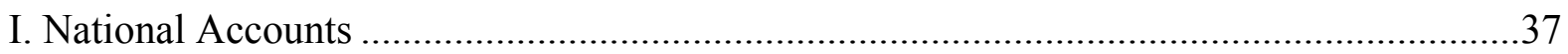

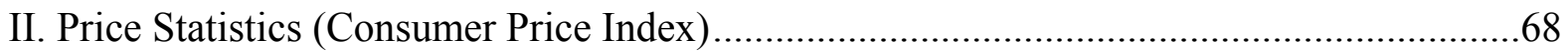

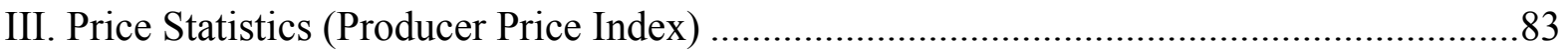

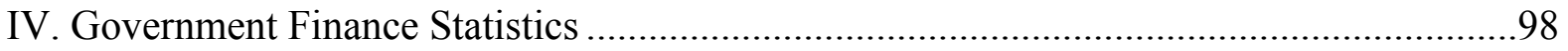

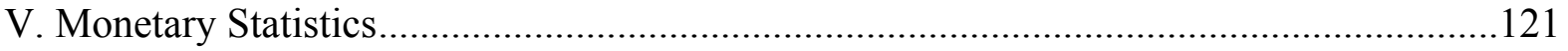

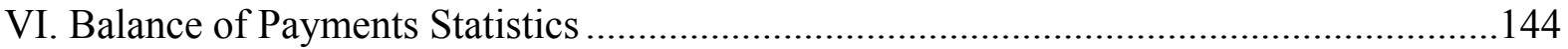

Tables

1. DQAF (July 2003): Summary of Results for National Accounts .................................65

2. DQAF (July 2003): Summary of Results for Price Statistics ....................................81

3. DQAF (July 2003): Summary of Results for Producer Price Index ..............................96

4. DQAF (July 2003): Summary of Results for Government Finance Statistics...............119

5. DQAF (July 2003): Summary of Results for Monetary Statistics ...............................142

6. DQAF (July 2003): Summary of Results for Balance of Payments Statistics...............166

Appendices

I. Summary of the General Data Dissemination System (GDDS) ...............................168

II. Data Quality Assessment Framework - Generic Framework..................................170

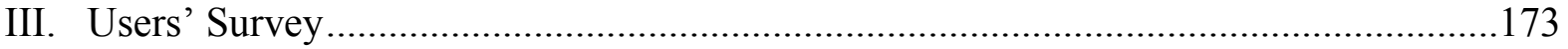




\section{ACRONYMS}

1995 ESA

1993 SNA

ALL

APD

ARC

ASYCUDA

BoA

BoPS

BPM5

COFOG

COICOP

$\mathrm{CPC}$

CPI

DFID

DMFAS

DQAF

DTOs

EU

FDI

GDP

GDDS

GFS

GFSM 1986

GFSM 2001

GFSY

HBS

INSTAT

IMF

ISWGNA

LSCS

LSMS

MD

MFSM

MOA

$\mathrm{MoF}$

MOU

NACE

NAS

OAR

OBL

ODCs

OMFS
European System of Accounts 1995

System of National Accounts 1993

Albanian lek

Accounting and Payments Department

Advance Release Calendar

Automated Information System for Customs Data

Bank of Albania

Balance of Payments and Surveys Section

Balance of Payments Manual, fifth edition

Classification of Functions of Government

Classification of Individual Consumption

Central Product Classification

Consumer Price Index

United Kingdom's Department For International Development

Debt Management and Financial Analysis System

Data Quality Assessment Framework

District Treasury Offices

European Union

Foreign Direct Investment

Gross Domestic Product

General Data Dissemination System

Government Finance Statistics

A Manual of Government Finance Statistics, 1986

Government Financial Statistics Manual 2001

Government Finance Statistics Yearbook

Household Budget Survey

Institute of Statistics

International Monetary Fund

Intersecretariat Working Group on National Accounts

Law on the Status of Civil Servants

Living Standard Measurement Survey

General Directorate of Macroeconomic and Fiscal Policies

Monetary and Financial Statistics Manual

Ministry of Agriculture

Ministry of Finance

Memorandum of Understanding

Statistical Classification of Economic Activities in the European

Communities

National Accounts Section (INSTAT)

Office of Administration of the Report

Organic Budget Law

Other Depository Corporations

Office of Monetary and Financial Statistics 


$\begin{array}{ll}\text { PPI } & \text { Producer Price Index } \\ \text { ROSC } & \text { Report on the Observance of Standards and Codes } \\ \text { SARS } & \text { Automatic System of the Statistical Reports } \\ \text { SBS } & \text { Structural Business Survey } \\ \text { SD } & \text { Bank of Albania's Statistics Department } \\ \text { SDDS } & \text { Special Data Dissemination Standard } \\ \text { SIS } & \text { State Institute of Statistics } \\ \text { SLAs } & \text { Savings and Loans Associations } \\ \text { SNA } & \text { System of National Accounts } \\ \text { SPO } & \text { State Planning Organization } \\ \text { SRFs } & \text { Standardized Report Forms } \\ \text { SUT } & \text { Supply and Use Table } \\ \text { UN } & \text { United Nations } \\ \text { UVI } & \text { Unit Value Indices } \\ \text { VAT } & \text { Value Added Tax }\end{array}$




\section{Detailed Assessment Using the Data Quality Assessment Framework (DQAF)}

The following detailed information on indicators of statistical practices in the areas of the national accounts, prices, government finance, money and banking, and balance of payments statistics was gathered from publicly available documents and information provided by the Albanian officials. This information, which is organized along the lines of the generic DQAF (see Appendix II), was used to prepare the summary assessment of data quality elements, based on a four-part scale of observance, shown in Albania's Report on the Observance of Standards and Codes (ROSC)—Data Module.

\section{National Accounts}

\section{Prerequisites of quality}

\subsection{Legal and institutional environment}

\subsubsection{The responsibility for collecting, processing, and disseminating the statistics is clearly specified}

The legal and institutional arrangements provide adequate support for collecting, processing, and disseminating statistics. The law On Official Statistics, No. 9180, dated February 5, 2004 (the $L a w$ ), sets out the legal framework for the collection, organization, production, and dissemination of official statistics in Albania. The Law reflects elements of the UN Fundamental Principles of Official Statistics. The Law empowers the Institute of Statistics (INSTAT) to propose a program of official statistics to the Statistics Council and implement the approved program of statistics. INSTAT is authorized under Article 8 to issue to all dataproducing agencies, make public, and keep up-to-date the guidelines for professional standards in the production of official statistics. INSTAT is responsible for examining the procedures for producing statistics used by any official statistics-producing agency, with a view to ensuring their statistics are reliable, impartial, and objective.

INSTAT is an independent government agency under the supervision of the Statistics Council, which in turn reports to the Council of Ministers. In executing its responsibilities, INSTAT develops the program of official statistics in coordination with other data-producing agencies. The program consists of a five-year national program of official statistics and a one-year operational plan. The five-year program is submitted for approval by Parliament, through the Prime Minister. The Statistics Council oversees the implementation of the fiveyear program and the annual operational plan. INSTAT prepares quarterly reports detailing progress in implementing the annual plan. The Statistics Council approves INSTAT's organizational structure and annual budget plan prior to submission to the Ministry of Finance.

According to the Government Decision (No. 704, dated November 11, 2005), "Approval of the Criteria of Representation, Selection, Appointment, Dismissal and Functioning Rules of Statistics Council," the Statistics Council has 11 members appointed by the Council of Ministers. The members comprise three from the academic community, three from civil 
societies, and five from data-producing agencies. The Council makes decisions by simple majority; the INSTAT General Director participates in meetings but does not have voting power.

INSTAT, through its National Accounts Section (NAS), is the only official producer of national accounts statistics. In carrying out its responsibilities, INSTAT is empowered by the Law to collect data from all entities. However, currently some other laws might cause potential conflicts with this provision of the law On Official Statistics, because no clear hierarchy establishes that the law On Official Statistics takes precedence over other laws. For example, the law governing the Tax Administration Department could prevent INSTAT from having access to audited records. Nevertheless, INSTAT manages to cooperate with the Tax Administration Department to obtain the necessary data.

\subsubsection{Data sharing and coordination among data-producing agencies are adequate}

Data sharing and coordination among data-producing agencies need strengthening to improve effectiveness and fulfill the requirement of the Law, including putting in place memorandums of understanding (MOUs) with other data-producing agencies. Article 8 of the Law assigns INSTAT the responsibility for proposing an official statistics program in coordination with other statistical institutions. In practice, INSTAT arranges and chairs (1) a quarterly advisory meeting, involving heads of statistics departments of all ministries and data-producing agencies to discuss matters of professional interest, and (2) an annual meeting with these agencies to discuss developments in the program of official statistics. INSTAT establishes an MOU with each statistical agency that maintains administrative records used in the production of statistics. These MOUs stipulate working arrangements and mutual obligations, including the data to be provided by the agency to INSTAT and the timetable for submission. INSTAT is empowered to approve statistical surveys to avoid duplication and uphold professional statistical standards. Article 12 of the Law specifies the duties of other reporting agencies, stating that all institutions shall give INSTAT access to registers, data files, and data collected, processed, and stored in the domain of the agencies. Clearly, this only applies to data needed for the production of statistics, to avoid or minimize response burden on the statistical units.

In practice, INSTAT generally has access to the data it needs, but the data sharing process could be improved. Delays in data production of other agencies have adversely affected the timely production of the national accounts. INSTAT has not finalized MOUs on data provision with key data-providing agencies; the MOU includes the description of data required, the format in which it will be reported, and the timeframe of data reporting. MOUs with key agencies (e.g., with the Bank of Albania, Ministry of Finance, and Ministry of Agriculture) are expected to be finalized in the near future.

Recommendation: Sign MOUs with key data-producing agencies. Enforce the implementation of MOUs to make sure that the necessary data are provided to INSTAT in the agreed format and timeframe. 


\subsubsection{Individual reporters' data are to be kept confidential and used for statistical purposes only}

The Law (Articles 4 and 15) clearly stipulates the confidentiality of data of individual reporters. It prevents any nonstatistical utilization of data that are collected and their unlawful disclosure. Individual reporters' data collected by INSTAT cannot be used for fiscal inspection purposes or investigation. The Law has a specific provision that aggregate data should comprise at least three reporting units, and the share of any one unit should not exceed 85 percent of the total. The Law also specifies the rights and obligations of statistical reporters.

All employees of the statistical system are required to protect the confidentiality of individual information. Any staff that violates the secrecy of statistical information is subject to fine and/or dismissal from office.

Owing to the lack of space, survey forms are processed in an open area, but the entrance to the building is guarded by security officers.

Recommendation: Improve the security of physical work places to prevent possible access to survey forms by outsiders.

\subsubsection{Statistical reporting is ensured through legal mandate and/or measures to encourage response}

Article 14 of the Law specifies the obligation of reporters (enterprises, institutions, and physical and legal persons) to supply data to INSTAT in a complete and truthful manner. The information shall be provided in the form and within the time period requested, and free of charge. Furthermore, Article 16 states that INSTAT has the right to collect and use administrative statistics for implementing the official statistics program. Failing to provide information to INSTAT is considered an administrative offense subject to fines at various specific levels (see also 0.1.2).

\section{$0.2 \quad$ Resources}

\subsubsection{Staff, facilities, computing resources, and financing are commensurate with statistical programs}

INSTAT's financial and staff resources are severely inadequate. According to a Eurostat study, ${ }^{3}$ Albania's national statistical institute, compared with those of other countries of the same size, is small. Financial constraints, at times, delay and/or limit the planned surveys necessary for producing statistics. Staff resources are limited in terms of both numbers and

\footnotetext{
3 "A Global Assessment of the Statistical System of the Republic of Albania," Eurostat and UN Economic Commission for Europe, April 2005.
} 
experience. As of April 2005,155 employees are equally divided between the Central Directorate and the Regional Directorates. The Regional Directorates are responsible for collecting survey data and publishing statistical bulletins for the regions. At present, the NAS has eight staff, while at least 12 staff are required to implement its work program agreed under the Twining Project approved by the government. Also, a serious shortage exists in staff and financial resources to conduct surveys. The shortage of financial resources has resulted in postponement or even abolition of statistical surveys and dissemination of statistics.

The qualifications of staff are adequate; all NAS staff have at least a university degree and are trained in statistical compilation. However, the high turnover of staff presents difficulties in maintaining a core of highly-skilled staff to provide continuity and institutional memory. For example, of the eight staff in the NAS, including Sector Head, four joined the department just last year. Apart from the Sector Head, only two have been with INSTAT for more than five years. High staff turnover results from uncompetitive salaries, as compared with other government agencies for comparable skills and responsibilities. Given this situation, INSTAT has become a training ground for technical staff who leave for similar but better paying jobs in other institutions. Furthermore, limited continuity of staff in NAS makes succession planning more complicated.

The NAS is facing mounting pressure from users to expand the scope of the national accounts and improve their timeliness. The NAS staff is responsible for compiling annual GDP by the production and expenditure approaches. INSTAT is also developing quarterly GDP and annual supply and use tables, albeit slowly.

Limited information technology has seriously constrained INSTAT's work in terms of timely data processing and dissemination. INSTAT's website does not have the most up-to-date available information because of technical problems and the lack of staff to post information on the website. Adequate computer facilities seem to be available for staff. The physical facilities are limited in terms of both office space and functionality for regular operations (e.g., four staff in a small office, limited meeting facilities, lack of enclosed space to process confidential survey data, etc.).

Recommendation: Provide financial resources to ensure implementation of a five-year national program of official statistics as required by the Law, particularly for censuses and surveys critically important to the production of the national accounts. Financial resources should be provided predictably to allow continuity in the implementation of statistical programs.

Recommendation: Provide sufficient staff resources commensurate with the implementation of the agreed statistical programs. Furthermore, staff compensation should be reviewed to ensure the competitiveness of INSTAT in attracting and retaining highly qualified staff.

Recommendation: Improve information technology to better facilitate data compilation and dissemination. 


\subsubsection{Measures to ensure efficient use of resources are implemented}

The Law requires the production of official statistics to be cost-effective; the work and cost of each statistical program must be in proportion to the importance of the work. INSTAT staff as civil servants are governed by the Civil Servant Law (Nr. 8549, November 11, 1999) regarding efficient use of resources and staff performance.

INSTAT management promotes a vision and a direction shared with staff in focusing on efficient use of resources, particularly in the current tight budgetary situation. Efficiencies are sought by encouraging consistency in concepts and methodologies across different statistics agencies, coordinating statistical work programs among agencies, taking measures to minimize respondents' burden through consultation among data-producing agencies regarding surveys, and retaining a core specialized team of survey enumerators in spite of their contractual appointments. Since 2005, INSTAT staff are subject to a formal annual performance review. INSTAT also has a system of reporting time spent on various work activities by individual staff. The information will be used for budgetary and work program planning purposes. Similar to other government agencies, INSTAT is subject to overall government regulations to execute its responsibilities in the most cost-efficient manner and is subject to a budgetary audit process.

INSTAT also seeks outside expert assistance to evaluate statistical methodologies and compilation systems, such as from Eurostat, the IMF, the World Bank, the Italian National Institute of Statistics, the United Kingdom's Department for International Development, the Swedish International Development Agency, and others.

\subsection{Relevance}

\subsubsection{The relevance and practical utility of existing statistics in meeting users' needs are monitored}

INSTAT monitors users' needs regularly and adequately using various means. From time to time, to promote the use of statistics, INSTAT organizes seminars for users from various groups (e.g., officials, media, academe, researchers, and students). Technical committees such as the Committee on Classification provide forums to discuss users' needs as well as technical issues. In 2005, INSTAT conducted a special "Image Survey on INSTAT" with about 1,000 respondents. The results of the survey will be used to improve processes and products, including services to data users. Staff of INSTAT participate in international statistical meetings, which promote awareness of users' needs, particularly in connection with EU statistical requirements. INSTAT also organizes conferences to get feedback on the quality of its products (e.g., "Albania Statistics towards the EU" in December 2005). 


\subsection{Other quality management}

\subsubsection{Processes are in place to focus on quality}

INSTAT's mission is to provide transparent, neutral, and timely statistics that help users judge the development of the transformation processes within the country. To achieve its mission, INSTAT's operations are guided by the basic principles of official statistics adopted by the Economic Commission for Europe and the UN's Fundamental Principles of Official Statistics. INSTAT management is sensitive to all dimensions of quality and seeks to strive for the optimum trade-offs between the various dimensions, such as reliability, sustainability, and efficiency. Staff training programs (e.g., staff orientation programs) emphasize the vision and operational culture of the institution regarding the importance of data quality.

\subsubsection{Processes are in place to monitor the quality of the statistical program}

The Law requires the Statistics Council to supervise the implementation of the program of official statistics under the leadership of INSTAT, including the five-year national program of official statistics. Further, INSTAT has various internal monitoring processes for its statistical programs. Managers undertake regular assessments — both formal and informal — to identify progress achieved and identify problems of statistical activities. INSTAT staff have access to expert guidance on the quality of statistics and on strategies for improving data production. INSTAT receives technical assistance from various agencies and donor countries, involved with various aspects of data quality, such as methodology, source data, data dissemination strategies, etc.

\subsubsection{Processes are in place to deal with quality considerations in planning the statistical program}

INSTAT places a high priority on quality considerations in developing and executing its statistical programs. It also takes a lead role in promoting quality considerations among dataproducing agencies through balancing trade-offs between various aspects of quality, such as accuracy and timeliness. For example, INSTAT has recently used an accelerated compilation program for national accounts that better balances accuracy and timeliness by adding a third release of the data, thus improving the timeliness from 18 months to 11 months after the reference period.

\section{Assurances of integrity}

\subsection{Professionalism}

\subsubsection{Statistics are produced on an impartial basis}

The Law emphasizes professionalism and impartiality in the production of official statistics and in the conduct of INSTAT's operations. Article 4 protects the professional independence of INSTAT staff and prevents interference from government, other state authorities, political parties, or any other interest groups - notably in the selection of data sources, statistical 
methods, and procedures, in the contents, form, and time of dissemination, and in the application of statistical confidentiality.

The Law describes the roles and tasks of the Statistics Council members and of INSTAT's General Director. It specifies that the appointment and dismissal of the General Director be proposed by the Statistics Council and be subject to the approval of the Prime Minister and the Council of Ministers. INSTAT staff is subject to the rules and regulations of the Civil Servant Law (Nr. 8549, November 11, 1999). Hiring staff is through competitive recruitment based on qualifications. INSTAT promotes professionalism in its culture, providing opportunities for professional development, such as participation in courses, access to professional literature, and encouragement of research, which is presented in various international and regional conferences.

\subsubsection{Choices of sources and statistical techniques as well as decisions about dissemination are informed solely by statistical considerations}

Article 4 of the Law requires that the selection of techniques, definitions, and methodologies be based only on statistical considerations. The choices of source data are based on measurement objectives and data requirements, taking into account cost effectiveness and respondents' burden. Decisions on dissemination of statistical content, format, and timing are based solely on statistical considerations. The Law (Article 17) specifies dissemination criteria, including simultaneous release to all users, appropriate media to provide broadest access, and fulfillment of requests from any organization or individual for nonpublished data. INSTAT's practices follow the requirements of the Law.

\subsubsection{The appropriate statistical entity is entitled to comment on erroneous interpretation and misuse of statistics}

INSTAT staff respond to erroneous interpretation and misuse of statistics, in accordance with Article 8 of the Law. However, INSTAT should provide explicit guidelines on responding to erroneous interpretation and misuse of statistics because staff are uncertain of their expected role and boundary in practice. To encourage the understanding and facilitate a correct interpretation of statistics, INSTAT provides seminars and briefings to media and other users of its products.

Recommendation: Develop and disseminate staff guidelines to clarify the role and boundary of INSTAT's staff in responding to erroneous interpretation and misuse of statistics. 


\subsection{Transparency}

\subsubsection{The terms and conditions under which statistics are collected, processed, and} disseminated are available to the public

INSTAT posts the Law on its website. Article 4 of the Law guarantees transparency by giving the right to respondents to have information on the legal basis, the purposes for which the data are required, and the protective measures adopted to protect confidentiality. All questionnaires issued by INSTAT clearly state the terms and conditions of the data collection and compilation, as well as the respondents' obligation to provide information.

\subsubsection{Internal governmental access to statistics prior to their release is publicly identified}

Strictly adhering to the Law, INSTAT provides equal access and simultaneous release of data to the public. There is no prior access to the data before the release.

\subsubsection{Products of statistical agencies/units are clearly identified as such}

Data released to the public are clearly identified as INSTAT data. All publications have the INSTAT logo and contact information.

\subsubsection{Advance notice is given of major changes in methodology, source data, and statistical techniques}

INSTAT provides advance notice of major changes in methodology, source data, and statistical techniques, normally through proposals outlined in the statistical programs. The Law requires that the five-year national program of official statistics containing development work be published in official gazettes to inform the public. More often, INSTAT provides details regarding the changes when the changes take place. For example, in connection with the release of the 2004 GDP estimates based on new methodologies and data sources, INSTAT produced a special publication to explain the changes, their rationale, and the impact of the changes to the data.

\subsection{Ethical standards}

\subsubsection{Guidelines for staff behavior are in place and are well known to the staff}

INSTAT's staff behavior is governed by the Civil Servant's Law. Further, INSTAT has its own Code of Conduct for its staff. All new staff attend an orientation program where they are informed of the ethical standards and professional culture of INSTAT. 


\section{Methodological soundness}

\subsection{Concepts and definitions}

2.1.1 The overall structure in terms of concepts and definitions follows internationally accepted standards, guidelines, or good practices

The INSTAT National Accounts Section (NAS) compiles national accounts statistics based broadly on the concepts and framework of the System of National Accounts 1993 (1993 SNA) and consistent with the European System of Accounts 1995 (1995 ESA). Time series are available from 1996 onward.

\section{$2.2 \quad$ Scope}

2.2.1 The scope is broadly consistent with internationally accepted standards, guidelines, or good practices

The NAS does not produce all of the 1993 SNA tables and accounts needed to meet the minimum requirement of the Intersecretariat Working Group on National Accounts (ISWGNA $)^{4}$ on a regular basis. INSTAT produces the following accounts:

- annual value added and GDP at current and constant (previous year) prices by 25 major activity groups based on NACE Rev. 1 (a summary of nine activities is published); and

- annual expenditure components of GDP at current and constant (previous year) prices.

In addition, the NAS is developing a limited supply and use table (covering seven activities) and has begun to develop quarterly national accounts. These statistics are not currently being disseminated. INSTAT has already developed a strategic plan that includes compilation of other accounts specified by the ISWGNA.

Recommendation: Expand the scope of annual accounts to include the income accounts, the capital account, and the rest of the world accounts, as articulated in the INSTAT Strategic Plan.

\footnotetext{
${ }^{4}$ ISWGNA recommends these accounts as minimum: annual value added and GDP at current and constant prices by activity; annual expenditures of GDP at current and constant prices; annual value added components at current prices by activity; sequence of accounts for the total economy (up to financial accounts) with an annual frequency; and annual rest of the world accounts (until net lending).
} 
In accordance with the $1993 S N A$, national accounts cover the whole territory of Albania. The concept of residence is consistent with the 1993 SNA and the Balance of Payments Manual, fifth edition. Migrant workers who work part of the year in another country are classified as resident of Albania. Economic territorial enclaves such as embassies and free zones are included as a part of the economy.

The production boundary is broadly in accordance with the $1993 \mathrm{SNA}$, with some exceptions. Own-account production of agricultural goods for own final consumption is covered, as well as construction of dwellings by households. However, illegal outputs sold to willing buyers are not included. INSTAT and Eurostat are developing estimates for the production value of illegal activities, but the estimates will not be included in the GDP figures.

The asset boundary conforms broadly with the $1993 \mathrm{SNA}$; for instance it includes agricultural work-in-progress and tangible and intangible assets (e.g., development of software). Capitalized production is valued appropriately at the cost of production. However, defenserelated assets that can be used for civilian purposes are included in government consumption rather than capital formation.

\subsection{Classification/sectorization}

\subsubsection{Classification/sectorization systems used are broadly consistent with internationally accepted standards, guidelines, or good practices}

The NAS follows the 1995 ESA regarding classifications and sectorization of institutional units and transactions. Government Decision No. 327 (July 18, 1994) adopted the European Union (EU) system of classification of all ministries and central institutions, local authorities, state administration, and all entities performing economic activities. ${ }^{5}$ Classification of GDP by activities follows the Statistical Classification of Economic Activities in the EU (NACE Rev. 1) down to the four-digit level. For dissemination purposes, the activities are grouped into nine major industrial groups: agriculture, hunting and forestry; extracting industry; manufacturing industry; construction; trade; hotels and restaurants; transport; post and communications; and other services.

Product classification follows the European system of Central Product Classification (CPA). Furthermore, a link between CPA classifications to the Central Product Classification (CPC) is used. The Classification of Individual Consumption (COICOP) and the Classification of Functions of Government (COFOG) have been adopted but are not yet used in the national accounts.

5 1993-2001 Statistical Yearbook: Republic of Albania, INSTAT, 2003. 


\subsection{Basis for recording}

\subsubsection{Market prices are used to value flows and stocks}

The valuation rules for recording flows and stocks follow broadly the 1993 SNA. As far as possible, market output is valued at basic prices before any taxes on products (VAT, import duties, excise, and other taxes) are added and subsidies on products are deducted. However, some figures are valued at producer price or purchaser (market) prices, including subsistence agricultural production. Output of the government's nonmarket services is appropriately measured by aggregating costs. Owner-occupied housing is valued using market rental values.

In line with the 1993 SNA valuation principle, intermediate consumption excludes deductible VAT. However, problems with the survey data result in nondeductible VAT being excluded. INSTAT has an ongoing project to make appropriate adjustments. Gross fixed capital formation is valued at purchaser prices. Based on data from the BoA, import and export data are valued f.o.b. and converted from foreign currencies using average monthly exchange rates.

No adjustment for holding gains/losses is made to the data for change in inventories.

Recommendation: Include nondeductible VAT in the valuation of intermediate consumption.

Recommendation: Remove holding gains/losses from changes in inventories.

\subsubsection{Recording is done on an accrual basis}

In principle, transactions are on an accrual basis in accordance with the 1993 SNA. According to the accounting law and standards, all units are obliged to record their accounts on an accrual basis. However, general government accounts are on a cash basis, and no estimates are made to convert taxes and subsidies onto an accruals basis. Work-in-progress for agricultural products is recorded when the harvest takes place.

Recommendation: Make adjustments to estimate taxes and subsidies from cash to an accrual basis in collaboration with MoF.

\subsubsection{Grossing/netting procedures are broadly consistent with internationally accepted standards, guidelines, or good practices}

Data are collected from enterprises, so transactions between their establishments are netted out. In Albania, enterprises with more than one establishment are very limited so the impact of this deviation from 1993 SNA is small. 


\section{Accuracy and reliability}

\subsection{Source data}

\subsubsection{Source data are obtained from comprehensive data collection programs that take into account country-specific conditions}

Inadequate source data severely limit the reliability of the national accounts estimates, despite some improvement achieved during the past few years. INSTAT reviews the adequacy of source data regularly and proposes improvements. However, the lack of financial resources limits what can be done to improve the coverage of the existing surveys and to conduct more frequent and regular surveys. Nevertheless, INSTAT continues to improve its use of source data, both for deriving GDP estimates and for cross-checking.

INSTAT has a regular program of monthly, quarterly, and annual surveys covering a wide range of economic activities, but the surveys are often of inadequate quality. ${ }^{6}$ The comprehensiveness of the surveys needs improvement in terms of geographical coverage and more details in the questionnaires to address shortcomings in the compilation of the national accounts. The lack of a labor force survey limits the cross-checking of the accuracy of the regular source data. Ad hoc surveys, such as the Living Standard Measurement Survey (LSMS), Household Budget Survey (HBS) (currently covers urban areas only), 2001 Population and Dwellings Census, and the 1998 General Agricultural Census, are used to supplement the regular data sources.

An up-to-date statistical business register provides the basis for sample surveys of enterprises based on the number of employees and industrial activities. Updated information is taken from the administrative files of the National Register of Legal Entities held by the Tax Authority. Hence, it includes only legal enterprises and not establishments. The statistical register is updated using the results of various surveys, including a survey of large enterprises (quarterly), the SBS (annual), a retail trade survey (quarterly), a survey of productive enterprises (quarterly), the survey of construction enterprises (quarterly), and a survey of foreign direct investment (FDI). However, the statistical business register does not include turnover data, which would improve the survey selection and the grossing-up of the results.

INSTAT introduced in 2005 the annual "Survey on Newly Created Enterprises" to enhance the update of the statistical business register, particularly on employment and industrial classification. Survey selection is based on a stratified sample of the population by number of employees. The units in the register are stratified into three series: small enterprises with 1-4

\footnotetext{
${ }^{6}$ The regular program includes the annual structural business surveys (SBS), annual balance sheets of enterprises, the annual Agricultural Survey by Ministry of Agriculture (MoA), a quarterly retail sales index (4-digit NACE), quarterly VAT records, and various quarterly surveys on short-term statistics (for manufacturing, construction, wholesale trade, hotel, and energy).
} 
employees, medium-sized with 5-49 employees, and large enterprises with 50 or more employees. There is also a General Register of Agriculture-Economic Units.

Recommendation: Expand source data and improve survey coverage to provide adequate basis for compilation of national accounts (such as labor force survey, countrywide HSB) and improve questionnaire content and design.

Recommendation: Given resource limitations, review the establishment of survey strategy to focus more on turnover rather than number of employees. Use tax record data to include turnover data on the statistical register.

Recommendation: Improve the effectiveness of the system of surveys to optimize the questionnaire content and design (e.g., appropriate classifications, valuation, etc.). 


\section{Production Approach:}

Source Data_Production approach

\begin{tabular}{|c|c|c|c|}
\hline No & Description & $\begin{array}{l}\text { Correspondence } \\
\text { with NACE. } \\
\text { Rev } 1\end{array}$ & Main sources \\
\hline 1 & Agriculture, hunting and forestry & A & $\begin{array}{l}\text { Agriculture balances; } \\
\text { Survey on agriculture from MoA- detailed } \\
\text { information about the supply and use of goods in } \\
\text { both quantity and value terms }\end{array}$ \\
\hline 2 & Fishing & B & $\begin{array}{l}\text { Agriculture balances; } \\
\text { Survey on agriculture from MoA- detailed } \\
\text { information about the supply and use of goods in } \\
\text { both quantity and value terms }\end{array}$ \\
\hline 3 & Mining and quarrying of energy producing materials & $\mathrm{CA}$ & $\begin{array}{l}\text { Annual balance sheet of enterprise-profit and loss } \\
\text { account; } \\
\text { Structural Business Survey; } \\
\text { Data from VAT files }\end{array}$ \\
\hline 4 & $\begin{array}{l}\text { Mining and quarrying except energy-producing } \\
\text { materials }\end{array}$ & $\mathrm{CB}$ & $\begin{array}{l}\text { Annual balance sheet of enterprise-profit and loss } \\
\text { account; } \\
\text { Structural Business Survey; } \\
\text { Data from VAT files }\end{array}$ \\
\hline 5 & Manufacture of products based on cereals & DA (partly) & $\begin{array}{l}\text { Annual balance sheet of enterprise-profit and loss } \\
\text { account; } \\
\text { Structural Business Survey; } \\
\text { Data from VAT files }\end{array}$ \\
\hline 6 & Other manufacture of food products & DA (partly) & $\begin{array}{l}\text { Annual balance sheet of enterprise-profit and loss } \\
\text { account; } \\
\text { Structural Business Survey; } \\
\text { Data from VAT files }\end{array}$ \\
\hline 7 & Manufacture of textile and leather products & DB and DC & $\begin{array}{l}\text { Annual balance sheet of enterprise-profit and loss } \\
\text { account; } \\
\text { Structural Business Survey; } \\
\text { Data from VAT files }\end{array}$ \\
\hline 8 & $\begin{array}{l}\text { Manufacture of wood, paper, furniture; publishing and } \\
\text { printing }\end{array}$ & DD, DE, DN & $\begin{array}{l}\text { Annual balance sheet of enterprise-profit and loss } \\
\text { account; } \\
\text { Structural Business Survey; } \\
\text { Data from VAT files }\end{array}$ \\
\hline 9 & $\begin{array}{l}\text { Manufacture of coke, refined petroleum products, and } \\
\text { nuclear fuel }\end{array}$ & $\mathrm{DF}$ & $\begin{array}{l}\text { Annual balance sheet of enterprise-profit and loss } \\
\text { account; } \\
\text { Structural Business Survey; } \\
\text { Data from VAT files }\end{array}$ \\
\hline 10 & $\begin{array}{l}\text { Manufacture of chemicals, chemical products, rubber } \\
\text { and plastic products }\end{array}$ & DG, DH & $\begin{array}{l}\text { Annual balance sheet of enterprise-profit and loss } \\
\text { account; } \\
\text { Structural Business Survey; } \\
\text { Data from VAT files }\end{array}$ \\
\hline 11 & Manufacture of other nonmetallic mineral products & DI & $\begin{array}{l}\text { Annual balance sheet of enterprise-profit and loss } \\
\text { account; } \\
\text { Structural Business Survey; } \\
\text { Data from VAT files }\end{array}$ \\
\hline 12 & $\begin{array}{l}\text { Manufacture of basic metals and fabricated metal } \\
\text { products }\end{array}$ & DJ & $\begin{array}{l}\text { Annual balance sheet of enterprise-profit and loss } \\
\text { account; } \\
\text { Structural Business Survey; } \\
\text { Data from VAT files }\end{array}$ \\
\hline 13 & Manufacture of machinery and equipment & DK, DL, DM & $\begin{array}{l}\text { Annual balance sheet of enterprise-profit and loss } \\
\text { account; } \\
\text { Structural Business Survey; } \\
\text { Data from VAT files }\end{array}$ \\
\hline 14 & Electricity, gas and water supply & $\mathrm{E}$ & $\begin{array}{l}\text { Annual balance sheet of enterprise-profit and loss } \\
\text { account; } \\
\text { Structural Business Survey; } \\
\text { Data from VAT files }\end{array}$ \\
\hline
\end{tabular}




\begin{tabular}{|c|c|c|c|}
\hline No & Description & $\begin{array}{l}\text { Correspondence } \\
\text { with NACE. } \\
\text { Rev } 1\end{array}$ & Main sources \\
\hline 15 & Construction & F & $\begin{array}{l}\text { Annual balance sheet of enterprise-profit and loss } \\
\text { account; } \\
\text { Structural Business Survey; } \\
\text { Data from VAT files }\end{array}$ \\
\hline 16 & Trade & G & $\begin{array}{l}\text { Annual balance sheet of enterprise-profit and loss } \\
\text { account; } \\
\text { Structural Business Survey; } \\
\text { Data from VAT files }\end{array}$ \\
\hline 17 & Hotels and restaurants & $\mathrm{H}$ & $\begin{array}{l}\text { Annual balance sheet of enterprise-profit and loss } \\
\text { account; } \\
\text { Structural Business Survey; } \\
\text { Data from VAT files }\end{array}$ \\
\hline 18 & Transport & I(partly) & $\begin{array}{l}\text { Annual balance sheet of enterprise-profit and loss } \\
\text { account; } \\
\text { Structural Business Survey; } \\
\text { Data from VAT files }\end{array}$ \\
\hline 19 & Post and communication & $\mathrm{I}$ (partly) & $\begin{array}{l}\text { Annual balance sheet of enterprise-profit and loss } \\
\text { account; } \\
\text { Structural Business Survey; } \\
\text { Data from VAT files; } \\
\text { Administrative data from Ministry of Transport }\end{array}$ \\
\hline 20 & Financial activities & $\mathrm{J}$ & $\begin{array}{l}\text { Balance sheet and income statement; the annual } \\
\text { report of the banking system (containing balance } \\
\text { sheets and profit and loss); } \\
\text { Annual report of insurance undertakings; Yearbook } \\
\text { on insurance businesses compiled by the Insurance } \\
\text { Supervision Authority. }\end{array}$ \\
\hline 21 & Real estate, renting, and business activities & K & $\begin{array}{l}\text { Annual balance sheet of enterprise-profit and loss } \\
\text { account; } \\
\text { Structural Business Survey; } \\
\text { Data from VAT files; } \\
\text { LSMS for imputed rent. }\end{array}$ \\
\hline 22 & $\begin{array}{l}\text { Public administration and defense, compulsory social } \\
\text { security }\end{array}$ & $\mathrm{L}$ & $\begin{array}{l}\text { Consolidated state budget - the report on the } \\
\text { revenues and expenditures of the state budget for } \\
\text { central and local government activities and social } \\
\text { security funds from MoF }\end{array}$ \\
\hline 23 & Education & $\mathrm{M}$ & $\begin{array}{l}\text { Consolidated state budget - the report on the } \\
\text { revenues and expenditures of the state budget for } \\
\text { central and local government activities; } \\
\text { Administrative data from Ministry of Education. }\end{array}$ \\
\hline 24 & Health & $\mathrm{N}$ & $\begin{array}{l}\text { Consolidated state budget - the report on the } \\
\text { revenues and expenditures of the state budget for } \\
\text { central and local government activities and social } \\
\text { security funds; } \\
\text { Administrative data from Ministry of Health. }\end{array}$ \\
\hline 25 & Other community, social, and personal service activities & $\mathrm{O}, \mathrm{P}$ & $\begin{array}{l}\text { Annual balance sheet of enterprise-profit and loss } \\
\text { account; } \\
\text { Structural Business Survey; } \\
\text { Data from VAT files. }\end{array}$ \\
\hline
\end{tabular}


The annual SBS provides information on enterprises in production industries, construction, transport and communication, trade, and some service activities. The SBS also collects data on profit/loss, very limited breakdowns of intermediate consumption, and compensation of employees. The classification is by NACE for activities. The survey comprises (1) samples for enterprises with 1-4 employees and (2) exhaustive coverage for those with five or more employees. Value of production is based on sales/turnover, change in inventories of finished products, work in progress, capitalized production, and subsidies. Data on inventories are collected only from larger enterprises. From the NAS's perspective, more source data are needed for national accounts purposes, particularly details of intermediate consumption, change in inventories, and capital formation.

In addition, annual enterprise balance sheets provide supplementary data on value added, output, intermediate consumption, and turnover. Data from VAT files of the Directorate of Taxation provide information on taxes and turnover. Furthermore, data for the financial sector and insurance are from BoA and the Insurance Supervision Authority, respectively.

The Agricultural survey uses an outdated sampling framework. MoA conducts an annual survey on farms based on "area sampling survey" method. However, this method is not consistent with the 1998 agricultural census and the 2001 population census. Nevertheless, INSTAT and MoA are cooperating to improve the agricultural survey, by next year on the basis of the Agricultural Census.

Recommendation: Increase the use of proper random sampling techniques. For existing surveys, review the questionnaire design, samples, and response rates to optimize the source data collection. 
Expenditure Approach:

Source Data—Expenditure approach

\begin{tabular}{|l|l|}
\hline \multicolumn{1}{|c|}{ Expenditure components } & Main Data Sources \\
\hline $\begin{array}{l}\text { Household final consumption } \\
\text { (Breakdown by COICOP is not available.) }\end{array}$ & $\begin{array}{l}\text { LSMS; } \\
\text { Retail trade; } \\
\text { Agricultural balances survey; } \\
\text { Balance of payments of BoA; } \\
\text { Annual balance sheet of enterprise; } \\
\text { Administrative data from Ministry of } \\
\text { Transport } \\
1998 \text { survey on NPISH on income and } \\
\text { expenses }\end{array}$ \\
Administrative data from Ministry of \\
Final consumption expenditure of NPISHs \\
Fovernment final consumption expenditure \\
Annual Structural Business Survey; \\
Annual Statement of Accounts of \\
assets \\
nonfinancial and financial enterprises; \\
Administrative data from the Ministries \\
-- \\
$\begin{array}{l}\text { Acquisitions less disposals of intangible } \\
\text { fixed assets } \\
\text { Additions to the value of nonproduced } \\
\text { nonfinancial assets } \\
\text { Changes in inventories }\end{array}$ & $\begin{array}{l}\text {-- } \\
\text { Acquisitions less disposals of valuables } \\
\text { Exports and imports of goods }\end{array}$ \\
$\begin{array}{l}\text { Annual balance sheet of enterprise- } \\
\text { balance sheet } \\
-- \\
\text { Directorate of Customs - customs } \\
\text { statistics and Balance of Payments of } \\
\text { BoA. } \\
\text { BoA- Balance of Payments }\end{array}$ \\
\hline
\end{tabular}

Source data are very limited for the expenditure approach, especially on household consumption. Data sources are mainly from the HBS (based on COICOP classification), government records, and foreign trade data. However, the HBS is not conducted regularly and does not cover the whole of Albania. The first Family Budget Survey in 1998 covered only Tirana, and the second HBS in 2000 covered Tirana and other urban areas with 5,389 households. INSTAT plans to launch the third HBS in 2006, which will cover the whole of Albania. Data are lacking for expenditure on private education and healthcare.

Supplementary data are from ad hoc surveys (e.g., LSMS [focusing mainly on povertyrelated data]), the social security fund, and data on government operations. These data are used to cross-check household consumption data. 


\section{Recommendation: Conduct HBS covering the entire country.}

Price statistics are available for the monthly CPI, monthly PPI, and unit value indices (UVI) of foreign merchandise trade. In addition, an annual construction cost index calculates the difference between basic input prices. Prices are also collected for agricultural products.

\subsubsection{Source data reasonably approximate the definitions, scope, classifications, valuation, and time of recording required}

Source data are not sufficiently consistent with the definitions, scope, and classifications of the national accounts statistics. ${ }^{7}$ Source data do not provide details on production taxes to allow proper valuation of transactions. As for the nonobserved economy, since 2005, an improvement in scope has been made to improve the estimates. The SBS needs better coverage of data on intermediate consumption, change in inventories, employment, and gross fixed capital formation. The accounting conventions need improvement (such as for agriculture data) to allow better differentiation between changes in inventories and capital formation. There is a lack of comprehensive employment information because there is no labor force survey, and other surveys have limited coverage of employment data.

Laudably, new questionnaires are subject to field piloting to ensure that the design is appropriate; for example, a pilot survey to improve the data on work in progress for the agricultural sector was field-tested in 2005 , before its full implementation.

Source data from enterprise balance sheets and the SBS are on a calendar year basis, consistent with the national accounts reference period. However, source data lack sufficient coverage to provide good estimates for the national accounts. The SBS does not cover private production data on health and education, even though the private sector has become a significant producer. The HBS only covers urban areas and lacks sufficient detailed breakdowns of expenditures (e.g., on private education and health care). Consumption data for NPISHs are from an outdated 1998 survey. The UVI is unreliable because of inaccurate valuations.

Source data on the production side provide at least 80 percent of formal activities. Since November 2005, improvements have been made to the estimates for the nonobserved economy by pulling together various source data and estimation methods. However, GDP estimates could be further improved (see Section 3.3.2).

Recommendation: Expand questions in the SBS to better capture source data for intermediate consumption, gross fixed capital formation, and change in inventories of appropriate categories (work-in-progress, raw materials, inventories for resale, etc.).

\footnotetext{
${ }^{7}$ NAS indicated that technical assistance is being provided by Eurostat and UN Economic Commission for Europe to improve source data for economic and social statistics.
} 
Recommendation: Launch the new HBS, covering the entire country, as soon as possible and establish a policy regarding the frequency of the survey to allow compilation of national accounts using the expenditure approach.

\subsubsection{Source data are timely}

Timeliness of source data is a major issue, resulting in delays of national accounts production. Also, the NAS indicated some delays in obtaining administrative information from $\mathrm{MoF}, \mathrm{BoA}$, etc. that have caused delays in the production of national accounts. It is hoped that with the newly introduced MOUs between INSTAT and the other data reporting agencies, more timely data will be reported to INSTAT.

Recommendation: Consider the collection of statistical data from enterprises earlier and with less completeness than balance sheet data, if needed, to ensure the timeliness of these source data.

\subsection{Assessment of source data}

3.2.1 Source data-including censuses, sample surveys and administrative records-are routinely assessed, e.g., for coverage, sample error, response error, and nonsampling error; the results of the assessments are monitored and made available to guide statistical processes

INSTAT routinely assesses the source data to ensure its accuracy. An automatic computer program cross-checks data from various sources, assesses temporal consistency, and compares time series. Staff confirm the accuracy of unusual responses from major respondents. They often pilot changes to questionnaires to allow an assessment of the changes.

Staff analyze the source data to correct for underreporting or misreporting. For example, the SBS questionnaire is reviewed every year to improve the quality and quantity of data with a view to implementing Eurostat requirements. Source data are analyzed in the context of main revisions, and revised data are incorporated into the national accounts statistics.

INSTAT monitors sampling errors of surveys regularly, especially for SBS, and has information on nonsampling errors. The SBS uses a random sample methodology for enterprises with fewer than five employees. The overall response rate is more than 95 percent. Special attention is given to cross-check outliers from surveys to confirm their accuracy and to capture important enterprises. Imputation is only made for item nonresponse based on a sound method of averaging the group. Out-of-scope activities, not yet covered by the current survey classification (nonsampling errors), declined to about 17 percent in 2004. Some of these are local establishments already captured by associated enterprises. The grossing-up factors are derived scientifically, based on sample design.

Staff routinely assess the accuracy of budget execution data, balance of payments data and price data. 


\subsection{Statistical techniques}

\subsubsection{Data compilation employs sound statistical techniques to deal with data sources}

The NAS has adequate procedures for minimizing errors. A computer program, based on ACCESS and EXCEL, is used to automatically cross-check source data from the SBS, VAT files, and the statistical business register (of enterprises). Automatic checks are used to minimize errors relating to data on production, intermediate consumption, and gross value added by activities. In addition, automatic generation of report tables with built-in validation is performed.

For SBS data processing, validation and editing procedures use data and logical controls. Some controls involve cleaning the data. Outliers are not replaced or modified. They are resolved in the grossing-up stage. Usually they are enterprises that have switched strata.

Imputation and adjustment for nonresponse are made using alternative sources for the same respondent from tax records, average data for the relevant industry group, data for other enterprises with similar characteristics, or extrapolation.

\subsubsection{Other statistical procedures (e.g., data adjustments and transformations, and statistical analysis) employ sound statistical techniques}

An internationally accepted methodology has been introduced to improve estimates of unobserved activities, but with very limited application. The results of the new estimates were incorporated in the release of the 2004 GDP figure and the revised 1996-2003 GDP estimates. The estimates of the nonobserved economy were based on a labor input method of comparing labor supply estimates from LSMS against labor demand from the SBS. Analysis was made to cross-check the plausibility of these estimates using a limited commodity flow approach. However, further cross-checks for reasonableness by using other data sources were not done. Furthermore, the assumption on labor productivity for nonobserved activities needs further investigation. For example, the estimate of additional value added by the construction sector from the nonobserved economy of 73 percent was not cross-checked with imports of building materials. Prior to the introduction of the new method, estimates of nonobserved activities were based on fixed ratios created by sector experts.

Recommendation: Improve the methodology to estimate nonobserved activities, especially for construction activity, by more cross-checking with other data sources for reasonableness of the estimates. Review the estimates by using more recent LSMS (2005) data and further investigate the productivity assumption for the construction sector.

For the production approach, the estimates of output and intermediate consumption are compiled at the one- or two-digit levels of NACE. Proper source data are available for output and intermediate consumption for all activities, so fixed ratios are not used.

Problems occur for some specific issues in the GDP compilation system. For some activities, the source data do not allow the precise identification of production data in accordance with 
the 1993 SNA (e.g., agricultural data do not allow the correct identification of changes in inventories). In addition, no adjustment for holding gains/losses is made to changes in inventories. Consumption of fixed capital is not based on the perpetual inventory method, and all government data are not on an accruals basis. On the other hand, output of owneroccupied dwellings is appropriately estimated from the comparable rent market, the 2001 Population and Dwellings Census, and data from the CPI. Work in progress of large construction projects is reported, and work in progress of private home construction is estimated. Further improvements to the estimates for work in progress for construction, including household own production, are being developed.

Following the 1993 SNA, the double-deflation method was implemented in November 2005. Corresponding deflators are used for output and a product breakdown of intermediate consumption. In addition, detailed PPI and UVI are used for output and intermediate consumption, split between domestic and foreign trade. It should be noted that the UVI data are not reliable owing to the inaccuracy of customs data. The mission was informed that PPI already includes prices for exports, in which case it is inappropriate to deflate output for domestic sales and exports separately.

Recommendation: If the PPI includes exported commodities, it should be used to deflate total output, given the very poor quality of UVI.

Volume measures of taxes/subsidies on products are estimated based on a mix of different approaches. A new appropriate method has been developed, of applying base-year tax rates to the volume of transactions, subject to specific taxes/subsidies. It is anticipated this will soon be implemented.

Output volume of trade margin is estimated using the CPI-as-deflator method, rather than the internationally accepted method of applying the base-year-margin rate to the corresponding volume of sales or by extrapolating the base-year-trade margin using volume extrapolators of sales.

Recommendation: Apply the appropriate methods to obtain volume measures for taxes/subsidies and trade margins.

GDP volume change is measured using annual chain indices.

Total GDP is derived from the production estimates. For the expenditure approach, independently derived components are only available for exports, imports, government consumption, and part of gross-fixed capital formation. A new methodology was adopted for the revised GDP data (for 1996-2004) in November 2005. However, this new methodology is based on unusually weak assumptions. Benchmark values were derived for 2000 using commodity flow techniques. Household consumption was then estimated for other years by assuming it represented 90 percent of the increase in total GDP, which seems questionable. The statistical discrepancy, combined with changes in inventories, was estimated on the very weak assumption that these represent no more than 10 percent of GDP at market price.

Consumption of NPISHs was based on an NPISH/GDP ratio from a very outdated survey 
(1998). Then, since changes in inventories are only collected for a limited coverage of enterprises, they are derived by residual. More importantly, these weak assumptions are not provided to the public when the data are released and could mislead users on the accuracy of the expenditure estimates. Prior to the adoption of this new methodology in 2005, the balancing items for the GDP estimates from the production and expenditure approaches were the combined change in inventories and statistical discrepancies. It would be better to acknowledge the lack of expenditure data by deriving household final consumption as a residual, making it clear in all published tables that this includes changes in inventories and errors and omissions in the rest of the GDP compilation processes.

Recommendation: Rationalize the methods used to derive the expenditure components of GDP. For years when final consumption components cannot be estimated, use a single balancing item on the expenditure side that combines household consumption, change in inventories, and statistical discrepancies. Accordingly, disseminate the methodology clearly to users.

Recommendation: Use data from the LSMS to improve household final consumption expenditure estimates.

Volume estimates of expenditure components are derived using appropriate deflators. Dedicated price indices/deflators are used to deflate GDP components at least at the one-digit level of the corresponding classifications. The CPI is used to deflate household final consumption. Government final consumption expenditure is derived by deflating the cost components of its output for final use.

\subsection{Assessment and validation of intermediate data and statistical outputs}

\subsubsection{Intermediate results are validated against other information where applicable}

The data compiled from the main sources used to compile the national accounts statistics are checked against other independent data sources whenever possible (e.g., data from the balance sheets of enterprises are checked against related indicators, such as tax records, volume and price trends).

\subsubsection{Statistical discrepancies in intermediate data are assessed and investigated}

A systematic procedure is used to routinely assess the potential discrepancies in intermediate data. However, adjustments to remove discrepancies are not necessarily based on appropriate techniques. For example, the limited source data on change in inventories resulted in the estimates being derived using a fixed ratio, instead of improving the source data.

Intermediate data are cross-checked as far as possible, including the use of commodity flow techniques, LSMS, and an ad hoc study, Living Conditions and Inequality in Albania by INSTAT. The estimates of nonobserved construction activity are based on labor input from very limited coverage and series of labor data without thorough cross-checking, for reasonableness, with other construction input material data. 
Recommendation: Expand further the cross-checking of intermediate data by making more use of available data.

\subsubsection{Statistical discrepancies and other potential indicators of problems in statistical outputs are investigated}

To facilitate the investigation of the consistency of the GDP estimates, INSTAT is developing supply and use tables (SUT) to balance the estimates by industry/product. Currently, the experimental SUT are very limited, covering only seven activities. At the present stage of development and with limited source data, the lack of quality expenditure components would cast in doubt the usefulness of SUT.

\subsection{Revision studies}

\subsubsection{Studies and analyses of revisions are carried out routinely and used internally to inform statistical processes (see also 4.3.3)}

During the past few years, in connection with the ongoing methodological improvements, revision studies and analyses of revisions have been carried out. No explicit directive exists for regular revision studies, but the national accounts team anticipates that such studies will continue. Findings from revision studies are used to investigate differences with a view to improving methodology and source data.

Recommendation: Introduce a policy to conduct revision studies regularly.

\section{Serviceability}

\subsection{Periodicity and timeliness}

\subsubsection{Periodicity follows dissemination standards}

National accounts data are compiled and disseminated annually, thus meeting the recommendation of the GDDS.

\subsubsection{Timeliness follows dissemination standards}

National accounts data are disseminated within 11 months after the end of the reference period, as compared with the GDDS recommendation of 9 months. This 11 -month timeliness was achieved for the first time when the NAS released the preliminary 2004 GDP estimates in November 2005 in connection with the INSTAT conference "Albania Statistics toward the EU." The 2004 GDP data were later published in the Structure and Changes of the Albania Economy Based on National Accounts in January 2006. The preliminary data are based on aggregated information.

During the mission in March 2006, INSTAT adopted a new schedule for annual national accounts. 
- The first release of preliminary data is within 11 months (in November of year $\mathrm{t}+1)$ after the reference year $\mathrm{t}$,

- the second release of revised data is within 17 months (in May of year $\mathrm{t}+2$ ) after the reference year $t$, and

- the third release of the final data within 23 months (in November of year $t+2$ ) after the reference year $t$.

To adhere to the improved schedule, it is important that all source data for the national accounts are made available to INSTAT by other data-producing agencies in line with the agreement in the five-year national program of official statistics.

Recommendation: Improve the timeliness of the national accounts to meet the recommendation of the GDDS.

\subsection{Consistency}

\subsubsection{Statistics are consistent within the dataset}

The GDP estimates from the production approach and the expenditure approach are not independently derived, preventing a meaningful consistency check. The GDP estimates from the expenditure approach are made to be consistent with the production approach. Prior to November 2005, more components from the expenditure approach were derived independently, but a combined series of changes in inventories and statistical discrepancies was still derived as a residual. The size of the balancing item has been significant and erratic. Based on the old estimates, the balancing item averaged 17 percent of GDP during 2001-03.

GDP estimates at current price, volume measures, and deflators are all consistent within the "value=volume x price" framework, and the totals are the sum of the components.

Recommendation: Improve the methodology to derive independent estimates of the expenditure components of GDP and assess the consistency of these estimates with the production approach.

\subsubsection{Statistics are consistent or reconcilable over a reasonable period of time}

The GDP figures for 1996 to 2004 are consistent. The latest major revision of the GDP estimates was made in November 2005, owing to improvements in methodology and source data. At that time, INSTAT revised the entire series of estimates and published an accompanying methodological note, describing the justification for the revisions and their size.

With the regular release of the GDP estimates, INSTAT provides information on the movements in the data. (See the note "GDP 1996-2002," published in September 2004.) 


\subsubsection{Statistics are consistent or reconcilable with those obtained through other data sources and/or statistical frameworks}

National accounts statistics are consistent with the balance of payments, financial statistics, and fiscal data. In compiling national accounts, INSTAT uses external data from the balance of payments and financial sector data from the BoA. The MoF provides the general government data. In addition, INSTAT uses the same institutional classification of the public sector as that used by the MoF.

\subsection{Revision policy and practice}

\subsubsection{Revisions follow a regular and transparent schedule}

During the mission, INSTAT established a new revision policy for the annual national accounts, reflecting an improved timeliness from 18 to 11 months for the first release of the preliminary GDP estimates. (See 4.1.2.) The revision policy and revision cycle have been disseminated on the website.

Recommendation: Apply the new revision policy consistently.

\subsubsection{Preliminary and/or revised data are clearly identified}

Not all publications on the national accounts (such as the Statistical Yearbook, Albania in Figures, and data released on INSTAT's website) identify the status of the data-that is, preliminary, revised, or final. In some special publications, mainly related to major changes in methodology, comparisons were made between the old and new estimates.

Recommendation: Clearly indicate the status of the published GDP data.

\subsubsection{Studies and analyses of revisions are made public (see also 3.5.1)}

INSTAT has no official directive on conducting or disseminating revision studies. However, under the ongoing project to improve the methodology of the national accounts and their source data, INSTAT is carrying out comprehensive revision studies. In this connection, it published a special report, Structure and Changes of the Albanian Economy Based on National Accounts, January 2006, which contains the size of revisions of GDP estimates between the 2004 release and the 2005 release. However, the publication is not widely disseminated and is not on the INSTAT website. INSTAT indicates it intends to continue to undertake revision studies and release the results to the public.

Recommendation: Disseminate all revision studies to the public. 


\section{Accessibility}

\subsection{Data accessibility}

5.1.1 Statistics are presented in a way that facilitates proper interpretation and meaningful comparisons (layout and clarity of text, tables, and charts)

National accounts are published clearly with tables and charts (in some publications). Usually, data are accompanied by a brief commentary on recent developments. Estimates are disseminated with a reasonable level of detail and as time series. Time series of major aggregates can also be downloaded from the INSTAT website. Depending on the type of publication - statistical yearbook or specialized national accounts publication - datasets are published with various levels of detail and with technical notes.

\subsubsection{Dissemination media and format are adequate}

Compilation and dissemination of national accounts are still evolving in Albania with the first release of the statistics only in 2002. Since then, INSTAT has continued to improve the dissemination of national accounts. However, the dissemination remains fragmentary, and up-to-date release formats are limited. Official dissemination is in hard copy, but CDs and a website are also used. Delays in the release of hard-copy publications prevent users from receiving the timely data. The major publications of the national accounts are Gross Domestic Product, 1996-2002, the Statistical Yearbook, and the Internet release of national accounts under "Economic Indicators." However, users have difficulty knowing which publication contains the first release of the GDP estimates and which publication includes the final GDP estimates. For example, Albania in Figures 2005 provides 2004 GDP estimates different from those in the publication Structure and Changes of the Albanian Economy Based on National Accounts, January 2006. The 2004 GDP estimates were not disseminated through the more regular note "Gross Domestic Product."

Recommendation: To improve users' access to more timely data, consider the use of nonhard-copy publications as the official mode of data dissemination (e.g., website release, press release, or $C D$ ).

Recommendation: Disseminate clearer information on the publications and the sequence of release of the national accounts statistics.

\subsubsection{Statistics are released on a preannounced schedule}

INSTAT disseminates an advance release calendar (ARC) for various data categories for the coming year. The Law, Article 8, requires INSTAT to produce, before the end of the calendar year, a detailed calendar indicating dates when particular official statistics will be disseminated in the following year. In principle, the ARC is published in January of the year-both by hard copy and through the website. In practice, the dissemination of the ARC on the website is not timely. 
Releases of the national accounts do not always adhere to the ARC although INSTAT exercises best efforts to do so. No procedure exists for updating the calendar to indicate the likelihood of delay in data releases or to keep users better informed as to when the data might actually be released.

Recommendation: Use a more flexible and user-friendly format for the ARC. For instance, provide a no-later-than date for the release of the GDP estimates and update the ARC to a specific date when the exact release date is known, perhaps one week before the actual release date.

Recommendation: Disseminate the data strictly according to the ARC to maintain INSTAT's credibility.

\subsubsection{Statistics are made available to all users at the same time}

The Law requires that official statistics shall be disseminated in such a way that all users have simultaneous access. INSTAT relies on hard copy for the official release of the data. Data on national accounts are released to all users at the same time. Extensive information on INSTAT's website informs the public of the release of the statistics and the modalities for accessing them.

\subsubsection{Statistics not routinely disseminated are made available upon request}

As long as data are not confidential, INSTAT provides additional data that are not routinely disseminated.

\subsection{Metadata accessibility}

5.2.1 Documentation on concepts, scope, classifications, basis of recording, data sources, and statistical techniques is available, and differences from internationally accepted standards, guidelines, or good practices are annotated

INSTAT disseminates various types of documentation related to national accounts on concepts, scope, classifications, and basis of recording, data sources, and statistical techniques - in hard copy and on the website. For major changes in methodology, revisions of the national accounts estimates are explained to users. The GDDS metadata provide a summary and are updated at least annually. INSTAT's website provides hyperlinks to various useful statistical information websites, including the GDDS website.

\subsubsection{Levels of detail are adapted to the needs of the intended audience}

National accounts metadata are presented with various levels of details - from a short release on the website (a note "Gross Domestic Product," year - of a few pages) to a more extensive explanation in the Statistical Yearbook. More specialized metadata with extensive technical information on national accounts are also produced occasionally, such as Structure and Changes of the Albanian Economy Based on National Accounts. 


\subsection{Assistance to users}

\subsubsection{Contact points for each subject field are publicized}

All INSTAT publications provide contact information through the section responsible for data dissemination. The website also provides details on organization and structure, including contact information for the head of the NAS. The GDDS provides more subject-specific contact information and can be accessed through INSTAT's website.

\subsubsection{Catalogs of publications, documents, and other services, including information on any charges, are widely available}

INSTAT's website contains extensive catalogs of publications, documents, and survey results. The Law, under Article 16, requires INSTAT to publish the prices for its publications. However, the website does not have the most up-to-date information on the latest publications. For example, it shows the Statistical Yearbook 1991-2000 and Albania in Figures for 2004, while the latest issues are the Statistical Yearbook 1993-2001, published in 2003, and Albania in Figures for 2005.

Recommendation: Keep the catalogs up-to-date. 
65

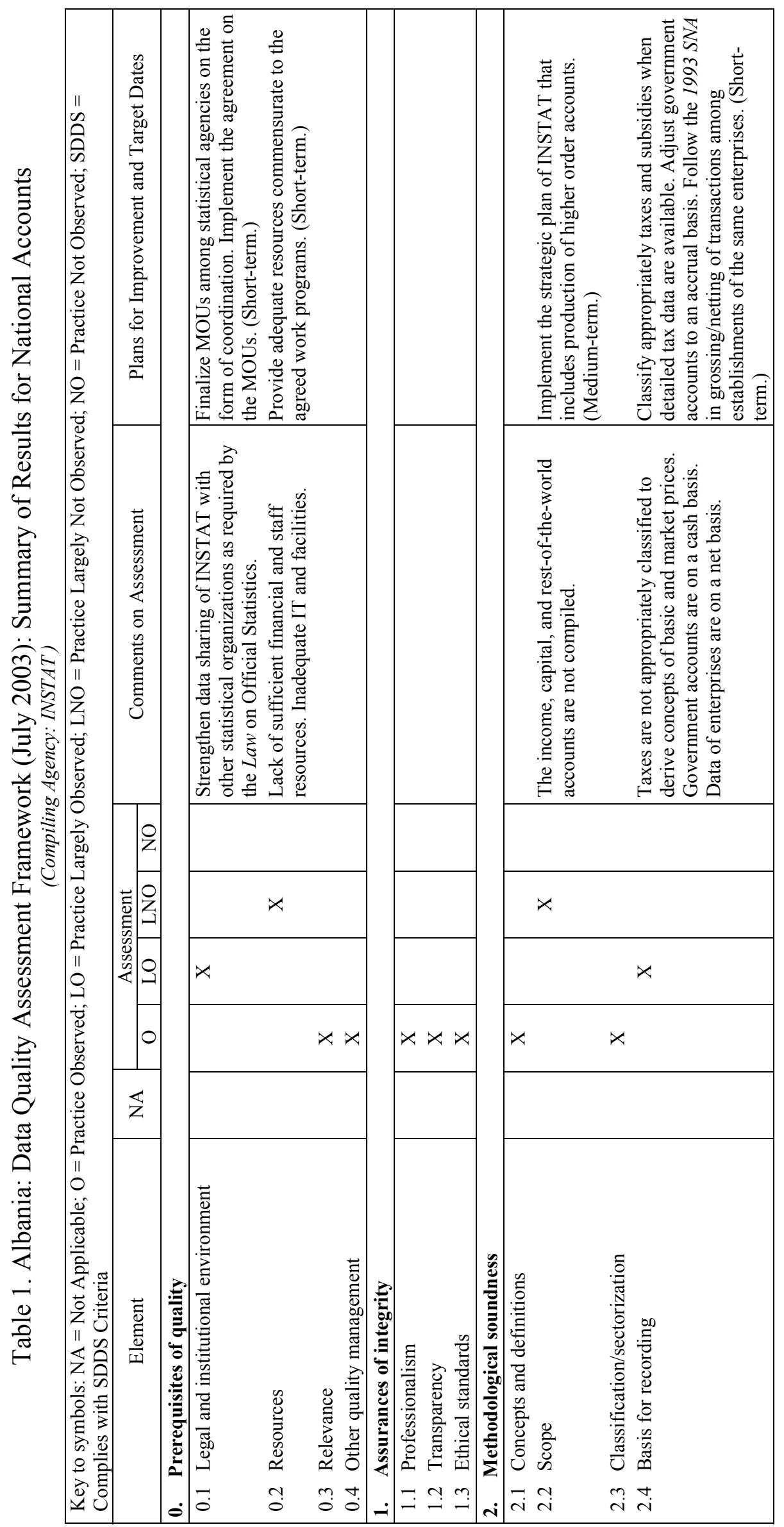


66

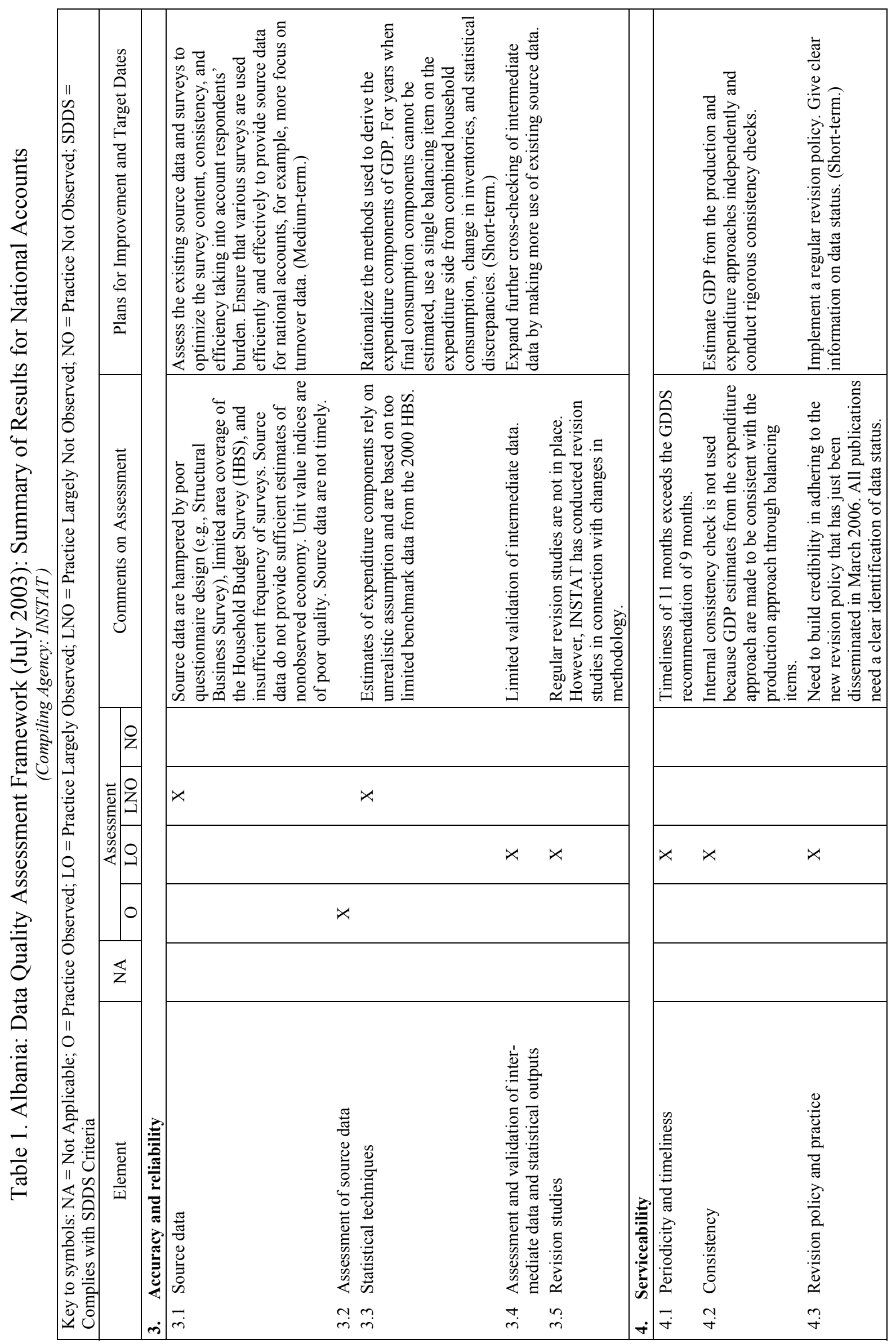




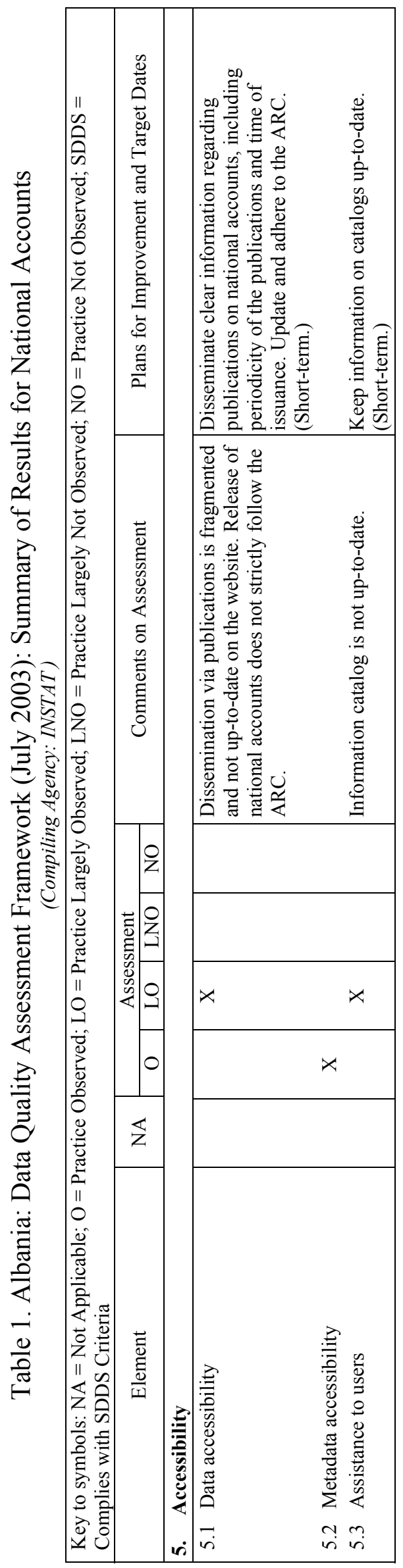




\section{Price Statistics (Consumer Price Index)}

\section{Prerequisites of quality}

\subsubsection{The responsibility for collecting, processing, and disseminating the statistics is clearly specified}

The legal and institutional arrangements provide adequate support for collecting, processing, and disseminating statistics. The law On Official Statistics, No. 9180, dated February 5, 2004 (the $L a w$ ), sets out the legal framework for the collection, organization, production, and dissemination of official statistics in Albania. The Law reflects elements of the UN Fundamental Principles of Official Statistics. The Law empowers the Institute of Statistics (INSTAT) to propose a program of official statistics to the Statistics Council and implement the approved program of statistics. INSTAT is authorized under Article 8 to issue to all dataproducing agencies, make public, and keep up-to-date the guidelines for professional standards in the production of official statistics. INSTAT is responsible for examining the procedures for producing statistics used by any official statistics-producing agency, with a view to ensuring their statistics are reliable, impartial, and objective.

INSTAT is an independent government agency under the supervision of the Statistics Council, which in turn reports to the Council of Ministers. In executing its responsibilities, INSTAT develops the program of official statistics in coordination with other data-producing agencies. The program consists of a five-year strategic plan and a one-year operational plan. The five-year plan is submitted for approval by Parliament, through the Prime Minister. The Statistics Council, with 11 members appointed by the Council of Ministers, oversees the implementation of the five-year strategic plan and the annual operational plan. INSTAT prepares quarterly reports detailing progress in implementing the annual plan. The Statistics Council approves INSTAT's organizational structure and annual budget plan prior to submission to the Ministry of Finance.

INSTAT is the only official producer of price indices, through its Price Indices Sector. In carrying out its responsibilities, the INSTAT is empowered by the Law to collect data from all entities.

\subsubsection{Data sharing and coordination among data-producing agencies are adequate}

The Consumer Price Index (CPI) program does not involve any data sharing with other dataproducing agencies.

\subsubsection{Individual reporters' data are to be kept confidential and used for statistical purposes only}

Confidentiality is upheld by INSTAT following the requirement of the Law. The Law (Articles 4 and 15) clearly stipulates the confidentiality of data of individual reporters. It prevents any nonstatistical utilization of data that are collected and their unlawful disclosure. 
Individual reporters' data collected by INSTAT cannot be used for fiscal inspection purposes or investigation. The Law has a specific provision that aggregate data should comprise at least three reporting units, and the share of any one unit should not exceed 85 percent of the total. The Law also specifies the rights and obligations of statistical reporters.

All INSTAT employees are required to protect the confidentiality of individual information. Any staff that violates the secrecy of statistical information is subject to fine and/or dismissal from office.

Owing to the lack of space, survey forms are processed in an open area, but the entrance to the building is guarded by security officers.

Recommendation: Improve the security of physical work places to prevent access to survey forms by outsiders.

\subsubsection{Statistical reporting is ensured through legal mandate and/or measures to encourage response}

Article 14 of the Law specifies the obligation of reporters (enterprises, institutions, and physical and legal persons) to supply data to INSTAT in a complete and truthful manner. The information shall be provided in the form and within the time period requested and free of charge. Furthermore, Article 16 states that INSTAT has the right to collect and use administrative statistics for implementing the official statistics program. Failing to provide information to INSTAT is considered an administrative offense subject to fines at various specific levels. (See also 0.1.2.)

\section{$0.2 \quad$ Resources}

\subsubsection{Staff, facilities, computing resources, and financing are commensurate with statistical programs}

INSTAT's financial and staff resources are severely inadequate. Financial constraints, at times, delay and/or limit the planned surveys necessary for producing statistics. Staff resources are limited in terms of both numbers and experience. Currently, 155 employees are equally divided between the Central Directorate and the Regional Directorates. The Regional Directorates are responsible for collecting survey data and publishing statistical bulletins for the regions. At present, only one professional works on the compilation of the CPI, with some clerical support for data entry. Although this is sufficient to operate the CPI program, the loss of the professional would endanger the program. Also a serious shortage exists in staff and financial resources to conduct surveys, such as the household budget survey. The shortage of financial resources has resulted in postponement or even abolition of statistical surveys and dissemination of statistics. 
The qualifications and training of the professional staff are good. Computer systems are adequate for the CPI program. The physical facilities are limited in terms of office space (e.g., four or five staff in a small office).

Recommendation: Increase the number of staff working on the CPI to provide back-up for the CPI program.

\subsubsection{Measures to ensure efficient use of resources are implemented}

The Law requires the production of official statistics to be cost-effective; the work and cost of each statistical program must be in proportion to the importance of the work.

INSTAT management promotes a vision and a direction shared with staff in focusing on efficient use of resources, particularly in the current tight budgetary situation. Efficiencies are sought by encouraging consistency in concepts and methodologies across different statistics agencies, coordinating statistical work programs among agencies, taking measures to minimize respondents' burden through consultation among data-producing agencies regarding surveys, and retaining a core specialized team of survey enumerators in spite of their contractual appointments. Since 2005, INSTAT staff are subject to a formal annual performance review. To further promote the efficient use of resources, INSTAT plans to initiate a program to measure managerial performance. Similar to other government agencies, INSTAT is subject to overall government regulations to execute its responsibilities in the most cost-efficient manner and is subject to a budgetary audit process.

INSTAT also seeks outside expert assistance to evaluate statistical methodologies and compilation systems, such as from Eurostat, the IMF, the World Bank, the Italian Institute of Statistics, the United Kingdom's Department for International Development, the Swedish International Development Agency, and others.

\section{$0.3 \quad$ Relevance}

\subsubsection{The relevance and practical utility of existing statistics in meeting users' needs are monitored}

INSTAT monitors users' needs regularly and adequately using various means. From time to time, to promote the use of statistics, INSTAT organizes seminars for users of various groups (e.g., officials, media, academe, researchers, and students). Technical committees such as the Committee on Classification provide forums to discuss users' needs as well as technical issues. In 2005, INSTAT conducted a special "Image Survey on INSTAT" with about 1,000 respondents. The results of the survey will be used to improve processes and products, including services to data users. INSTAT staff participate in international statistical meetings, which promote awareness of users' needs, particularly in connection with the EU statistical requirements. INSTAT also organizes conferences to get feedback on the quality of its products (e.g., "Albania Statistics towards the EU" in December 2005). 


\subsection{Other quality management}

\subsubsection{Processes are in place to focus on quality}

INSTAT's mission is to provide transparent, neutral, and timely statistics that help users judge the development of the transformation processes within the country. To achieve its mission, INSTAT's operations are guided by the basic principles of official statistics adopted by the Economic Commission for Europe and the UN's Fundamental Principles of Official Statistics. INSTAT management is sensitive to all dimensions of quality and seeks to strive for the optimum trade-offs between the various dimensions, such as reliability, sustainability, and efficiency. Staff training programs (e.g., staff orientation programs) emphasize the vision and operational culture of the institution regarding the importance of data quality.

\subsubsection{Processes are in place to monitor the quality of the statistical program}

The Law requires the Statistics Council to supervise the implementation of the program of official statistics under the leadership of INSTAT. Further, INSTAT has various internal monitoring processes for its statistical programs. Managers undertake regular assessmentsboth formal and informal - to identify progress achieved and problems of statistical activities. INSTAT staff have access to expert guidance on the quality of statistics and on strategies for improving data production. INSTAT receives technical assistance from various agencies and donor countries involved with various aspects of data quality, such as methodology, source data, data dissemination strategies, etc.

\subsubsection{Processes are in place to deal with quality considerations in planning the statistical program}

INSTAT places a high priority on quality considerations in developing and executing its statistical programs. It also takes a lead in promoting quality considerations among dataproducing agencies through balancing trade-offs between various aspects of quality, such as accuracy and timeliness.

\section{Assurances of integrity}

\subsection{Professionalism}

\subsubsection{Statistics are produced on an impartial basis}

The Law emphasizes professionalism and impartiality in the production of official statistics and in the conduct of INSTAT's operations. Article 4 protects the professional independence of INSTAT staff and prevents interference from government, other state authorities, political parties, or any other interest groups - notably in the selection of data sources, statistical methods, and procedures, in the contents, form, and time of dissemination, and in the application of statistical confidentiality. 
The Law describes the roles and tasks of the Statistics Council members and of the INSTAT General Director. It specifies that the appointment and dismissal of the General Director be proposed by the Statistics Council and be subject to the approval of the Prime Minister and the Council of Ministers. INSTAT staff is subject to the rules and regulations in the Civil Servant Law (Nr. 8549, November 11, 1999). Hiring staff is through competitive recruitment based on qualifications. INSTAT promotes professionalism in its culture, providing opportunities for professional development, such as participation in courses, access to professional literature, and encouragement of research, which is presented in various international and regional conferences.

\subsubsection{Choices of sources and statistical techniques as well as decisions about dissemination are informed solely by statistical considerations}

Article 4 of the Law requires that the selection of techniques, definitions, and methodologies be based only on statistical considerations. The choices of source data are based on measurement objectives and data requirements, taking into account cost effectiveness and respondents' burden. Decisions on dissemination of statistical content, format, and timing are based solely on statistical considerations. The Law (Article 17) specifies dissemination criteria, including simultaneous release to all users, appropriate media to provide broadest access, and fulfillment of requests from any organization or individual for nonpublished data. INSTAT's practices follow the requirements of the Law.

\subsubsection{The appropriate statistical entity is entitled to comment on erroneous interpretation and misuse of statistics}

INSTAT staff are entitled to respond to erroneous interpretation and misuse of statistics. To encourage the understanding and facilitate a correct interpretation of statistics, INSTAT provides seminars and briefings to media and other users of its products.

\subsection{Transparency}

\subsubsection{The terms and conditions under which statistics are collected, processed, and disseminated are available to the public}

INSTAT posts the Law on its website. Article 4 of the Law guarantees transparency by giving the right to respondents to have information on the legal basis, the purposes for which the data are required, and the protective measures adopted to protect confidentiality. All questionnaires issued by INSTAT clearly state the terms and conditions of the data collection and compilation, as well as the respondents' obligation to provide information.

\subsubsection{Internal governmental access to statistics prior to their release is publicly identified}

Strictly adhering to the Law, INSTAT provides equal access and simultaneous release of data to the public. There is no prior access to the data before the release. 


\subsubsection{Products of statistical agencies/units are clearly identified as such}

Data released to the public are clearly identified as INSTAT data. All publications quote INSTAT's name, its logo, and contact information.

1.2.4 Advance notice is given of major changes in methodology, source data, and statistical techniques

INSTAT provides advance notice of major changes in methodology, source data, and statistical techniques, normally through its proposals in the statistical programs. The Law requires that INSTAT's five-year program of official statistics containing development work be published in official gazettes to inform the public. More often, INSTAT provides details regarding the changes when the changes take place.

\subsection{Ethical standards}

\subsubsection{Guidelines for staff behavior are in place and are well known to the staff}

INSTAT's staff behavior is governed by the Law on the Status of Civil Servants. Further, INSTAT has its own Code of Conduct for its staff. All new staff attend an orientation program where they are informed of the ethical standards and professional culture of INSTAT.

\section{Methodological soundness}

\subsection{Concepts and definitions}

2.1.1 The overall structure in terms of concepts and definitions follows internationally accepted standards, guidelines, or good practices

In general, the weights and price quotes used to compile the CPI are consistent with the 1993 System of Accounts (1993 SNA) and the Consumer Price Index Manual. The weights and prices are classified at the detailed 7-digit level of COICOP for all products.

\subsection{Scope}

2.2.1 The scope is broadly consistent with internationally accepted standards, guidelines, or good practices

The weights for the existing CPI were derived from the 2000 Household Budget Survey (HBS), which only covered urban areas, accounting for 45 percent of all households. However, the new HBS, currently in preparation, will cover rural, as well as urban, households. The 2000 HBS covered all households, irrespective of size or income level. The consumption activities of households that were engaged in productive activities, such as farming, were also included. However, as only urban households were covered, this was of 
minor importance. The 2000 HBS captured all purchases of market goods and services for consumption. It also covered own-account production for own final consumption - though, again, this would have been negligible. No attempt was made to collect purchases of illegal goods because it was considered that this would have endangered response.

Recommendation: Change the weights as soon as possible to cover the whole of Albania.

\subsection{Classification/sectorization}

\subsubsection{Classification/sectorization systems used are broadly consistent with internationally accepted standards, guidelines, or good practices}

Households are defined according to the $1993 \mathrm{SNA}$, as are their transactions. COICOP is used to classify the CPI.

\subsection{Basis for recording}

2.4.1 Market prices are used to value flows and stocks

The CPI weights are based on household expenditure at purchaser prices. The items to be priced are specified as precisely as possible, including the type of outlet to be visited.

\subsubsection{Recording is done on an accrual basis}

Prices of goods and services are recorded in the period they are purchased.

2.4.3 Grossing/netting procedures are broadly consistent with internationally accepted standards, guidelines, or good practices

The 2000 HBS did not collect data on the sale of secondhand goods. Therefore, only the purchase value of such items is included in the CPI weights.

Recommendation: Try to collect sale of secondhand goods in the new HBS, and use this in deriving the CPI weights.

\section{Accuracy and reliability}

\subsection{Source data}

3.1.1 Source data are obtained from comprehensive data collection programs that take into account country-specific conditions

The weights for the CPI were derived from the $2000 \mathrm{HBS}$, covering only urban households. However, the new HBS, currently in preparation, will cover urban and rural households. It is 
recognized that the structure of household consumption will have changed significantly since 2000.

The HBS uses a two-stage sampling methodology. First, a random sample of enumeration areas is selected. Then households are selected using an interval sample. In 2000, 6,000 households were selected, but only 5,387 responded. No attempt was made to replace nonresponding households. This is likely to have introduced a downward bias in the results. This is because it is generally found that high-income households are more likely to refuse to take part in HBS.

Price collection aims to cover all types of outlets, including informal markets. However, the selection of outlets is not based on scientific techniques. Outlets are selected visually with the aim of covering all types within each area. Prices are collected for 2,062 different products. Most products are priced in 10 outlets, but fewer outlets are needed for certain items not subject to much regional price variation. In total 20,174 price quotations are collected each month. The prices are collected by contract enumerators employed by the regional offices. Collection is undertaken between the 5th and 25th of the month, with each item collected on the same day every month. Price specification is as precise as possible ensuring that the same item is selected each month. Prices are collected in 11 cities in Albania-it is not considered feasible to collect prices in more rural areas.

Recommendation 1: In the new HBS, replace nonresponding households with similar households in the same locality.

Recommendation 2: Investigate the feasibility of selecting outlets scientifically.

3.1.2 Source data reasonably approximate the definitions, scope, classifications, valuation, and time of recording required

The source data generally satisfy the requirements of the CPI program. Prices for most products are collected on the same day of each month. However, for goods subject to rapid price change (e.g., vegetables), prices are collected on two days.

\subsubsection{Source data are timely}

Price collection is timely enough to meet the needs of the CPI program. The enumerators report the data to the regional offices, where it is checked, collated, and emailed to headquarters. 


\subsection{Assessment of source data}

3.2.1 Source data - including censuses, sample surveys and administrative records - are routinely assessed, e.g., for coverage, sample error, response error, and nonsampling error; the results of the assessments are monitored and made available to guide statistical processes

The only assessment made of the source data is to check for outliers. Clearly, the survey methods do not provide any information on errors. No checks are made on the quality of the data reported by enumerators, that is, by revisiting a sample of outlets to double-check the price quotes.

Recommendation: Introduce a program of checks on the reliability of the price quotes reported by the enumerators.

\subsection{Statistical techniques}

\subsubsection{Data compilation employs sound statistical techniques to deal with data sources}

The CPI compilation software does not undertake any checks on the data; checks are done manually. Temporarily missing items are imputed using the monthly change for the respective group of items. However, this can only be done for three consecutive months; if the item is still missing, it is replaced with a similar product. Seasonally unavailable items are also imputed using the values for the related group. New items can only be introduced into the CPI when it is rebased. No adjustments are made for quality change in products.

Recommendation 1: Update the CPI compilation software to incorporate a range of automatic data checks.

Recommendation 2: Introduce new products into the CPI as soon as they become important.

Recommendation 3: When a quality change is detected, try to make an adjustment to the CPI.

\subsubsection{Other statistical procedures (e.g., data adjustments and transformations, and statistical analysis) employ sound statistical techniques}

The CPI weight for housing services includes an estimate for imputed rent for owneroccupiers, in line with international recommendations. This estimate was based on the average rent actually paid by tenants, as reported in the $2000 \mathrm{HBS}$. The estimate was adjusted to reflect the higher rent paid by households in Tirana. It was not possible to use a more detailed geographical breakdown because of the limited data available - only about 5 percent of households in Albania pay rent.

Elementary-level indices for the CPI are derived using the monthly price relative constructed from the average prices for each product. INSTAT is planning to adopt the internationally 
recommended approach of using geometric means for the new CPI. Insofar as an investigation has found that this approach produces similar results to the existing method, this change will have little impact on the figures. Higher-level indices are derived using the widely accepted Laspeyres formula.

The current weight reference period is 2000, while the price reference period is December 2001. However, the 2000 weights were uprated to the prices of December 2001. The new weight reference period will be within seven years of the old one, but it is still considered too long a gap, given the rapid changes in consumption patterns in recent years. It is recognized that conducting an HBS is an expensive operation, but it should be undertaken as frequently as possible.

Recommendation 1: When deriving imputed rent for the new weights, use the most detailed geographical breakdown possible.

Recommendation 2: Try to undertake an HBS at least every few years, if not every year.

\subsection{Assessment and validation of intermediate data and statistical outputs}

\subsubsection{Intermediate results are validated against other information where applicable}

The CPI compiler validates the data against all other available price indices, such as the PPI, to ensure they are moving in similar ways.

\subsubsection{Statistical discrepancies in intermediate data are assessed and investigated}

Any unusual movements in CPI components are investigated during compilation, and the data are revised, if necessary.

3.4.3 Statistical discrepancies and other potential indicators of problems in statistical outputs are investigated

Only one CPI is produced, so there are no differences to be investigated.

\subsection{Revision studies}

3.5.1 Studies and analyses of revisions are carried out routinely and used internally to inform statistical processes (see also 4.3.3)

Once published, the CPI is not subject to revision except when new weights are introduced. At the time of the last rebasing, differences between the old and new weights were assessed. 


\section{Serviceability}

\subsection{Periodicity and timeliness}

\subsubsection{Periodicity follows dissemination standards}

The CPI is compiled and published monthly, thus meeting the GDDS recommendations and SDDS requirements.

\subsubsection{Timeliness follows dissemination standards}

The CPI is published within nine days after the end of the reference period, well within the GDDS recommendation of one to two months and the SDDS requirement of no more than one month.

\subsection{Consistency}

\subsubsection{Statistics are consistent within the dataset}

Only one official CPI series is produced, and the data are consistent within this dataset.

\subsubsection{Statistics are consistent or reconcilable over a reasonable period of time}

The CPI is fully consistent from 1993 onwards, with appropriate techniques used to link the old and new series at the time of rebasing.

\subsubsection{Statistics are consistent or reconcilable with those obtained through other data sources and/or statistical frameworks}

Checks between the CPI and other price indices, such as the Producer Price Index (PPI), ensure they are largely consistent.

\subsection{Revision policy and practice}

\subsubsection{Revisions follow a regular and transparent schedule}

Revisions are only made to the CPI when it is rebased.

\subsubsection{Preliminary and/or revised data are clearly identified}

The publications do not make it clear that the CPI is not subject to revisions.

Recommendation: Include a statement on the revision policy for the CPI in every publication and on the website. 


\subsubsection{Studies and analyses of revisions are made public (see also 3.5.1)}

At the time of the last rebasing, details of the impact of the new weights were published.

\section{Accessibility}

\subsection{Data accessibility}

5.1.1 Statistics are presented in a way that facilitates proper interpretation and meaningful comparisons (layout and clarity of text, tables, and charts)

The layout of the publications is good, incorporating charts as well as tables. The press release, appropriately, provides fairly aggregate data, but other publications give more detailed breakdowns.

\subsubsection{Dissemination media and format are adequate}

As noted above, the CPI is disseminated via a press release and in other publications. The data are also included on the INSTAT website with a downloadable Excel spreadsheet.

\subsubsection{Statistics are released on a preannounced schedule}

An advance release calendar is published in the beginning of the year, which shows the dates when the CPI will be released throughout the year. These dates are strictly followed. The advance release calendar is also on the INSTAT website, but the calendar for last year is shown.

Recommendation: Update the advance release calendar on the INSTAT website.

\subsubsection{Statistics are made available to all users at the same time}

Interested users can pick up the CPI press release from the INSTAT office. INSTAT also sends the press release by post or email to anyone who puts their name on a circulation list. The website is also freely available.

\subsubsection{Statistics not routinely disseminated are made available upon request}

More detailed breakdowns than are published are made available on request. 


\subsection{Metadata accessibility}

5.2.1 Documentation on concepts, scope, classifications, basis of recording, data sources, and statistical techniques is available, and differences from internationally accepted standards, guidelines, or good practices are annotated

When the CPI was developed, a methodological guide, produced with technical assistance from a foreign expert, was published in English. However, it has not been subsequently updated and is not posted on the website. A fairly brief guide is given in INSTAT's Yearbook.

Recommendation: Produce and publish an updated methodological guide in Albanian and English.

\subsubsection{Levels of detail are adapted to the needs of the intended audience}

As noted above, an appropriately brief guide is included in the Yearbook, but more detailed and up-to-date information is not made available.

\subsection{Assistance to users}

\subsubsection{Contact points for each subject field are publicized}

The publications only give a general contact point for the dissemination branch of INSTAT, but this appears to provide a good service to users.

Recommendation: Include contact details for a named individual in all publications.

5.3.2 Catalogs of publications, documents, and other services, including information on any charges, are widely available

A catalog of INSTAT publications, including prices, is on its website. 


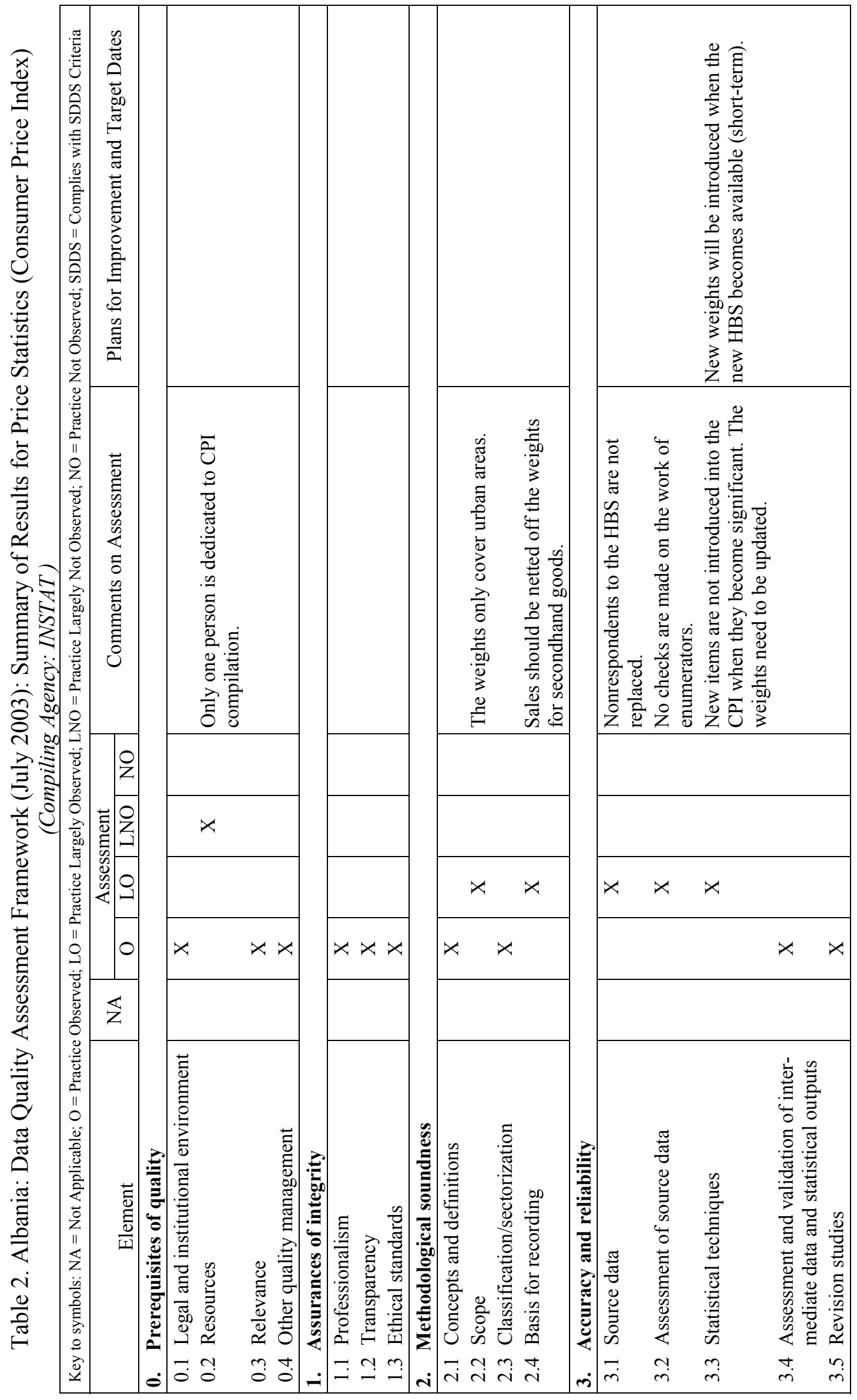




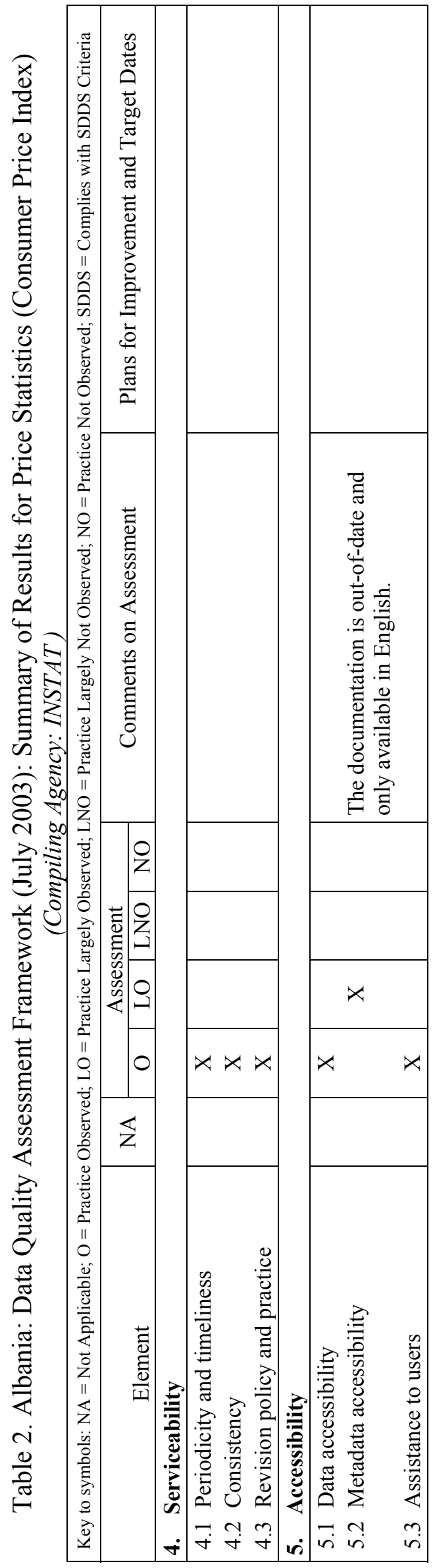




\section{Price Statistics (Producer Price Index)}

\section{Prerequisites of quality}

\subsubsection{The responsibility for collecting, processing, and disseminating the statistics is clearly specified}

The legal and institutional arrangements provide adequate support for collecting, processing, and disseminating statistics. The law On Official Statistics, No. 9180, dated February 5, 2004 (the Law), sets out the legal framework for the collection, organization, production, and dissemination of official statistics in Albania. The Law reflects elements of the UN Fundamental Principles of Official Statistics. The Law empowers the Institute of Statistics (INSTAT) to propose a program of official statistics to the Statistics Council and implement the approved program of statistics. INSTAT is authorized under Article 8 to issue to all dataproducing agencies, make public, and keep up-to-date the guidelines for professional standards in the production of official statistics. INSTAT is responsible for examining the procedures for producing statistics used by any official statistics-producing agency, with a view to ensuring their statistics are reliable, impartial, and objective.

INSTAT is an independent government agency under the supervision of the Statistics Council, which in turn reports to the Council of Ministers. In executing its responsibilities, INSTAT develops the program of official statistics in coordination with other data-producing agencies. The program consists of a five-year strategic plan and a one-year operational plan. The five-year plan is submitted for approval by Parliament, through the Prime Minister. The Statistics Council, with 11 members appointed by the Council of Ministers, oversees the implementation of the five-year strategic plan and the annual operational plan. INSTAT prepares quarterly reports detailing progress in implementing the annual plan. The Statistics Council approves INSTAT's organizational structure and annual budget plan prior to submission to the Ministry of Finance.

INSTAT is the only official producer of price indices, through its Price Indices Sector. In carrying out its responsibilities, the INSTAT is empowered by the Law to collect data from all entities.

\subsubsection{Data sharing and coordination among data-producing agencies are adequate}

The Producer Price Index (PPI) program does not involve any data sharing with other dataproducing agencies.

\subsubsection{Individual reporters' data are to be kept confidential and used for statistical purposes only}

Confidentiality is upheld by INSTAT following the requirement of the Law. The Law (Articles 4 and 15) clearly stipulates the confidentiality of data of individual reporters. It prevents any nonstatistical utilization of data that are collected and their unlawful disclosure. 
Individual reporters' data collected by INSTAT cannot be used for fiscal inspection purposes or investigation. The Law has a specific provision that aggregate data should comprise at least three reporting units, and the share of any one unit should not exceed 85 percent of the total. The Law also specifies the rights and obligations of statistical reporters.

All the employees of the statistical system are required to protect the confidentiality of individual information. Any staff that violates the secrecy of statistical information is subject to fine and/or dismissal from office.

Owing to the lack of space, survey forms are processed in an open area, but the entrance to the building is guarded by security officers.

Recommendation: Improve the security of physical work places to prevent access to survey forms by outsiders.

\subsubsection{Statistical reporting is ensured through legal mandate and/or measures to encourage response}

Article 14 of the Law specifies the obligation of reporters (enterprises, institutions, and physical and legal persons) to supply data to INSTAT in a complete and truthful manner. The information shall be provided in the form and within the time period requested and free of charge. Furthermore, Article 16 states that INSTAT has the right to collect and use administrative statistics for implementing the official statistics program. Failing to provide information to INSTAT is considered an administrative offense subject to fines at various specific levels. (See also 0.1.2.)

\section{$0.2 \quad$ Resources}

\subsubsection{Staff, facilities, computing resources, and financing are commensurate with statistical programs}

INSTAT's financial and staff resources are severely inadequate. Financial constraints, at times, delay and/or limit the planned surveys necessary for producing statistics. Staff resources are limited in terms of both numbers and experience. Currently, 155 employees are equally divided between the Central Directorate and the Regional Directorates. The Regional Directorates are responsible for collecting survey data and publishing statistical bulletins for the regions. At present, only one professional works on the compilation of the PPI, with some clerical support for data entry. although this is sufficient to operate the PPI program, the loss of the professional would endanger the program. Also a serious shortage exists of staff and financial resources to conduct surveys, such as the Structural Business Survey used for the PPI weights. The shortage of financial resources has resulted in postponement or even abolition of statistical surveys and dissemination of statistics. 
The qualifications and training of the professional staff are good. Computer systems are adequate for the PPI program. The physical facilities are limited in terms of office space (e.g., four or five staff in a small office).

Recommendation: Increase the number of staff working on the PPI to provide backup for the program.

\subsubsection{Measures to ensure efficient use of resources are implemented}

The Law requires the production of official statistics to be cost-effective; the work and cost of each statistical program must be in proportion to the importance of the work.

INSTAT management promotes a vision and a direction shared with staff in focusing on efficient use of resources, particularly under the current tight budget. Efficiencies are sought by encouraging consistency in concepts and methodologies across different statistics agencies, coordinating statistical work programs among agencies, taking measures to minimize respondents' burden through consultation among data-producing agencies regarding surveys, and retaining a core specialized team of survey enumerators in spite of their contractual appointments. Since 2005, INSTAT staff are subject to a formal annual performance review. To further promote the efficient use of resources, INSTAT plans to initiate a program to measure managerial performance. Similar to other government agencies, INSTAT is subject to overall government regulations to execute its responsibilities in the most cost-efficient manner and is subject to a budgetary audit process.

INSTAT also seeks outside expert assistance to evaluate statistical methodologies and compilation systems, such as from Eurostat, the IMF, the World Bank, the Italian Institute of Statistics, the United Kingdom's Department for International Development, the Swedish International Development Agency, and others.

\subsection{Relevance}

\subsubsection{The relevance and practical utility of existing statistics in meeting users' needs are monitored}

INSTAT monitors users' needs regularly and adequately using various means. From time to time, to promote the use of statistics, INSTAT organizes seminars for users of various groups (e.g., officials, media, academe, researchers, and students). Technical committees such as the Committee on Classification provide forums to discuss users' needs as well as technical issues. In 2005, INSTAT conducted a special "Image Survey on INSTAT" with about 1,000 respondents. The results of the survey will be used to improve processes and products, including services to data users. INSTAT staff participate in international statistical meetings, which promote awareness of users' needs, particularly in connection with the EU statistical requirements. INSTAT also organizes conferences to get feedback on the quality of its products (e.g., conference on "Albania Statistics towards the EU" in December 2005). 


\subsection{Other quality management}

\subsubsection{Processes are in place to focus on quality}

INSTAT's mission is to provide transparent, neutral, and timely statistics that help users judge the development of the transformation processes within the country. To achieve its mission, INSTAT's operations are guided by the basic principles of official statistics adopted by the Economic Commission for Europe and the UN's Fundamental Principles of Official Statistics. INSTAT management is sensitive to all dimensions of quality and seeks to strive for the optimum trade-offs between the various dimensions, such as reliability, sustainability, and efficiency. Staff training programs (e.g., staff orientation programs) emphasize the vision and operational culture of the institution regarding the importance of data quality.

\subsubsection{Processes are in place to monitor the quality of the statistical program}

The Law requires the Statistics Council to supervise the implementation of the program of official statistics under the leadership of INSTAT. Further, INSTAT has various internal monitoring processes for its statistical programs. Managers undertake regular assessmentsboth formal and informal - to identify progress achieved and problems in statistical activities. INSTAT staff have access to expert guidance on the quality of statistics and on strategies for improving data production. INSTAT receives technical assistance from various agencies and donor countries involved with various aspects of data quality, such as methodology, source data, data dissemination strategies, etc.

\subsubsection{Processes are in place to deal with quality considerations in planning the statistical program}

INSTAT places a high priority on quality considerations in developing and executing its statistical programs. It also takes a lead in promoting quality considerations among dataproducing agencies through balancing trade-offs between various aspects of quality, such as accuracy and timeliness.

\section{Assurances of integrity}

\subsection{Professionalism}

\subsubsection{Statistics are produced on an impartial basis}

The Law emphasizes professionalism and impartiality in the production of official statistics and in the conduct of INSTAT's operations. Article 4 protects the professional independence of INSTAT staff and prevents interference from government, other state authorities, political parties, or any other interest groups - notably in the selection of data sources, statistical methods, and procedures, in the contents, form, and time of dissemination, and in the application of statistical confidentiality. 
The Law describes the roles and tasks of the Statistics Council members and of the INSTAT General Director. It specifies that the appointment and dismissal of the General Director be proposed by the Statistics Council and be subject to the approval of the Prime Minister and the Council of Ministers. INSTAT staff is subject to the rules and regulations in the Civil Servant Law (Nr. 8549, November 11, 1999). Hiring staff is through competitive recruitment based on qualifications. INSTAT promotes professionalism in its culture, providing opportunities for professional development, such as participation in courses, access to professional literature, and encouragement of research, which is presented in various international and regional conferences.

\subsubsection{Choices of sources and statistical techniques as well as decisions about dissemination are informed solely by statistical considerations}

Article 4 of the Law requires that the selection of techniques, definitions, and methodologies be based only on statistical considerations. The choices of source data are based on measurement objectives and data requirements, taking into account cost effectiveness and respondents' burden. Decisions on dissemination of statistical content, format, and timing are based solely on statistical considerations. The Law (Article 17) specifies dissemination criteria, including simultaneous release to all users, appropriate media to provide broadest access, and fulfillment of requests from any organization or individual for nonpublished data. INSTAT's practices follow the requirements of the Law.

\subsubsection{The appropriate statistical entity is entitled to comment on erroneous interpretation and misuse of statistics}

INSTAT staff are entitled to respond to erroneous interpretation and misuse of statistics. To encourage the understanding and facilitate a correct interpretation of statistics, INSTAT provides seminars and briefings to media and other users of its products.

\subsection{Transparency}

\subsubsection{The terms and conditions under which statistics are collected, processed, and disseminated are available to the public}

INSTAT posts the Law on its website. Article 4 of the Law guarantees transparency by giving the right to respondents to have information on the legal basis, the purposes for which the data are required, and the protective measures adopted to protect confidentiality. All questionnaires issued by INSTAT clearly state the terms and conditions of the data collection and compilation, as well as the respondents' obligation to provide information.

\subsubsection{Internal governmental access to statistics prior to their release is publicly identified}

Strictly adhering to the Law, INSTAT provides equal access and simultaneous release of data to the public. There is no prior access to the data before the release. 


\subsubsection{Products of statistical agencies/units are clearly identified as such}

Data released to the public are clearly identified as INSTAT data. All publications quote INSTAT's name, its logo, and contact information.

\subsubsection{Advanced notice is given of major changes in methodology, source data, and statistical techniques}

INSTAT provides advance notice of major changes in methodology, source data, and statistical techniques, normally through its proposals in the statistical programs. The Law requires that INSTAT's five-year program of official statistics containing development work be published in official gazettes to inform the public. More often, INSTAT provides details regarding the changes when the changes take place.

\subsection{Ethical standards}

\subsubsection{Guidelines for staff behavior are in place and are well known to the staff}

INSTAT's staff behavior is governed by the Law on the Status of Civil Servants. Further, INSTAT has its own Code of Conduct for its staff. All new staff attend an orientation program where they are informed of the ethical standards and professional culture of INSTAT.

\section{Methodological soundness}

\subsection{Concepts and definitions}

2.1.1 The overall structure in terms of concepts and definitions follows internationally accepted standards, guidelines, or good practices

The PPI follows the concepts of the 1993 SNA and the Producer Price Manual. The industrial classification used is NACE Rev. 1 down to the class (4-digit) level. Additionally a version of the PPI is based on products, rather than industries, which uses the CPC classification down to the 8-digit level. However, the product-based PPI is not published nor used by anyone in INSTAT.

Recommendation: Cease production of the product-based PPI.

\section{$2.2 \quad$ Scope}

2.2.1 The scope is broadly consistent with internationally accepted standards, guidelines, or good practices

The PPI covers all production industries, that is, mining, manufacturing, energy, and water supply. Agriculture is also covered but is not considered reliable, because the sizable 
nonenterprise activities are not included. Hence, it is planned to drop the agriculture sector when the PPI is rebased. It is common practice in countries not to include agriculture in the PPI.

The PPI price collection program separately identifies prices for exported goods from those for domestic sales. However, the published PPI measures changes in all prices, including those for exports.

Recommendation: Cease publication of the PPI for agriculture.

\subsection{Classification/sectorization}

2.3.1 Classification/sectorization systems used are broadly consistent with internationally accepted standards, guidelines, or good practices

All the classifications used are based on internationally accepted standards.

\subsection{Basis for recording}

\subsubsection{Market prices are used to value flows and stocks}

The weights for the PPI are based on turnover at market prices.

\subsubsection{Recording is done on an accrual basis}

The PPI weights are derived from sales, which means they are recorded on an accrual basis, in conformity with established accounting standards.

\subsubsection{Grossing/netting procedures are broadly consistent with internationally accepted standards, guidelines, or good practices}

Data are only reported at the enterprise level. This means that transactions between establishments of the same enterprise will be netted out.

\section{Accuracy and reliability}

\subsection{Source data}

3.1.1 Source data are obtained from comprehensive data collection programs that take into account country-specific conditions

The weights and price collection programs are based on the Business Register and annual Structural Survey of 1998. The Business Register is derived from tax records and is updated annually, but only the number of employees is supplied. Hence, the annual Structural Survey is used to collect data on turnover. When an enterprise ceases business, it is not replaced, 
even though the data to do so are available. Instead, the weights of the other enterprises in that subindustry are recalculated to give the same total. The original enterprises were selected to cover 80 percent of the turnover of each subindustry. Clearly, over time the coverage of turnover is likely to have reduced. Since the data collection programs make use of the Business Register, informal activities that are unlikely to register with the tax authorities are not covered. INSTAT is changing the base year of the PPI to 2005. The price questionnaires are being redesigned with the aid of international experts.

Recommendation: Replace any enterprise that goes out of business with another enterprise of a similar size in the same subindustry.

3.1.2 Source data reasonably approximate the definitions, scope, classifications, valuation, and time of recording required

The source data, for both prices and the weights, fully meet the needs of the PPI program.

\subsubsection{Source data are timely}

Prices are collected for each month but only once every quarter. This is because enumerators have to be used to collect the data, since other means such as mailing systems have proved unreliable. The cost of hiring enumerators has precluded a monthly collection program. During the month following the end of each quarter, the regional INSTAT offices send out enumerators to collect data for each month of the previous quarter. These forms are then sent to headquarters within 45 days of the end of the quarter, where they are processed.

Recommendation: Introduce monthly price collection as soon as possible, which will require additional resources.

\subsection{Assessment of source data}

3.2.1 Source data-including censuses, sample surveys and administrative records-are routinely assessed, e.g., for coverage, sample error, response error, and nonsampling error; the results of the assessments are monitored and made available to guide statistical processes

Enterprises are not selected using random sampling techniques, so error rates cannot be derived. Reported data are reviewed in headquarters for extreme values, which are queried with respondents. Data collected by enumerators from enterprises are occasionally doublechecked when a problem is identified. However, no regular program of such checks exists for the PPI program.

Recommendation: Introduce random checks on the accuracy of the PPI price data collected by enumerators. 


\subsection{Statistical techniques}

\subsubsection{Data compilation employs sound statistical techniques to deal with data sources}

The computer software does not incorporate any checks on the data. The results of any queries of the data from enterprises are not documented. Missing prices are imputed using the change in the average price of the other quotes for the same, or similar, products. This method is used irrespective of the length of time that the price has been missing. In other words, permanently unavailable products will not be replaced until the weights are changed. However, new products reported by surveyed enterprises can be introduced. To do so, a base year price is imputed using the change in prices for related products. A base-year weight is also derived by deflating the current period price using the PPI for the relevant group. The other weights for the enterprise are then adjusted to accommodate the new item.

Recommendation 1: Incorporate computerized data checks into the compilation procedures.

Recommendation 2: Document any changes made to source data.

Recommendation 3: When an enterprise permanently ceases production of an item, replace it with another item.

\subsubsection{Other statistical procedures (e.g., data adjustments and transformations, and statistical analysis) employ sound statistical techniques}

The price for each product reported by every surveyed enterprise is inputted to the computer. An elementary index is then derived for each quote, using the change in price since the base year. These elementary indices are aggregated for every enterprise using the base year weights. Then the indices for the enterprises are weighted together for each subindustry and so on for the higher levels.

The weight reference period is 1998 - the same as the base year for the PPI. The PPI was expanded to cover energy and water supply in 2000 , but the weights for these activities were still from 1998. INSTAT recognizes that the planned new base year of 2005 is too long after 1998. Since the PPI was only introduced in 1998, INSTAT have not needed to link a new index to the old one, but they are aware of the correct procedure.

Recommendation: Rebase the PPI to 2005 as soon as possible and introduce a regular program for rebasing the index at least every six years. 


\subsection{Assessment and validation of intermediate data and statistical outputs}

\subsubsection{Intermediate results are validated against other information where applicable}

No comparisons are made between the industry-based and product-based PPIs, or with the implicit deflators from the national accounts. However, the consumer price index (CPI) data are compared to the PPI.

Recommendation: Validate the PPI results with all other available price indices.

\subsubsection{Statistical discrepancies in intermediate data are assessed and investigated}

Any unusual movements in PPI components are investigated and the data are changed, if necessary.

3.4.3 Statistical discrepancies and other potential indicators of problems in statistical outputs are investigated

As noted above, no comparisons are made between the two versions of the PPI. However, the same prices are used in both indices, so the scope for differences is limited.

\subsection{Revision studies}

3.5.1 Studies and analyses of revisions are carried out routinely and used internally to inform statistical processes (see also 4.3.3)

The introduction of the new 2005 base year will be the first time the PPI will have been revised.

Recommendation: When the PPI is rebased, investigate the differences over the old index.

\section{Serviceability}

\subsection{Periodicity and timeliness}

\subsubsection{Periodicity follows dissemination standards}

The PPI is compiled monthly, in line with the GDDS and SDDS.

\subsubsection{Timeliness follows dissemination standards}

The PPI for the months of each quarter is not published until about nine weeks after the end of the quarter. This means that the index for the first month of each quarter is not published until more than four months later. This does not meet the SDDS requirement of one month or even the GDDS recommendation requirement of two months. 
Recommendation: Work towards publishing the PPI each month and within one month of the end of the reference period. Use the INSTAT website to disseminate the PPI data in a more timely manner.

\subsection{Consistency}

\subsubsection{Statistics are consistent within the dataset}

The weight for each enterprise in the industry-based PPI includes all its activities, not just those for which prices are collected. This means that the industry weights are not consistent with those for the product-based PPI.

\subsubsection{Statistics are consistent or reconcilable over a reasonable period of time}

The PPI is fully consistent over time since the 1998 base year.

4.2.3 Statistics are consistent or reconcilable with those obtained through other data sources and/or statistical frameworks.

The PPI is checked for consistency with the CPI and is used in the deflation of the national accounts.

\subsection{Revision policy and practice}

\subsubsection{Revisions follow a regular and transparent schedule}

No revisions have ever been made to the PPI.

\subsubsection{Preliminary and/or revised data are clearly identified}

The publications do not make it clear that the PPI is not subject to revisions.

Recommendation: Include a statement on the revision policy for the PPI in every publication and on the website.

\subsubsection{Studies and analyses of revisions are made public (see also 3.5.1)}

Since the PPI has never been revised, revision studies are not an issue.

Recommendation: Publish the results of the investigation of the impact of the new 2005 rebasing. 


\section{Accessibility}

\subsection{Data accessibility}

\subsubsection{Statistics are presented in a way that facilitates proper interpretation and meaningful comparisons (layout and clarity of text, tables, and charts)}

The layout of the publications is good, incorporating charts as well as tables. The press release, appropriately, provides fairly aggregate data, but other publications give more detailed breakdowns. However, the press release only provides the data for the months of the quarter in question.

Recommendation: Include a time series of at least one year in the press release and on the website.

\subsubsection{Dissemination media and format are adequate}

As noted above, the PPI is disseminated via a press release and other publications. The data are also included on the INSTAT website with a downloadable Excel spreadsheet.

\subsubsection{Statistics are released on a preannounced schedule}

An advance release calendar is published at the beginning of the year, which shows the dates when the PPI will be released throughout the year. These dates are strictly followed. The advance release calendar is also on the INSTAT website, but the calendar for last year is shown.

Recommendation: Update the advance release calendar on the INSTAT website.

\subsubsection{Statistics are made available to all users at the same time}

Interested users can pick up the PPI press release from the INSTAT offices. INSTAT also sends the press release by post or email to anyone who puts their name on a circulation list. Clearly, the website is also freely available.

\subsubsection{Statistics not routinely disseminated are made available upon request}

More detailed breakdowns than are published are made available on request, as long as they do not breach the rules on confidentiality. 


\subsection{Metadata accessibility}

5.2.1 Documentation on concepts, scope, classifications, basis of recording, data sources, and statistical techniques is available, and differences from internationally accepted standards, guidelines, or good practices are annotated

When the PPI was developed, a methodological guide, produced with technical assistance from a foreign expert, was published in English. However, it has not been subsequently updated and is not posted on the website. A fairly brief guide is given in INSTAT's Yearbook.

Recommendation: Produce and publish an updated methodological guide in Albanian and English.

\subsubsection{Levels of detail are adapted to the needs of the intended audience}

As noted above, an appropriately brief guide is included in the Yearbook, but more detailed and up-to-date information is not made available.

\subsection{Assistance to users}

\subsubsection{Contact points for each subject field are publicized}

The publications only give a general contact point for the dissemination branch of INSTAT, but this appears to provide a good service to users.

Recommendation: Include contact details for a named individual in all publications.

5.3.2 Catalogs of publications, documents, and other services, including information on any charges, are widely available

A catalog of INSTAT publications, including prices, is on its website. 
96

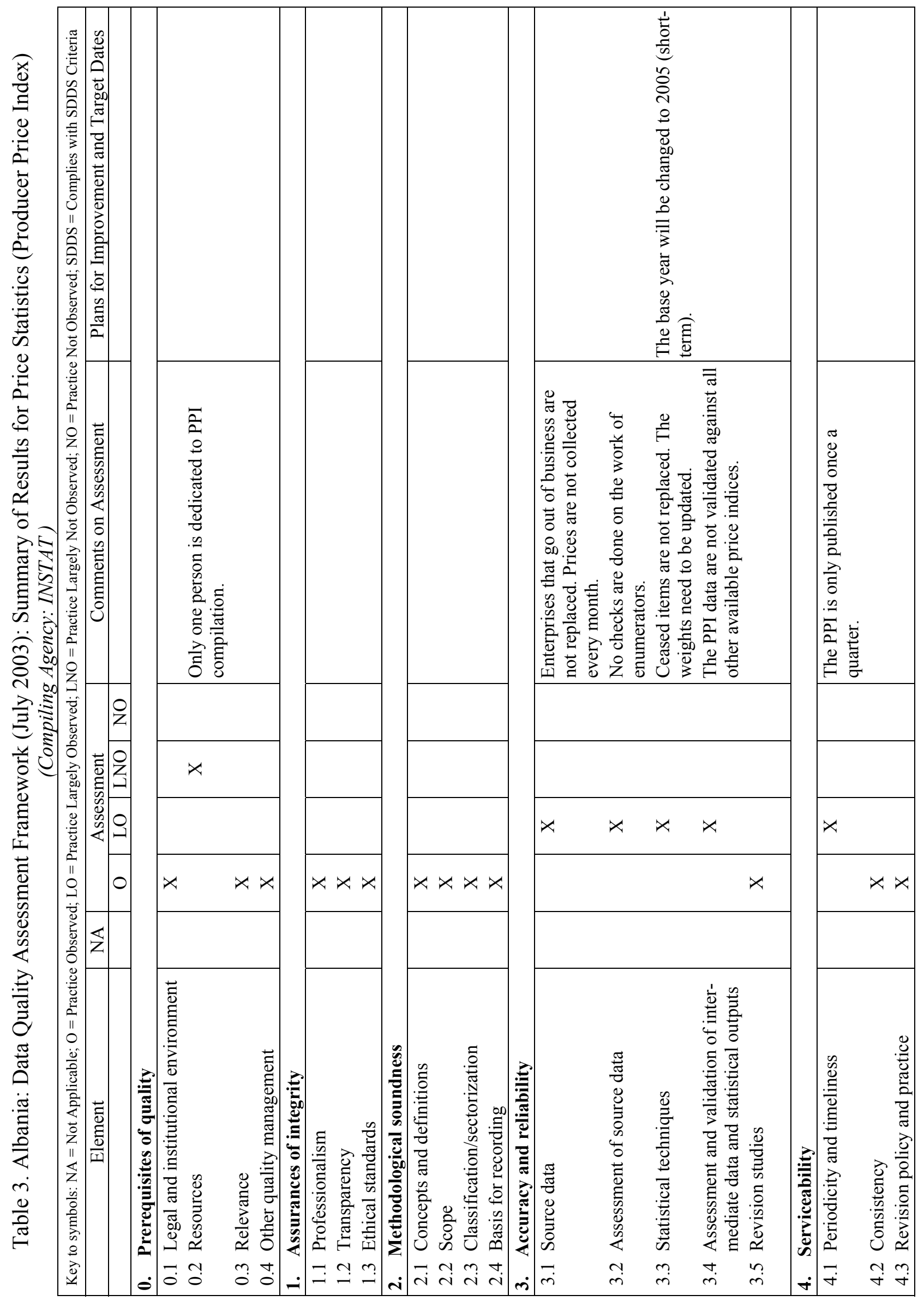




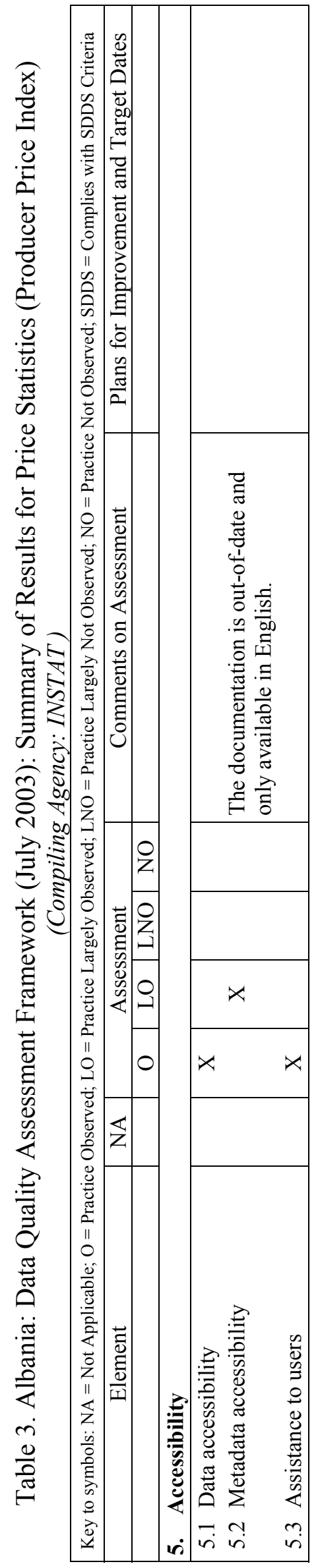




\section{Government Finance Statistics}

\section{Prerequisites of quality}

\subsection{Legal and institutional environment}

\subsubsection{The responsibility for collecting, processing, and disseminating the statistics is clearly specified}

The Organic Budget Law (OBL) No. 8379 of July 29, 1998 provides the principles governing the preparation, proposal, and approval of the State budget and responsibilities for its implementation. This includes the compilation of government finance statistics (GFS) (Chapter V) for the consolidated general government. ${ }^{8}$ The $O B L$ authorizes the MoF to specify accounting procedures and statistical reporting requirements for budgetary institutions, special and extrabudgetary funds, and local governments. The $O B L$ also requires the Minister to prepare an annual final statement of accounts that broadly conforms to the classifications of A Manual of Government Finance Statistics 1986 (GFSM 1986) to be presented to the Council of Ministers and the Parliament. A presentation on the government debt (foreign and domestic) situation twice a year is also required.

Within the MoF, responsibility for GFS is primarily located in the General Directorate of Macroeconomic and Fiscal Policies (MD), where the statistics are compiled as the result of close and well-established collaborative effort with the following departments: the General Treasury Directorate (Treasury), General Budget Directorate (Budget), the Information Technology, and Debt Departments (see 0.2 Resources, below). The modalities-including a detailed timetable - of this collaboration as it pertains to monthly, quarterly, and annually disseminated GFS are outlined in the Guideline on State Budget Reporting for Fiscal Year XXXX, MoF Protocol Number 295 of January 16, 2006 and other similar directives.

The MoF, through technical assistance provided by the United Kingdom's Department For International Development (DFID), has recently drafted a new $O B L$. The draft $O B L$ (under internal review at the time of the mission) is aimed at addressing the need for more comprehensive and timely data for fiscal policy analysis, given the rapid evolution of the Albanian economy. The mission was advised that a primary function of the $O B L$ will be to further strengthen, among other things, the legislative basis under which the MoF collects, processes, and disseminates fiscal statistics commensurate with the adoption of a mediumterm budget framework. It is expected that the new law will be enacted in 2007.

\footnotetext{
${ }^{8}$ In Albania, GFS refers to fiscal data compiled and disseminated, for analytical purposes, according to internationally accepted standards contained in A Manual of Government Finance Statistics 1986 (GFSM 1986). The authorities indicated an intent to begin migrating toward the Government Finance Statistics Manual 2001 (GFSM 2001) and requested IMF training and technical assistance during late 2006 to facilitate this.
} 


\subsubsection{Data sharing and coordination among data-producing agencies are adequate}

The flow of administrative budget data to the MoF from other ministries and government agencies is well established. The MoF is collaborating with INSTAT to formalize data sharing protocols in the area of national accounts compilation through a bilateral agreement under final review. The agreement is expected to be implemented in $2006 .{ }^{9}$ The Treasury, as the primary fiscal data-compiling entity, maintains the source accounts on the central, local, and extrabudgetary (Social Security Fund and the Health Insurance Fund) government transactions. It maintains the effective and timely flow of these source data to the MD, which compiles and disseminates GFS derived from these sources. Contacts are maintained between MoF (Treasury and Debt Directorates) and the BoA on external financing and debt. This is to promote a proper understanding of data requirements and to avoid duplication of effort and reporting. In addition, a National Statistics Council-on which the MoF is represented-has provided a forum for regular meetings to discuss data sharing and coordination issues among data-producing agencies.

\subsubsection{Individual reporters' data are to be kept confidential and used for statistical purposes only}

Ensuring confidentiality is not an issue since GFS data are obtained as a by-product of budget and treasury systems. Adequate procedures are in place to protect the confidentiality of fiscal data. MoF staff are guided by the rules, regulations, and administrative procedures of the Law on the Status of Civil Servants (Civil Service Law) of 1999 relating to the disclosure of confidential data. Access to confidential data requires clearance and is tightly supervised.

\subsubsection{Statistical reporting is ensured through legal mandate and/or measures to encourage response}

All fiscal data are obtained from the budget and treasury systems, which requires that all 36 district treasury offices (DTOs) provide the Treasury with detailed monthly reports on the operations of central and local government units. To ensure proper reporting, the MoF provides hands-on training for staff of DTOs, and, should the need arise, Treasury officials visit DTOs to resolve reporting issues. Similarly, returns from the social security and health care institutes are regularly provided through well-established mechanisms.

\footnotetext{
${ }^{9}$ The agreement emulates a similar protocol being established between INSTAT and the BoA.
} 


\section{$0.2 \quad$ Resources}

\subsubsection{Staff, facilities, computing resources, and financing are commensurate with statistical programs}

Staff resources are inadequate for current GFS compilation demands and do not allow capacity for any additional development work. The MD, under the General Directorate for Macro and Fiscal Policies, currently comprises seven staff. ${ }^{10}$ However, only one person-a recent university graduate recruited in 2005-is charged with compiling the general government statistics disseminated in the quarterly Fiscal Statistics of Government and the monthly Economy and Budget publication. In addition, this person must develop Albania's GFS methodology (including the development of underlying MoF accounting and reporting rules for source data units needed for implementing the GFSM 2001 methodology). As part of the overall downsizing of government implemented in 2005, the MD lost two positions, one of which would have been assigned to GFS compilation and related development activities. Furthermore, the Budget, Treasury, Debt, and Information Technology Departments, which support the MD's statistical efforts, have seen similar reductions, further constraining statistical operations.

No MD staff have been trained in the GFS methodology or, given Albania's aspirations toward accession, the European debt and deficit methodologies. More resources are required to develop and implement the GFSM 2001 and EU fiscal data-reporting requirements.

Computer resources are largely outdated for current tasks. The current computing system does not have the flexibility to access government accounting records and automatically compile fiscal data in conformity with GFSM 1986 (or GFSM 2001). The authorities are midway through a World Bank-financed project aimed at increasing the level of automation of the Treasury's accounting system. The modern computer system (Oracle) being put in place consists of a series of customized modules-Budget, Treasury, Accounting, Debt, Tax, Customs, Social Security, Health Insurance, BoA, among others. It is designed to automate many aspects of data collection and processing, database maintenance, and the compilation and dissemination of GFS. The system is expected to be fully operational by end-2006. ${ }^{11}$ The

\footnotetext{
${ }^{10}$ Consisting of a Director, two-currently vacant-Heads of Unit (Statistics and Forecasts, and Fiscal Analysis, respectively), and two specialists for each of these units.

${ }^{11}$ Formally, the project was scheduled to be completed in June 2006. However, staff indicated that several actions have yet to be completed, including hardware generalization (financed by the World Bank), network infrastructure, online connectivity, and testing for full implementation (three to six months), which may extend the overall period of implementation. Based on the mission's understanding of the project, its goals, and the implications for efficiently compiling comprehensive GFS commensurate with international standards, MoF management is encouraged to ensure the project's completion and to actively promote its adoption throughout the organization.
} 
system will facilitate the construction and storing of bridge and derivation tables that define the links between accounting and budgeting source data and the existing GFS analytical framework, which should facilitate the compilation of data according to the GFSM 2001. Adequate protection of computer resources is provided, including availability of emergency back-up systems. Building facilities appear adequate.

Recommendation: Increase-by restoring the position lost in the November 2005 restructuring-and strengthen staff resources dedicated to working on GFS through the establishment of a stable complement of trained professional staff and a funding horizon that is amenable to medium-term planning and sustained statistical development. Nominate staff for GFS training at the IMF. ${ }^{2}$

\subsubsection{Measures to ensure efficient use of resources are implemented}

Given the recent reductions in staff, the MoF's management is keenly aware of its constrained budgetary scenario, is constantly searching for ways to improve the efficient use of resources, and endeavors to sets priorities among its tasks to ensure the most efficient use of these resources. Work flows are regularly monitored but not directly costed, because GFS is a by-product of the overall budget process. In view of the limited staff and other resources for data compilation, no further efficiency gains are envisioned.

Staff performance is assessed in the context of an annual performance review exercise, as stipulated under provisions of the Civil Service Law.

\subsection{Relevance}

\subsubsection{The relevance and practical utility of existing statistics in meeting users' needs are monitored}

Officials manifest a keen awareness of the need for ongoing quality improvements in fiscal data. Official requests pertaining to data compiled and disseminated by the MD are taken into account. Queries received are instrumental in determining the content (tables and charts) of the MoF's statistical publications, most recently reflected in the expanded presentation in Fiscal Statistics of Government.

The steadily increasing participation of MoF staff in technical meetings and seminars organized by international and regional organizations is seen as providing valuable input with regard to addressing new and emerging data requirements. Feedback received from the

${ }^{12}$ One staff-from the Macroeconomic and Treasury Departments, respectively-attended the threeweek GFS course offered at the IMF's Joint Vienna Institute in summer 2006. The mission also suggested that the MoF nominate a candidate for the six-week GFS course to be held in Washington in February 2007. The authorities were supportive. 
National Statistics Council—on which the MoF is represented-and, occasionally, other government units that use MoF outputs also helps to ensure that users' needs are monitored.

\subsection{Other quality management}

\subsubsection{Processes are in place to focus on quality}

MoF staff evidence a high level of awareness of quality as the cornerstone of the budget, treasury, and debt operations that underlie the compilation of GFS. The MoF's general workplace rules and regulations also stipulate quality commitment. Compilers follow wellestablished procedures to check the accuracy and consistency of the data.

\subsubsection{Processes are in place to monitor the quality of the statistical program}

As part of his mandate, the Deputy Minister regularly meets with the heads of all district treasury offices and government spending units to discuss and clarify data-reporting issues that may arise in implementing the $O B L$. They discuss the $O B L$ 's provisions regarding the inspection, monitoring, accounting, reporting, and auditing of the execution of the state and local budgets and the financial plans of special funds (Article 2). In addition, the Supreme State Audit, fully independent, has a mandate to undertake an independent review of fiscal data regularly and advise on issues pertaining to quality. ${ }^{13}$

\subsubsection{Processes are in place to deal with quality considerations in planning the statistical program}

Processes are in place to monitor adequately the quality of compiled and disseminated GFS. Checks of coverage, classification, missing or erroneous recordings, their internal consistency, and the consistency between data coming from alternative data sources (INSTAT's GDP figures and the BoA's Unified Treasury Account and external debt data) are regularly monitored. All deviations between data disseminated by the MoF, INSTAT, and BoA are thoroughly checked, for example in the regular meetings of the interagency National Accounts Steering Committee (for the twining project), in which the Director of the MoF's MD participated.

\footnotetext{
${ }^{13}$ The Supreme State Audit is an independent external audit institution in the Republic of Albania. Its functions and assignments are determined in the constitution and Organic Law No. 8270, dated 23.12.1997 (completed with relevant amendments in Law No. 8599, dated 1.06.2000) On the Supreme State Audit.
} 


\section{Assurances of integrity}

\subsection{Professionalism}

\subsubsection{Statistics are produced on an impartial basis}

The MoF has established a tradition of professional independence, as further evidenced by the efforts aimed at adopting of new legislation (an updated $O B L$ is under preparation) that extends its prerogatives and authority in compiling and disseminating Albania's GFS. The annual final statement of accounts data are audited by the Supreme State Audit to ensure impartiality. In addition to auditing government final accounts, the audit institution also carries out a detailed annual audit program of central government agencies, extrabudgetary funds, and state-owned enterprises. Findings and recommendations are published regularly.

\subsubsection{Choices of sources and statistical techniques as well as decisions about dissemination are informed solely by statistical considerations}

No evidence exists of political interference in the choice of data sources and statistical techniques in the compilation of GFS. The $O B L$ gives the MoF independence to choose sources and methods, which are made as part of agency-wide decisions taking into account costs and resources. In GFS, the existing sources and statistical techniques are consistent with those used in many other countries that adhere to the recommendations of the GFSM 1986; also, the changes to the IT infrastructure are commensurate with those implemented in other countries. MoF publishes substantial information on its statistical techniques on its website (in Albanian), which is linked to the IMF's DSBB and Albania's GDDS fiscal metadata.

\subsubsection{The appropriate statistical entity is entitled to comment on erroneous interpretation and misuse of statistics}

The MoF regularly monitors the coverage of its data in the media. The Spokesperson for the Minister comments on erroneous interpretations and misuse of official statistics when deemed necessary. To this end, the MD-in consultation with other directorates-also provides advice on technical aspects of the statistics, and endeavors to provide explanatory material to aid the interpretation of the statistics, particularly its statistical publications.

\subsection{Transparency}

\subsubsection{The terms and conditions under which statistics are collected, processed, and disseminated are available to the public}

The terms and conditions under which GFS are compiled and disseminated are embedded in the various laws and the internal administrative regulations of the MoF. The $O B L$, available on the MoF website, defines transparency as follows: "Transparency for the purposes of this law is the provision of readily accessible, comprehensive, timely, understandable, and 
internationally comparable information to the Assembly and the public about: the functions, organization, programs and activities of general government entities; the outputs produced by those entities; the relationship between those outputs and policy objectives and policy goals; financial forecasts and public accounts." Additional information on the terms and conditions applying to GFS is made public on the MoF's website (in Albanian), which is linked to the IMF's DSBB and Albania's GDDS fiscal metadata therein.

\subsubsection{Internal governmental access to statistics prior to their release is publicly identified}

There is no internal governmental access to fiscal data prior to their release.

\subsubsection{Products of statistical agencies/units are clearly identified as such}

The MoF is clearly identified as the source of fiscal data.

\subsubsection{Advance notice is given of major changes in methodology, source data, and statistical techniques}

To ensure widespread awareness of current and future initiatives relating to the move toward a medium-term budget framework in Albania, the MoF has invited users, including members of the media, to attend (and report on) meetings where changes in methodology, source data, and statistical techniques are discussed. MoF publications also contain footnotes to alert users of such changes.

\subsection{Ethical standards}

\subsubsection{Guidelines for staff behavior are in place and are well known to the staff}

In general, the Civil Service Law and the related Ethical Code are seen as governing the ethical conduct of staff. Specific questions related to the law and code are included in the public exams all candidates for employment must take. In addition, newly recruited staff attend mandatory training at the Public Administration Training Center. The training, among other things, is aimed at instilling ethical guidelines in day-to-day work practices. The MoF (Customs and Tax Departments) has a special code of regulations that further govern the behavior of staff engaged in these areas. Staff are reminded of ethical standards during annual performance reviews. 


\section{Methodological soundness}

\subsection{Concepts and definitions}

\subsubsection{The overall structure in terms of concepts and definitions follows internationally accepted standards, guidelines, or good practices}

The concepts and definitions used to compile budget and financial execution data generally follow the guidelines of GFSM 1986. The distinction between domestic and foreign financing and debt is based on the residency criteria of the IMF's Balance of Payments Statistical Manual (fifth edition, 1993).

A formal "migration path" from the current GFSM 1986-based presentation to the GFSM 2001 framework has not been articulated. However, the compilers of fiscal statistics expressed interest in moving toward the GFSM 2001 framework, as they consider it superior to the previous framework for fiscal policy purposes, and significantly aligned with Albania's national data requirements given the rapidly evolving economy. ${ }^{14}$ The authorities identified a series of technical actions in the Budget and Treasury Departments aimed at facilitating migration that is well advanced. The mission also met with the team responsible for designing and implementing a supporting accrual-compatible data infrastructure (Oracle) being put in place by the IT Department with the financial support of the World Bank. ${ }^{15}$ The system and the various modules that comprise it will provide the MoF with advanced fiscal data management-and GFS compilation-capabilities that will complement existing and planned statistical functions while also permitting resource efficiency and staff productivity gains. The mission provided limited technical assistance primarily aimed at facilitating GFSM 2001-based data reporting to STA ${ }^{16}$ and explored with the authorities the feasibility of establishing a migration path for implementing the GFSM 2001. Based on demonstrated commitment of the MoF staff, significant progress may be possible.

\footnotetext{
14 The GFSM 2001 methodology recommends compiling a comprehensive and integrated set of data useful to fiscal sustainability and vulnerability analysis based on balance sheets (quarterly and annual) covering transactions and other economic flows, accrual based statements of government operations (quarterly and annual), and cash flow statements (monthly, quarterly, and annual). In this regard, the mission was pleased to observe that consideration was being made for compiling balance sheet data for general government commensurate with those that currently exist among all spending units.

15 The MD, Treasury, Budget, and Debt Departments are included in all discussions.

${ }^{16}$ GFS for the consolidated general government were recently reported to the IMF in broad accordance with the classifications of the GFSM 2001 for inclusion in the Government Finance Statistics Yearbook (GFSY).
} 
Recommendation: Establish a documented plan to migrate in stages toward fully implementing the GFSM 2001 methodology and identify all the institutional units that would play a significant role in the migration.

\section{$2.2 \quad$ Scope}

2.2.1 The scope is broadly consistent with internationally accepted standards, guidelines, or good practices

The scope of the general government sector in Albania is in line with international standards and encompasses the budgetary central government (President, Parliament, Council of Ministers, 14 ministries, 8 nonministerial departments, and various central institutions, which represent a total of 1,522 individual budget institutions), local government (36 districts and 43 municipalities [including Tirana, which is both a district and a municipality], which represent a total of 2,163 individual units), and two extrabudgetary funds (the social security fund and the health insurance fund).

In accordance with the provisions pertaining to fiscal reporting contained in the $1998 O B L$ statistics broadly consistent with the GFSM 1986 are produced for the National Budget, that is, the consolidated general government, state budget (all components), local government budgets (all components), State Social Insurance Fund budget, and the Health Insurance Fund. These data cover basic revenues and expenditures, special funds of line ministries, and investment projects (domestically and foreign financed) when the associated grants/loans/financing pass through the Unified Treasury Account maintained at the BoA. However, owing to source data limitations, compiling data on investment projects financed through grants provided by foreign donors remains problematic (see 3.1.1). Data also are provided on general government gross debt, classified by residency (i.e., domestic and foreign) of the counterparty to the liabilities. As such, the fiscal data cover all economic flows of the general government and the stock of general government debt, in accordance with GFSM 1986. Monthly data are considered preliminary, while quarterly and annual data

are considered final. All datasets are based on full coverage of the general government sector.

\subsection{Classification/sectorization}

\subsubsection{Classification/sectorization systems used are broadly consistent with internationally accepted standards, guidelines, or good practices}

As stipulated by the $O B L$, accounting data are generally classified using the methodology set out in GFSM 1986 and are provided separately for each level of government, as well as for the consolidated general government. There are some improvements over the GFSM 1986 classifications in the national presentation. The breakdown of expenditure (economic and functional classification) more closely approximates the GFSM 2001 framework. Similarly, the inclusion of privatization receipts and of general government's lending to nonfinancial 
corporations in financing (instead of in net lending minus repayments) is in line with the GFSM 2001. ${ }^{17}$

Classification for State Budget revenues and other receipts consist of (Article 4 of the $O B L$ ) the following:

- tax revenues;

- non-tax revenues including economic activities of budget institutions, administrative fees and user charges, fines and forfeitures, repayment of loans and other non-tax revenues according to the law;

- revenues from the sale of state property;

- domestic and external grants, both grants in cash, in-kind and commodities;

- domestic and external borrowing by the government for financing capital investment and any budget deficit; and

o other revenues in accordance with law.

All revenues raised or received form one Consolidated Fund, the cash resources of which are maintained in a single account called the Unified Treasury Account at the BOA.

The expenditure classification for budget institution expenditures and other payments consists of (Article 7 of the $O B L$ ) the following:

- current expenditure including salaries, wages and allowances, expenditure on goods and other services, current transfers, and interest payments;

- capital expenditure including construction, reconstruction, acquisition and transfer of capital assets;

- lending and equity participation; and

- repayment of principal on borrowing.

Article 12 of the $O B L$ stipulates that the means allowed for financing the deficit is articulated in the State Budget. Chapter IV of the $O B L$ provides guidelines on transactions pertaining to government borrowing and debt.

The authorities indicated that the classification of data for each subsector of general government according to GFSM 2001 is being carried out. A bridge table has been created from the "budget classification" to the national presentation of fiscal data used in Fiscal Statistics of Government. Additional bridge tables (i.e., destination codes) from those data are used to compile data according to the economic and functional classifications of the GFSM 1986 framework, as prescribed in the $O B L .^{18}$

${ }^{17}$ These exceptions result from implementing recommendations provided by the IMF's European Department country team for surveillance purposes.

${ }^{18}$ Work on embedding the GFSM 2001 classifications for transactions and stocks is well advanced. 
Recommendation: Streamline interdepartmental (Budget, Treasury, Debt, and Information Technology) tasks that support the adoption of GFSM 2001-based data compilation, including for high-frequency data (monthly cash flow and quarterly government operations data) as well as quarterly nonfinancial public sector debt.

\subsection{Basis for recording}

2.4.1 Prices are used to value flows and stocks reflect actual cash payments (GFSM 1986 guidelines).

In accordance with the GFSM 1986, flows are valued on the basis of the amount of cash received (cash deposits) and cash payments made (cash withdrawals). Debt is recorded at face value (i.e., the amount to be repaid at the end of the contract), rather than market value, and the amounts denominated in foreign currency are converted to leks at the official daily exchange rates, as provided by the BoA.

Recommendation: Commensurate with the phased migration toward the GFSM 2001 framework, market prices should be used to value all flows and stocks.

\subsubsection{Recording is done on a cash basis (GFSM 1986 guidelines)}

Recording of operations through the Treasury system (used for monitoring budget execution) is on a strictly cash basis. ${ }^{19}$ The State Social Security Fund and the Health Insurance Fund use the accrual basis of recording but use the cash basis for reporting to the MoF for budget execution (and GFS) purposes.

Recommendation: Commensurate with the phased migration toward the GFSM 2001 framework, provisions should be made for recording transactions on an accrual basis.

2.4.3 Grossing/netting procedures are broadly consistent with internationally accepted standards, guidelines, or good practices (GFSM 1986 guidelines)

Grossing/netting procedures are consistent with the GFSM 1986. All transactions are shown on a gross basis, except for tax refunds and financing transactions, which are shown net. Fiscal data on the subsectors of the general government are recorded on a gross basis, and intersectoral flows are eliminated in consolidation.

\footnotetext{
${ }^{19}$ In parallel, a substantially modified accrual accounting and reporting system (used for financial reporting within all spending agencies) exists, permitting the compilation of annual balance sheets for all spending agencies.
} 


\section{Accuracy and reliability}

\subsection{Source data}

\subsubsection{Source data are obtained from comprehensive data collection programs that take into account country-specific conditions}

Current administrative systems provide data covering the full range of economic stocks and flows for general government (central and local government units as well as extrabudgetary funds). The main data sources of GFS are the administrative systems for monitoring budget execution and debt management based in each of the 36 DTOs, which are required to report as specified by the MoF under the provisions of the $O B L .{ }^{20}$ Comprising the basis of the Treasury's fiscal database ${ }^{21}$ are the reports of 1) the DTOs-budget execution and financing; 2) the Debt Management and Financial Analysis System (DMFAS), which includes short-, medium- and long-term debt; 3) project implementation units for foreign-financed project; and 4) the extrabudgetary funds. Surveys are not needed because all information is provided through administrative sources. The only significant weakness in source data is in the availability of data on certain external donor financed (grants) projects that do not pass through the treasury system. ${ }^{22}$ These sources allow consolidation for general government and its subsectors and may also be used to provide information on some stocks and accounting information.

The Treasury keeps data sources under continuous (monthly) review. The Treasury (Accounting Department) has developed a series of reports and formats designed to collect, process, and store financial information in a timely and efficient manner. Any changes in the presentation of financial information and budget execution are coordinated processes between the reporting and compiling units.

Recommendation: Strengthen source data coverage with regard to external donor financed projects by requiring that large projects pass through the Treasury (Accounting Department) system, including for the purpose of reconciling fiscal data with data in other macroeconomic statistical areas.

\footnotetext{
${ }^{20}$ Reporting units may also develop their own internal systems.

${ }^{21}$ Developed and maintained by the Debt Department using software provided by the United Nations.

${ }^{22}$ The MoF has limited oversight authority—and thereby access to data-with regard to external donor-financed projects where funds (grants) do not pass through the Treasury system (BoA and commercial banks). Only limited cooperation is offered by external donors that provide resources directly to government units, and improvement may require enactment of supporting legislation (see 3.4.3).
} 


\subsubsection{Source data reasonably approximate the definitions, scope, classifications, valuation, and time of recording required}

The definitions, scope, sectorization, time of recording, and valuation of transactions and debt embedded in source data are adequately identified in the $O B L$ and the Guidelines on State Budget Performance, as well as in the monthly reports - the data source - that result from the directives therein. All general government units report according to the national "budget classification," which serves as a harmonizing chart of accounts to collect and compile fiscal data. The social security and health funds have their own charts of accounts. The MoF has designed reporting forms for these funds, which are sufficiently detailed to allow compilation of GFS. Using data from the Treasury system, together with reported data from these funds, the MoF is able to compile GFS for the consolidated general government sector and its subsectors.

Recommendation: In the context of the development and implementation of the new Oraclebased IT infrastructure, construct as soon as feasible a national chart of accounts for all general government subsectors aligned with GFSM 2001 classifications. ${ }^{23}$

\subsubsection{Source data are timely}

Pursuant to the practices mandated in the Guideline on State Budget Reporting, which is sent to all spending units and posted (in Albanian) on the MoF website, source data-including financial information-are quite timely. The data permit the compilation and dissemination of monthly, quarterly, and annual general government accounts well in excess of GDDS recommendations (and SDDS prescriptions). Monthly reports from the budget execution agencies are submitted by each of the 36 DTOs within 5 to 10 days of the end of the month, and annual reports of unaudited data are available by February 15. Reports from the social security and health insurance funds are received with a similar timeliness, as are the reports compiled by the BoA on the cash balances of all general government spending units. Central government debt data are submitted by the $11^{\text {th }}$ of the month after the reference month, and the data are finalized by the $17^{\text {th }}$ of the month. These data serve as the basis for recording state debt in DMFAS. The final budget execution data approved by Parliament-and used for compiling GFS-are available within six months after the end of the fiscal year. ${ }^{24}$

\footnotetext{
${ }^{23}$ May require additional resources.

${ }^{24}$ Preliminary consolidated annual general government data are available in February.
} 


\subsection{Assessment of source data}

3.2.1 Source data-including censuses, sample surveys and administrative records-are routinely assessed, e.g., for coverage, sample error, response error, and nonsampling error; the results of the assessments are monitored and made available to guide statistical processes

Source data are assessed carefully. All data come from administrative and accounting sources required to report detailed monthly data under the specific provisions of the $O B L$ and the practices mandated in the Guidelines on State Budget Reporting. Numerous automated and manual procedures are used to check the accuracy of budget execution data-payment orders are checked against financing plans submitted; internal controls are applied within and between reports; cross-checks are made between the Treasury balance and other balances (i.e., the Unified Treasury Account at the BoA); and data are subject to internal and external audit. The results of these reviews are monitored and made available to guide internal planning. A largely identical approach is employed for assessing data from local governments and the two extrabudgetary funds.

Data inconsistencies, out-of-trend values, and any inconsistencies with other related data sources are confirmed with DTOs and other reporting units, and documented, as they occur. GFS compilers address any questions concerning the accuracy of source data through direct contacts with reporters. Procedures for routine discussions of data reconciliation are also in place for facilitating the monitoring of monetary and fiscal records related to government deposits and external debt. The status of the data used for each period is noted in the GFS publications, as relevant (e.g., preliminary/revised/final).

\subsection{Statistical techniques}

\subsubsection{Data compilation employs sound statistical techniques to deal with data sources}

All data come from administrative and accounting sources, which are required under the $O B L$ and the Guidelines on State Budget Reporting to report on a timely basis; as a result, procedures to allow for estimation are not needed, and no surveys or imputations are employed. Preliminary data are routinely replaced by final data. As a result of the extensive checks applied to the data, few changes take place between preliminary and final data. GFS data are based on comprehensive information and existing compilation procedures, which strive to minimize processing errors, such as in coding, editing, and tabulation.

\subsubsection{Other statistical procedures (e.g., data adjustments and transformations, and statistical analysis) employ sound statistical techniques}

Generally accepted statistical methods are used to adjust/consolidate GFS derived from accounting records. Suspect submissions (e.g., reports of DTOs) or data discrepancies identified in the consolidation are investigated and resolved, frequently through direct contacts. MoF staff reported that significant further refinements are being tested to permit 
greater accuracy in consolidating stock and flow statistics. No other statistical procedures are employed.

Recommendation: To facilitate compilation and ensure continuity, fully document the bridge tables being developed to link national charts of accounts with GFSM 2001 classifications.

\subsection{Assessment and validation of intermediate data and statistical outputs}

\subsubsection{Intermediate results are validated against other information where applicable}

Fiscal data reported by the BoA and INSTAT are fully consistent with the MoF data. In particular, financing data are checked and validated with BoA data on government deposits, the issuance of domestic securities, and sources of external financing.

The reports of the DTOs and other spending agencies sent to the MoF (Treasury) are validated to ensure proper classifications. In this context, evidence indicates well-established procedures to fully ensure that accounting data are accurate and that final reporting of statistics is based only on the latest most accurate and reliable source data. Significant effort also is expended on internal and external audits and on reconciling data. ${ }^{25}$

\subsubsection{Statistical discrepancies in intermediate data are assessed and investigated}

All discrepancies between GFS and intermediate budgetary data, and those between the intermediate budgetary and accounting data, are investigated. Expenditure by economic type and by function is cross-checked for consistency, and fiscal data are cross-checked against all other intermediate data, such as information from tax and customs administrations and the transactions for the government executed by the BoA.

\subsubsection{Statistical discrepancies and other potential indicators of problems in statistical outputs are investigated}

Discrepancies between the banking system (data on government accounts at commercial banks and at the BoA) and between the budget execution reports (e.g., between the deficit/surplus and financing and between financing and changes in gross debt) are investigated and resolved to the extent possible before release of data. For example, data on external debt stocks and related flows are checked with creditor information. Such reconciliations are also carried out in preparing the MoF's fiscal package (part of the annual budget cycle).

\footnotetext{
${ }^{25}$ All public sector entities are subject to external audit.
} 
The MoF also attempts to conduct bilateral data reconciliations with external donors and creditors, and investigates significant discrepancies. However, cooperation is limited in cases where the external donor provides resources directly to recipients/projects (see 3.1.1).

\subsection{Revision studies}

\subsubsection{Studies and analyses of revisions are carried out routinely and used internally to inform statistical processes (see also 4.3.3)}

Any cross-checks with intermediate data that give rise to discrepancies requiring revisions are documented in an internal memorandum (issues, conclusions, and recommendations) prepared by the Budget, Treasury, MD, and Debt Directorates (as relevant). The memorandum is sent to the Minister on a monthly basis, as needed. Follow-up is usually at the level of Deputy Minister with the data-providing agency, usually by phone but occasionally through formal letters and on-site meetings. The resulting documentation (outcome) is used as a reference to address similar future occurrences and to inform statistical processes.

\section{Serviceability}

\subsection{Periodicity and timeliness}

\subsubsection{Periodicity follows dissemination standards}

With the inception of the regular publication of the quarterly publication Fiscal Statistics of Government in 1998, Albania exceeds the GDDS recommendations for the periodicity of fiscal data-and has met or exceeded the SDDS prescriptions-as follows:

- $\quad$ Statistics for consolidated general government operations are disseminated both on a quarterly and an annual basis.

- $\quad$ Statistics for central government operations are disseminated monthly in the publication Economy and Budget.

- $\quad$ Monthly statistics for central government debt are disseminated quarterly.

- $\quad$ Statistics for central government budgetary operations are disseminated on both a monthly and quarterly basis.

- Statistics for central government debt are disseminated both quarterly and annually.

\subsubsection{Timeliness follows dissemination standards}

With the inception of the regular publication of the quarterly publication Fiscal Statistics of Government in 1998, Albania exceeds the GDDS recommendations for the timeliness of 
fiscal data—and has met or exceeded the SDDS prescriptions—as follows:

- $\quad$ Preliminary annual statistics for general government operations are disseminated within one quarter.

- Monthly statistics for central government operations are disseminated within one month in the publication Economy and Budget.

- Quarterly statistics for central government debt are disseminated within one quarter.

- Quarterly statistics for central government budgetary operations are disseminated within one quarter.

- Preliminary annual statistics for central government debt are disseminated within one quarter.

\subsection{Consistency}

\subsubsection{Statistics are consistent within the dataset}

The disseminated central government finance data are internally consistent, and the concepts, definitions, and classifications for monthly, quarterly, and annual fiscal data are the same.

Data are internally consistent for the general government account as well as the accounts for the other levels of government, with the sum of monthly transaction data equaling the annual data. ${ }^{26}$ On the revenue and expenditure sides, the aggregates are consistent with their components, and balances are consistent with these aggregates. In the process of consolidating the general government accounts, staff fully reconcile transfers from the budget to other levels of governments. The sum of the transaction data for the subsectors of the general government, after consolidation, is consistent with data on the consolidated general government. During recent years, the statistical discrepancies have been minimal in the final annual data.

\subsubsection{Statistics are consistent or reconcilable over a reasonable period of time}

Fiscal data are consistent with expected trends and reflect discretionary changes, external shocks, and developments in economic activity. For general government statistics, changes due to major methodological improvements or changes in the statistical system, concepts, etc., which rarely occur, are explained through footnotes, and the time-series are revised in

\footnotetext{
${ }^{26}$ This equality reflects both the accuracy of monthly data compiled by the General Treasury Department and the ongoing, albeit limited, revisions made occasionally to monthly data during the year as additional detail becomes available.
} 
the relevant publications. The historical series in the underlying fiscal database for the general, central, and local governments-available free to all interested users on the MoF website (in Albanian)-is also reconstructed.

\subsubsection{Statistics are consistent or reconcilable with those obtained through other data sources and/or statistical frameworks}

An interagency committee works to check consistency with the BoA's monetary and balance of payments statistics and with INSTAT's national accounts statistics; cash-based government statistics constitute a data source for these other frameworks. The definition of general government in GFS is the same as the definition for general government in the monetary statistics. As such, the GFS financing data and data on government financial assets and liabilities held by other sectors are broadly consistent with monetary and financial statistics. Grants and other transactions are largely consistent with balance of payments data provided by the BoA, although shortcomings remain in terms of obtaining details on many significant grants in kind from abroad (see 3.1.1).

Intersectoral inconsistencies have occurred owing to structural changes in the economy-as reflected in the ongoing revisions to national accounts data disseminated by INSTAT (fiscal activity as a percentage of GDP) - that have not been addressed in a coordinated manner in published datasets. To address this, MoF now recognizes changes in GDP figures stemming from methodological changes in the compilation of the national accounts through footnotes to the publication Fiscal Statistics of Government. The MD is also preparing supplemental tables for inclusion therein that have been made fully consistent and cross-checked against INSTAT's national accounts aggregates, such as savings, net lending/borrowing, government consumption, gross fixed capital formation, and consumption of fixed capital.

\subsection{Revision policy and practice}

\subsubsection{Revisions follow a regular and transparent schedule}

Monthly and quarterly fiscal data, as released, are considered to be preliminary and can be revised in the annual figures owing to changes in reported data, such as the reclassification of previously disseminated monthly data (or rarely on the release of audited annual data). Because these preliminary data are checked extensively, revisions are marginal when preliminary data are replaced with final data. Minor errors are recorded in the next reporting period, and significant errors, which are rare, are applied to the period in which the activity took place.

Since 2004, the revisions have followed a regular annual cycle. However, the revisions cycle is not made known to the public, and reasons underlying the revisions (e.g., the availability of revised data) are not explained. Concerning government domestic debt statistics, there are no revisions made on a regular, well-established, and transparent schedule that is publicized. Foreign debt statistics are revised to take late submissions into account. Again, none of these practices are made known to the public. 
Recommendation: When revisions, inside or outside any revision cycle, are called for, they should be made known to the public (e.g., through the publication Fiscal Statistics of Government and documented in the freely accessible database maintained on the MoF website).

\subsubsection{Preliminary and/or revised data are clearly identified}

Preliminary data are identified, and distinction is made between previously disseminated data and revised data in the MoF's publications.

\subsubsection{Studies and analyses of revisions are made public (see also 3.5.1)}

Owing to the nature of the statistics and the full coverage of the general government sector, no specific studies or analyses of revisions to monthly data-which tend to be routine and generally small both in size and number-are made public.

\section{Accessibility}

\subsection{Data accessibility}

5.1.1 Statistics are presented in a way that facilitates proper interpretation and meaningful comparisons (layout and clarity of text, tables, and charts)

The MoF website permits easy access to the bilingual (Albanian/English) Fiscal Statistics of Government publication, which contains a GFSM 1986-based national presentation of fiscal data; it also contains a hyperlink to lengthy time series data. Most of the fiscal data are presented in a way that allows major aggregates and balancing items to be identified and related to detailed underlying data. The national presentation is used mainly to monitor budget implementation and to formulate future fiscal policy.

For the annual figures, a large number of GFS time series are available. By special request, the MoF provides data for government consumption and other national aggregates.

Recommendation: In addition to disseminating the national format, disseminate general government finance statistics when feasible, according to the GFSM $2001 .^{27}$

\subsubsection{Dissemination media and format are adequate}

Detailed tables (in Albanian and English), broadly consistent with the recommendations of the GFSM 1986, are disseminated by the MoF in the quarterly Fiscal Statistics of Government, which also contains information on the final budget outcome in the June issue.

${ }^{27}$ Would require additional resources as well as training in GFS methodology. 
All these data are released by the MoF on its website. Preliminary annual data are disseminated in the December issue of the monthly bulletin Economy and Budget, which is released (in Albanian) in February (i.e., with a two-month lag). General government operation data are available cumulatively for the year-to-date. In addition, the monthly publication Economy in Focus briefly describes trends in public finance along with highlights for the real, monetary, and external sectors. Finally, a new publication, Main Macroeconomic Indicators, is disseminated on the MoF's website.

Time series and more detailed breakdowns of the data are available free through the Treasury's Web-based database as well as on request either in paper or electronic formats.

\subsubsection{Statistics are released on a preannounced schedule}

A calendar of release dates for fiscal data is included in the online catalog (see 5.3.2). Annual, quarterly, and monthly data are released as per the directives contained in the $O B L$ and the Guideline on State Budget Reporting, which are posted (in Albanian) on the MoF website.

\subsubsection{Statistics are made available to all users at the same time}

Statistics are made available to all users at the same time, free through hardcopy and web dissemination formats. There is no prior release or preferential access to the data.

\subsubsection{Statistics not routinely disseminated are made available upon request}

Nonpublished, nonconfidential, disaggregated data are made available upon request without charge. The availability of nonpublished but nonconfidential data and the terms and conditions under which they are made available has not been publicized in the MoF publications.

\subsection{Metadata accessibility}

5.2.1 Documentation on concepts, scope, classifications, basis of recording, data sources, and statistical techniques is available, and differences from internationally accepted standards, guidelines, or good practices are annotated

Sufficiently detailed statements (in Albanian) on accounting concepts, scope, classifications, and basis of recording are contained in the $O B L$, which serve as the basis for compiling GFS that broadly conforms with GFSM 1986. Bridge tables showing the links between source (accounting) data and GFS - and therefore international standards-are documented but not disseminated. GFS metadata prepared by the MoF for participation in the GDDS are available on the IMF's DSBB website, which is linked to the MoF's website, and are regularly updated. 
Recommendation: Prepare additional documentation (in English) explaining the concepts, scope, classifications, basis of recording, data sources, and statistical techniques used in compiling GFS, as well as differences from internationally accepted standards and guidelines (ideally with reference to the GFSM 2001, given the planned migration to this standard). ${ }^{28}$

\subsubsection{Levels of detail are adapted to the needs of the intended audience}

The presentations of fiscal data are thorough enough to provide adequate information for experts to assess strengths and weaknesses of the government finance statistics. The level of detail in the monthly and quarterly releases appears to meet the data needs of most users. The metadata accompanying the data presentation in the quarterly Fiscal Statistics of Government orient users concerning the basic framework under which the fiscal statistics have been produced.

\subsection{Assistance to users}

\subsubsection{Contact points for each subject field are publicized}

Prompt and knowledgeable service and support is available. The quarterly flagship publication Fiscal Statistics of Government the monthly information bulletin Economy in Focus provides users with contact information for queries (an individual [Director of the MD], a contact phone number, an e-mail address, and the MoF's website). Similar information is given in the monthly Economy and Budget. The GDDS metadata on the IMF's DSBB website, linked to the MoF website, also list contact persons for fiscal data.

\subsubsection{Catalogs of publications, documents, and other services, including information on any charges, are widely available}

A concise catalog of publications is available on the MoF website. All data disseminated through hard copy and web-based media are provided free of charge.

\footnotetext{
${ }^{28}$ Would require additional resources.
} 


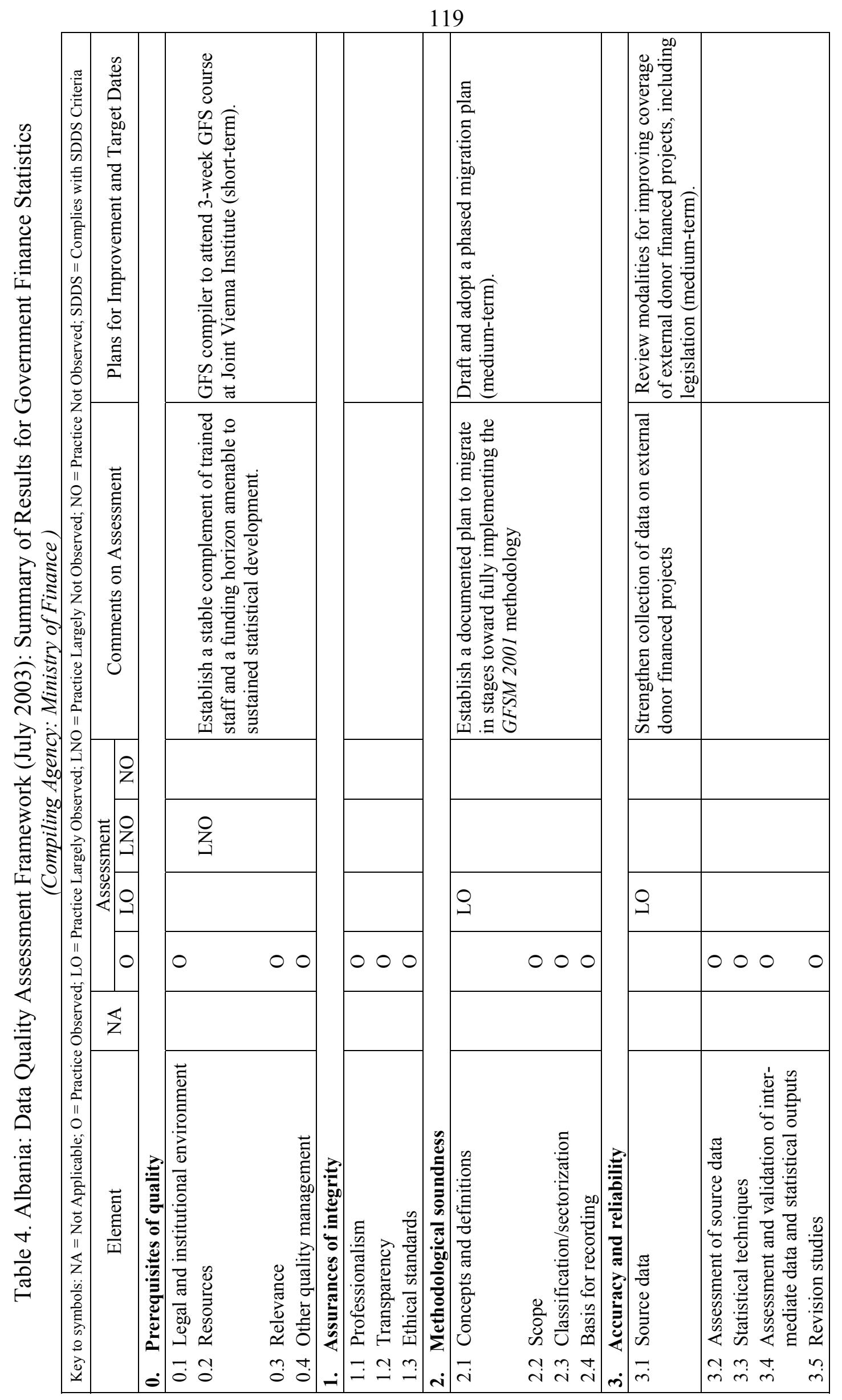




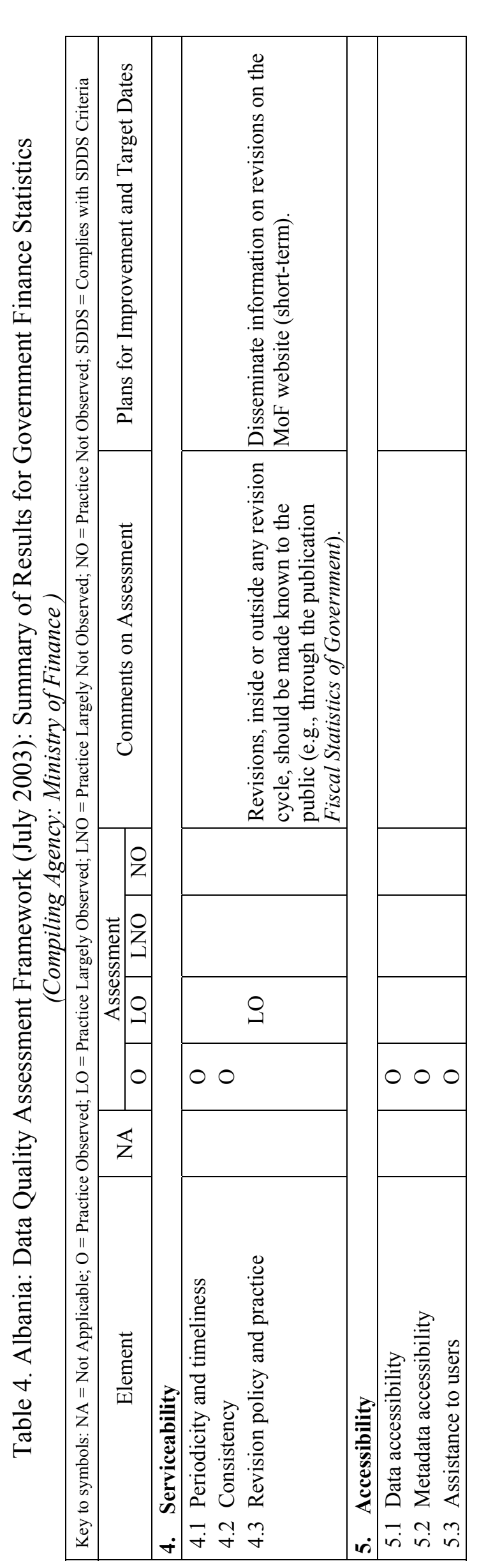




\section{Monetary Statistics}

\section{Prerequisites of quality}

\subsection{Legal and institutional environment}

\subsubsection{The responsibility for collecting, processing, and disseminating the statistics is clearly specified}

The Bank of Albania (BoA), by tradition, is responsible for compiling and disseminating monetary statistics, although the BoA's law On the Bank of Albania ${ }^{29}$ (Law) does not specifically spell out this mandate. At the same time, as stipulated in Article 3 (4) of the Law, the BoA has responsibility for conducting monetary policy, which requires monetary statistics. Consequently, the BoA derives its authority for compiling monetary statistics from its responsibility for conducting monetary policy. No other agencies are involved in the compilation of monetary statistics.

Article 24 (5) and Article 27 of Chapter IV of the Law defines the authorities of the BoA in establishing rules for the reporting information necessary for the BoA to carry out its tasks and perform its functions, which are binding upon banks, juridical, and physical persons. The relationship between the BoA and banks with regard to reporting is also defined by Law No. 8365 of July 2, 1998 On Banks in the Republic of Albania (Banking Law) ${ }^{30}$ under Articles 41 and 43.

On data dissemination, Chapter IV, Article 24 (3) of the Law states that "The Bank of Albania shall prepare periodic analyses on economic and monetary matters, publish the outcome and submit proposals and measures to the Government of the Republic of Albania." Also, Chapter VIII, Article 69 states that "The Bank of Albania shall publish monthly its summary balance sheet;" "at the end of each financial year, shall prepare the report and the financial statements;" and "the report and the balance sheet of the Bank of Albania should be published in the form determined by the Bank, after their approval by the Supervisory Council of the Bank of Albania."

The responsibility for compiling monetary statistics resides with the BoA's Statistics Department (SD). This department was created in November 2005 (based on the BoA's Supervisory Council Resolution No. 79 of October 31, 2005), with a view to enhancing the BoA's statistics functions. This reflects the increased importance the BoA management attaches to statistics.

\footnotetext{
${ }^{29}$ The current Law was adopted in 1992 and since then has been amended to the most recent version, dated December 1997.

${ }^{30}$ The Banking Law is currently being revised.
} 


\subsubsection{Data sharing and coordination among data-producing agencies are adequate}

Different departments of the BoA interact during the process of compiling monetary statistics. Well-established arrangements exist within the BoA for ensuring the flow of source data to the SD for use in compiling monetary statistics. The Accounting and Payments Department (APD) produces monthly balance sheet data of the BoA and makes them available to the SD in hard copy and floppy disk. The commercial banks transmit their monthly balance sheet data to the BoA's SD (Office of Administration of the Reports (OAR)) both in hardcopy and on floppy disk. The savings and loans associations (SLAs) submit their individual report forms (balance sheets) on a quarterly basis to the OAR through the two unions in which they are grouped. The BoA uses a unified reporting system for the commercial banks, incorporating the requirements of BOA departments, and a database system for storage of, and common access to, the reported data.

The OAR checks for the accuracy of the source data and makes them available to the SD's Office of Monetary and Financial Statistics (OMFS), which is in charge of monetary statistics compilation and dissemination. The SD also coordinates with the Supervision Department to check the accuracy of data and to incorporate possible revisions arising from on-site supervision.

The BoA communicates regularly with other data-producing agencies, namely the national statistical institute (INSTAT) and the Ministry of Finance (MoF). The BoA has established formal data-sharing agreements with these agencies. A Memorandum of Understanding with INSTAT, covering the provision and sharing of data with a defined timetable, is in the final stage of completion and is expected to be signed in the near future. The BoA receives data from INSTAT and the MoF and disseminates them through its publications and website.

\subsubsection{Individual reporters' data are to be kept confidential and used for statistical purposes only}

Confidentiality is important in statistical work and is rigorously observed in practice by the BoA. Article 58 (1) of the Law states that "No person who serves or has served as a member of the Supervisory Council, management or staff or as an auditor, agent or correspondent of the Bank of Albania shall, in a manner unauthorized by law, or international agreement where Bank of Albania is a party, permit access to, disclose or publicize nonpublic material information which has obtained in the performance of his Bank of Albania duties or use such information, or allow such information to be used for personal gain." However, the Law might be interpreted as not providing the legal assurance that these data would only be used for statistical purposes; Article 58 (2) states that "such persons may disclose nonpublic material information to tax authorities of the Republic of Albania."

Recommendation: Strengthen the BoA law to provide full legal assurances that individual reporters' data may be used only for statistical purposes. 
The "Code of Ethics of the Bank of Albania" and the "Regulation for Transparency and Confidentiality in the Bank of Albania" also contain provisions on confidentiality. All these documents are posted on the BoA's website (www.bankofalbania.org).

The BoA implements procedures that prevent the dissemination of individual information. These procedures include appropriate security measures for accessing the database containing individual data and password protection of the computer center to allow access only to authorized staff. The perimeter of the BoA is secured, and all visitors are screened and phone contact is established with visited staff before access is granted. The BoA's Protocol and Archive Office keeps all the hard copies of the individual records for 10 years, after which the records are transferred and archived at the State Archive.

In some special instances, disclosure of individual banks' information cannot be avoided, such as in the case when a bank or group of banks has a dominant position in a given instrument, which allows the disclosure of individual information even when the data are aggregated. For example, currently there is only one Albanian bank that has branches outside the country, and its position in Shares and other equity in the other depository corporations survey can be identified. This position is publicly known, because the bank publishes its balance sheet statement.

\subsubsection{Statistical reporting is ensured through legal mandate and/or measures to encourage response}

The Law explicitly empowers the central bank to collect data. Chapter IV, Articles 24 (5) and 27 serve as the legal basis for the collection of information needed for the compilation of monetary statistics. Formal provisions for the reporting by banks to the BoA are also contained in the Banking Law (Articles 41 and 43). Article 44 of the Banking Law specifies penalties "in case of violation of its provisions." In the case of the SLAs, the Law No. 8782 of May 2001 On Savings and Loans Associations (Articles 47 and 50) and the BoA's Regulation No. 44 of June 2005 serve as the legal basis for their reporting to the BoA.

A BoA database (Automatic System of the Statistical Reports (SARS)) contains all data reported to the BoA by commercial banks for supervision and monetary statistics purposes. Various BoA departments can access the SARS, ensuring the maximum utilization of the available data. The SARS does not yet contain data reported by the SLAs. However, the monetary statistics compilers are not using the SARS to generate monetary data but instead use Excel files, which are more flexible for monetary statistics compilation. A BoA working group reviews reporting requirements (e.g., deliberates on new data requirements and elimination of items no longer needed).

The BoA provides reporting banks, the SLAs, and their unions with written instructions for completing their monthly balance sheet data. The SD staff regularly contacts reporting banks via email and telephone to discuss or clarify data issues. The BoA has not yet introduced an electronic (online) reporting system for commercial banks and the SLAs, which could make the reporting easier for them. 
Recommendation: Implement an electronic (online) reporting system for commercial banks and other financial institutions to enhance efficiency of monetary compilation.

\section{$0.2 \quad$ Resources}

\subsubsection{Staff, facilities, computing resources, and financing are commensurate with statistical programs}

Although current staff resources suffice for monetary compilation, more resources are needed if the BoA is to implement its plan to compile other financial statistics such as the financial corporations survey and flow data. Computing resources are deemed adequate in both quality and quantity for the collection of source data, compilation, and dissemination of monetary statistics. Currently, physical conditions of offices and the distribution of staff according to the functions they perform do not seem adequate for staff to effectively perform the required tasks. The BoA provides funding for the identified needs of the current statistical program. However, in a medium-term perspective, funding should be planned to ensure a fully automated process of collection and processing of the source data.

The BoA's SD has two units - the Sector of Financial Statistics (SFS) and the Sector of Balance of Payments and Surveys. Within the SFS, the OMFS is in charge of compiling and disseminating monetary statistics. One specialist and the head of the OMFS are directly involved in compiling and disseminating monetary statistics. They have university degrees in finance or economics and, in addition to on-the-job training, have participated in monetary and financial statistics courses organized by the IMF. The head of the OMFS is currently engaged in postgraduate studies. The SD staff also participate in seminars held by other central banks and international financial institutions.

The BoA's salary levels are adequate for the nature of the work and generally are higher than those in government ministries in Albania.

All staff in the OMFS are equipped with computers. The provision of computing resources is under the responsibility of the BoA's Information Technology Department. This department has systems in place to protect the BoA's computer resources and maintain operation in the event of an emergency. However, the system for collecting and processing data is only partially computerized because reporting units do not transmit data electronically (online). Data entry of the individual records in SARS database is manual.

The current facilities do not allow for adequate staff space. Moreover, owing to space constraints, staff from different units are sharing the same office.

Recommendation: Although current staff resources suffice for monetary statistics compilation, additional resources are needed in the Information Technology Department to (1) design the SARS database for a better performance including the generation of monetary data and (2) implement an electronic (online) reporting system for commercial banks and other financial institutions. More resources are needed in the SD to expand monetary 
statistics to cover also other financial corporations and to compile and present flow data for the financial sector, as recommended by the Monetary and Financial Statistics Manual (MFSM).

\subsubsection{Measures to ensure efficient use of resources are implemented}

The BoA seeks efficiency through a variety of (at least four) channels. First, managers evaluate the performance of staff monthly, semiannually, and annually. Second, the BoA periodically reviews work processes to reprioritize work and ensure its efficiency. The recent establishment of the SD is recognition of the importance of statistics within the BoA. Third, the SD staff participates in the review of regulatory acts concerning changes in accounting methodology at the BoA and banks, during the stage that drafts of said changes are being prepared, which makes it possible to take the requirements of monetary statistics into account. For example, the SD staff is currently participating in the review of the banks' chart of accounts. Fourth, whenever necessary, the SD consults outside experts for advice (e.g., experts from the IMF or other central banks).

The BoA has medium-term development plans, in which its statistical activities are included. The medium-term development plan for 2003-05 is posted on the BoA's website. A new plan for 2006-08 is currently being finalized.

Clear budgeting procedures are used for allocating resources. In accordance with these procedures, the BoA's budget is prepared, based on requirements of all departments, and approved by the BoA's Supervisory Council. In the framework of the annual program and annual budget of the BoA, the SD reviews its resources and assesses additional funding needs.

\section{$0.3 \quad$ Relevance}

\subsubsection{The relevance and practical utility of existing statistics in meeting users' needs are monitored}

The BoA seeks to monitor the relevance of monetary statistics in meeting user needs in various ways. First, the BoA provides detailed explanations on the various aspects of its monetary statistics by making appropriate materials available on its website. Second, in its publications and on its internet website, the BoA encourages suggestions and comments for improvements in their content and provides an e-mail address where users can direct queries. Third, the BoA plans to conduct surveys to better identify users' needs; the first survey is planned for end-2006.

The BoA management is sensitive to users' views to identify emerging data requirements. In November 2000, the BoA, in collaboration with INSTAT, organized the first conference "Statistical Information in Albania." The conference was attended by representatives of governmental agencies, private sector, academia, and international organizations. The BoA staff participate in meetings organized by other Albanian data-producing agencies, and the SD staff participate in meetings with users organized by other departments of the BoA. For 
example, in the framework of inflation targeting that BoA intends to adopt, an open forum was organized in December 2005, which discussed the preconditions for adopting inflation targeting and in which the SD staff participated. Moreover, in January 2006, the BoA set up an inflation targeting task force with representatives from management, the Research Department, and the Monetary Policy Department. The SD staff participate in the mentioned task force meetings to discuss aspects related to statistics.

The BoA staff also participate in international statistics conferences and seminars organized by international and regional organizations to keep abreast of new developments in statistical standards and best practices that may be applied in the monetary statistics. In this context, it should be mentioned that Albania is among the first countries to prepare and transmit to the IMF Statistics Department (STA) monetary data using the new standardized report forms (SRFs) designed in accordance with the methodology in the MFSM.

\section{$0.4 \quad$ Other quality management}

\subsubsection{Processes are in place to focus on quality}

The BoA management attaches importance to its work on statistics, is sensitive to data quality issues, and takes initiatives to improve data flows between the BoA and other agencies. The recent establishment of the SD highlights the increased importance of statistics at the BoA.

The BoA's activities are governed by the principle "quality creates confidence." The BoA staff is fully conscious of the importance of quality in building trust among monetary statistics users, and they are sensitive to the different dimensions of data quality.

\subsubsection{Processes are in place to monitor the quality of the statistical program}

The SD, collaborating with the Supervision Department, verifies that data reporting practices followed by commercial banks and the SLAs are consistent with the guidelines and regulations established by the BoA. Validation procedures undertaken by the OAR for assessing the plausibility of reported data are based on a Manual of Control Procedures agreed upon by both the SD and Supervision Department. The agreement ensures that reporting forms for statistical purposes are consistent with those for supervisory purposes. If OAR and OMFS staff identify unusual movements in data, they investigate in-depth for possible misclassifications or other errors, and the Supervision Department is informed.

The SD regularly consults with other BoA departments involved in developing and implementing monetary policy (such as the Monetary Policy Department, the Supervision Department, and the Research Department) to identify their data requirements.

The BoA does not conduct regular official surveys of users of monetary statistics. However, users have an opportunity for two-way communication with the BoA (comments or consultation), for example by using the e-mail addresses or telephone numbers posted on the 
BoA's website. The BoA considers comments and requests from external data users as important feedback for monitoring the quality of monetary statistics. User comments are considered in introducing improvements in the data and their presentation.

The reliability and accuracy of the balance sheets of the BoA, commercial banks, and the SLAs - the primary source data for monetary statistics - are enhanced by an external auditing process required by law. The Law (Article 68) stipulates that the BoA's annual financial statement shall be examined by an authorized external auditor in compliance with international auditing standards, and the audit report be published. Currently, the Deloitte \& Touche company is performing an external audit of the BoA. The Central Bank Survey produced by the OMFS based on the accounting records of the BoA is also audited on a quarterly basis by the BoA's Internal Audit Department. For commercial banks, the Banking Law (Articles 39 and 40) contains specific rules and regulations that banks have to follow in conducting their external audit. For the SLAs, the Law On Savings and Loans Associations (Article 49) contains provisions for the auditing of the SLAs' accounts by external auditors.

\subsubsection{Processes are in place to deal with quality considerations in planning the statistical program}

The BoA management recognizes the importance of and need for trade-offs between accuracy and timeliness of data. Data accuracy is checked at all stages of the preparation of information. Nevertheless, the timeliness of information is recognized as one of the key parameters. The BoA presents final data for the other depository corporations within the timeframe established under the IMF's GDDS.

\section{Assurances of integrity}

\subsection{Professionalism}

\subsubsection{Statistics are produced on an impartial basis}

The Law mandates the professional independence of the BoA. Article 1 (3) of the Law stipulates the independence of the BoA as follows: "the Bank of Albania shall be entirely independent from any other authority in the pursuit of its objectives and the performance of its tasks." Proceeding from its legal status, the BoA defines its own methodology for compiling and disseminating monetary statistics, taking into account international standards. The terms and conditions under which the monetary statistics are produced promote the professional independence of the BoA.

The BoA performs its activities as established by the Supervisory Council, consisting of a Governor, two Vice-Governors, and six other members. Article 44 of the Law indicates that the Governor of the BoA is appointed by the President of Albania on the recommendation of the Prime Minister. The Governor is appointed for a seven-year term, is responsible to Parliament, and can only be removed by Parliament. 
The BoA is guided in its personnel hiring and promotion policies by the principle of professional competence. Recruitment and promotion are based on relevant aptitude and expertise. Minimum requirements for potential recruits include education background and written tests.

The professional development of statistical staff in the BoA is promoted through on-the-job training, full post-university studies supported by the BoA's Human Resources Department and SD, monetary and financial statistics courses organized by the IMF, and technical assistance provided by the IMF and other international organizations. Following the technical assistance received from the IMF, the BoA staff started implementing the methodology in the MFSM and preparing the SRFs for transmission of monetary data for publication in International Finance Statistics.

Moreover, the BoA encourages research by its staff. The SD staff has prepared a selfassessment of the Albanian monetary statistics by using the IMF's Data Quality Assessment Framework (DQAF), published in the BoA's Economic Bulletin of June 2005. The SD staff also prepared a paper on the comparison between the data dissemination practices in Albania and the IMF's Special Data Dissemination Standard (SDDS), which was published in the BoA's Economic Bulletin of September 2005. A recent paper prepared by the SD staff ("A survey of time series on deposits, loans, and net foreign assets of the Bank of Albania") was published in the BoA's Economic Bulletin of December 2005. The article aims to enhance staff expertise as well as provide assistance to users for correct interpretation of monetary data.

\subsubsection{Choices of sources and statistical techniques as well as decisions about dissemination are informed solely by statistical considerations}

The BoA chooses data sources and statistical techniques based solely on statistical considerations. The BoA staff seeks to ensure that the sources used in the compilation of monetary statistics are comparable to sources for analogous indicators in other areas of macroeconomic statistics such as the system of national accounts, balance of payments, and government finance statistics.

Decisions about dissemination are informed solely by statistical considerations. The BoA disseminates (through its publications and website) a wide range of monetary statistics and detailed metadata to aid users in understanding the disseminated data.

\subsubsection{The appropriate statistical entity is entitled to comment on erroneous interpretation and misuse of statistics}

The BoA tracks the use and interpretation of monetary statistics in the financial press and the mass media. If an erroneous interpretation or misuse of the monetary statistics arises in the media, the BoA's Press Office comments and provides clarification in the media and publishes these on its website. If needed, the BoA contacts the reporters and other interested parties to have the erroneous interpretation corrected. 
To avoid misuse or incorrect interpretation of monetary statistics, the BoA is active in developing a "culture of statistics" and organizes various seminars for the media. The BoA has a training program for the media. In accordance with this program for March-July 2006, the SD conducted on April 27, 2006 a seminar on how to "read" and correctly interpret the statistics produced by the BoA.

\subsection{Transparency}

\subsubsection{The terms and conditions under which statistics are collected, processed, and disseminated are available to the public}

The laws and regulations under which statistics are collected, processed, and disseminated by the BoA are available to the public. The BoA law, the Banking Law, the SLA law, and the regulations issued by the $\mathrm{BoA}$ are available on its website. The advance release calendar for key external and financial data disseminated by the BoA, along with monetary data and metadata, are also posted on the website.

The BoA's publications always indicate the address of the BoA's website, where more information about the BoA, other data series for monetary statistics and other macroeconomic statistics, and related working papers are disseminated.

\subsubsection{Internal governmental access to statistics prior to their release is publicly identified}

Access to statistics is provided simultaneously to all users when the data are posted on the BoA's website.

\subsubsection{Products of statistical agencies/units are clearly identified as such}

Monetary statistics are clearly identified as BoA products, with its name and logo. When the BoA publishes data produced by other agencies or posts them on its website, it clearly indicates the source. The BoA requests attribution when its statistics are used for reproduction or re-dissemination.

\subsubsection{Advance notice is given of major changes in methodology, source data, and statistical techniques}

Advance notice of major changes in methodology, source data, or statistical techniques is given to the public. 


\subsection{Ethical standards}

\subsubsection{Guidelines for staff behavior are in place and are well known to the staff}

Ethical standards of official behavior for the BoA staff are established by the Code of Ethics of the Bank of Albania. These guidelines, well known to BoA staff, establish the main principles and rules for staff integrity, objectivity, professional competence, efficiency, professional independence, maintaining confidentiality of data, and avoiding conflict of interest, among others. New staff members are informed of the Code of Ethics of the Bank of Albania during their training period. The staff is also reminded periodically of the ethical standards of the BoA.

\section{Methodological soundness}

\subsection{Concepts and definitions}

\subsubsection{The overall structure in terms of concepts and definitions follows internationally accepted standards, guidelines, or good practices}

The framework used by the BoA in compiling the analytical accounts of the central bank and the analytical accounts of other depository corporations is consistent with the guidelines of the MFSM. The data compilers derive the broad money survey (depository corporations survey) by consolidating the analytical accounts of the BoA, of all registered domestic and foreign commercial banks, and of the SLAs. Analytical accounts of other depository corporations - Survey of other depository corporations and Sectoral balance sheet of depository corporations - cover commercial banks and SLAs, in accordance with the MFSM.

Key aggregates identified in the depository corporations' survey are net foreign assets, net claims on central government, claims on resident sectors other than government (broken down by claims on state and local government, public nonfinancial corporations, other nonfinancial corporations, other financial corporations, and other resident sectors), currency in circulation outside depository corporations, deposits included in broad money, deposits excluded from broad money, loans, and other items (net).

The definitions of monetary aggregates are as follows:

- M1 is defined as currency in circulation plus demand deposits and sight deposits in national currency of residents other than central government.

- M2 is defined as M1 plus term deposits in national currency of residents other than central government.

- M3 is defined as M2 plus foreign currency deposits of residents other than central government.

Following the publication of the MFSM, the BoA prepared a plan for implementing the MFSM's methodology that included revising procedures and formats for collecting, compiling, and disseminating monetary statistics. The BoA also started preparations of the 
SRFs for the collection and reporting of monetary data that are in full compliance with the sectorization and classification principles recommended by the MFSM. In January 2005, the BoA reported to STA test monetary data based on the SRFs. ${ }^{31}$

The BoA staff also started preparations for the expansion of the institutional coverage of monetary statistics so as to compile and disseminate data on the entire financial sector.

Recommendation: It would be desirable that further work in the area of monetary statistics include compilation of flow data.

\subsection{Scope}

2.2.1 The scope is broadly consistent with internationally accepted standards, guidelines, or good practices

At end-February 2006, the depository corporations sector in Albania comprised the BoA, 17 commercial banks, and 133 SLAs grouped in two unions. Most of the commercial banks (11) have foreign capital, three banks have foreign and domestic capital, and three banks have domestic capital only.

For analytical purposes, the MFSM defines the Other Depository Corporations (ODCs) subsector to consist of all resident financial corporations (except the central bank) and quasicorporations mainly engaged in financial intermediation, whose liabilities consist of deposits or financial instruments considered as deposit substitutes that are included in the national definition of money. The national definition of broad money is thus fundamental to the methodology of the MFSM, in that it determines which units in the financial corporations sector are classified as ODCs. In Albania, commercial banks and the SLAs are currently the deposit-taking financial institutions fulfilling both criteria that classify them as the ODCsthat is, they are mainly engaged in financial intermediation and are the only institutions issuing liabilities that are included in the M3 aggregate. In this regard, the scope of the currently compiled broad money survey is consistent with the MFSM recommendations. All domestic branches and domestic headquarters of depository corporations are covered in the Albanian monetary statistics.

\footnotetext{
${ }^{31}$ Albania's monetary data based on SRFs were published in the first issue of the International Financial Statistics Supplement in September 2006.
} 


\subsection{Classification/sectorization}

\subsubsection{Classification/sectorization systems used are broadly consistent with internationally accepted standards, guidelines, or good practices}

The sectorization adopted for monetary statistics fully conforms with the MFSM. The definition of residency in monetary statistics is consistent with the Balance of Payments Manual, fifth edition (BPM5) and the 1993 SNA.

The resident sector is divided into the following subsectors: nonfinancial public corporations, private nonfinancial corporations, central government, which covers government ministries and institutions at the same level; local government and public administration covering all municipalities; depository corporations; other financial corporations, covering insurance companies, pension funds, other financial intermediaries and financial auxiliaries; and other resident sectors including households and nonprofit institutions serving households.

The classification of financial instruments used for monetary statistics conforms to the MFSM guidelines. The monetary data separately identify monetary gold and SDRs, currency and deposits, securities other than shares, loans, shares and other equities, and other accounts receivable/payable. Financial instruments are classified by type, maturity, and currency denomination (domestic and foreign). At present, depository corporations in Albania do not engage in financial instruments such as insurance technical reserves and financial derivatives; hence, these instruments are not identified in the balance sheets of the institutions covered by the monetary statistics.

The treatment of securities repurchase operations as collateralized loans is fully consistent with the MFSM recommendations. The BoA does not currently engage in gold swaps (the exchange of monetary gold for foreign exchange).

\subsection{Basis for recording}

\subsubsection{Market prices are used to value flows and stocks}

In line with MFSM recommendations, loans and deposits are recorded at their book value and are not adjusted for expected loan losses. Provisions for expected loan losses are recorded as separate entries on the liability side of the balance sheets and included in other accounts payable in the analytical accounts of the central bank, commercial banks, and SLAs.

Treasury bills held in the portfolio of the BoA and commercial banks are recorded at market value. For commercial banks, investment securities other than treasury bills are recorded at their acquisition price and are not revalued until redemption. Long-term securities available for trading are also recorded at their acquisition price.

Positions denominated in foreign currencies are revalued at the BoA's official exchange rate. The official exchange rate is the mid-point between the buying and selling market exchange 
rates of six commercial banks that account for most of the interbank foreign exchange transactions. Positions with the IMF are revalued monthly using the end-of-period official BoA exchange rate of the Albanian lek (ALL) to the SDR. Gold is revalued on a monthly basis using the end-of-period closing price for gold on the London Bullion Metal Auction and the official U.S. dollar/ALL exchange rate.

As recommended in the MFSM, holding gains and losses arising from changes in market values (or fair values) of financial assets and liabilities and from changes in the exchange rates are recorded in the revaluation account.

The MFSM recommends that data be compiled on stocks and on each of the three flows components: transactions, revaluations, and other changes in the volume of assets. The BoA does not yet compile data on flows.

Recommendation: Revalue long-term securities for investment and available for trading held by the banking sector using estimated fair value.

\subsubsection{Recording is done on an accrual basis}

In accordance with the accrual accounting principles recommended in the MFSM, interest accrued but not paid on financial instruments should be incorporated into the outstanding amount of the financial asset or liability, rather than being treated as part of other accounts receivable/payable.

The accounts of the BoA and those of the commercial banks are recorded on an accrual basis. For the financial instruments of the BoA and commercial banks, accrued interest receivable and payable are classified under the appropriate sector and instrument category. SLA accounts are reported on a cash basis, with the exception of loans recorded on an accrual basis.

The MFSM also recommends that interest arrears be included with the underlying instruments. The current practice of the BoA is consistent with the MFSM.

Financial transactions are recorded at the time they occur. Liability/asset positions between the BoA and commercial banks are checked for consistency, and any differences are investigated and documented.

Recommendation: Adopt accrual accounting for SLAs so as to apply fully the MFSM guidelines on accrual accounting.

\subsubsection{Grossing/netting procedures are broadly consistent with internationally accepted standards, guidelines, or good practices}

In accordance with the MFSM, the accounts of the central bank, commercial banks, and the SLAs are collected and compiled on a gross basis. Also, claims on particular transactors are 
not netted against liabilities to those transactors. Provisions against loans are shown on a gross basis on the liability side, and loans are included in domestic credit on a gross basis on the asset side.

The broad money survey shows underlying gross data for net foreign assets and net claims on central government.

In the broad money survey, claims and liabilities between depository corporations are appropriately canceled out, while preserving the presentation of data on claims on or liabilities to other domestic sectors and nonresidents.

\section{Accuracy and reliability}

\subsection{Source data}

\subsubsection{Source data are obtained from comprehensive data collection programs that take into account country-specific conditions}

A comprehensive and up-to-date financial sector institutional units register, including depository corporations and other financial intermediaries, is available from the Supervision Department. The source data for compiling the central bank survey are the balance sheet data prepared by the BoA's APD on a monthly basis. These balance sheet data are generated by an electronic general ledger system based on complete accounting records. The source data for commercial banks are their monthly balance sheets (assets and liabilities and other annex tables) reported to the BoA. The source data for the SLAs are their quarterly individual balance sheets transmitted by the two unions of the SLAs to the BoA.

The source data, generated from commercial banks and the SLAs accounting records in the form designed by the BoA, are transmitted in hard copy and floppy disk to the OAR where their accuracy is checked. When problems are detected, the OAR contacts the banks and the SLAs to correct the errors. Data entry in the SARS database is manual.

Commercial banks use an accounting manual prepared by Ernst and Young, which has been adopted in detail for reporting purposes to the BoA. The reporting system is unified in the sense that the report forms use consistent concepts and definitions and serve both statistical and supervisory purposes. The SLAs do not have an accounting manual. The Law No. 8782 of May 2001 on the creation of the SLAs and their unions indicates that the accounting framework of these institutions should be based on the general accounting law for Albanian companies. However, the BoA's Regulation No. 44 of June 2005 states that the SLAs' reports to the BoA should fulfill the needs of the SD and Supervision Department and, thus, follow the accounting principles and the charts of accounts of banks. The source data for banks and the SLAs contain sufficient detail for monetary statistics requirements as regards sectorization and instrument categories. 
In cases where monetary statistics cannot rely exclusively on balance sheet data, then supplementary data, such as information on maturity of deposits, is used. The information enables monetary statistics compilers to subtract from the total amount of deposits those deposits with maturity longer than two years (financial instrument introduced in 2005) that are not included in the national definition of broad money.

Supplementary sources are also used to obtain information on securities held in the portfolio of BoA, including information on accrued interest and valuation gains/losses related to these securities.

The source data are kept under continuous review to ensure that the data collection system remains comprehensive, reflects recent developments, and meets new data demands. The reporting system is reviewed at the end of each year, taking into account changes in reporting requirements. The reviews also take into account ongoing revisions to the charts of accounts and issues raised by data users. The most recent revision of the reporting system took place in December 2005 and refers to the collection of detailed information on maturity of deposits that is used, as mentioned above, to adjust deposits for monetary aggregates purposes.

\section{Recommendation: Develop electronic (online) reporting and fully computerized data entry procedures.}

\subsubsection{Source data reasonably approximate the definitions, scope, classifications, valuation, and time of recording required}

The source data, reported in accordance with the BoA requirements, reasonably approximate the definitions, scope, timing of recording and classification, needed for compiling MFSMbased monetary statistics. One deviation in accounting practice is that securities held to maturity are recorded at their acquisition price.

The BoA provides commercial banks and SLAs with guidance in the form of reporting instructions and ad-hoc consultation in completing the balance sheets. The commercial banks' chart of accounts, introduced in 1999, is kept continuously under review for changes arising from the evolution of financial instruments. The commercial banks' chart of accounts is currently being revised. The OAR and monetary statistics compilers maintain regular contact with reporting units to resolve data issues that have implications for the accuracy of the classification of accounting data for use in monetary statistics.

Compilers are aware of differences in valuation practices of securities and recording basis of financial instruments other than loans of SLAs, as well as of differences between balance sheets and supplementary data sources.

Information obtained from on-site supervision of commercial banks and SLAs is used to validate or confirm the accuracy of the reported data as regards definition, scope, classification, valuation, and time of recording of accounts. 


\subsubsection{Source data are timely}

The APD produces monthly balance sheet data for the BoA. It makes them available to the SD no later than 10 days after the end of the reference month, with the exception of December, for which final data are available two-three months later (when the outcome of the annual external audit of the BoA becomes available). Commercial banks transmit their monthly balance sheet data to the OAR in both hard copy and on floppy disk by the $20^{\text {th }}$ day after the month-end. The unions of the SLAs submit the individual balance sheets of their members also to the OAR. The reporting of the SLAs is on a quarterly basis by the $50^{\text {th }}$ day after the quarter-end.

While most commercial banks respect the reporting deadline, a few banks may at times be delayed, which has an adverse impact on the timeliness of monetary statistics.

\subsection{Assessment of source data}

3.2.1 Source data-including censuses, sample surveys and administrative records—are routinely assessed, e.g., for coverage, sample error, response error, and nonsampling error; the results of the assessments are monitored and made available to guide statistical processes

The BoA monetary data compilers, in collaboration with other BoA units involved in source data collection such as the OAR, review the reporting system for its adequacy in providing reliable and timely source data. Also, through the SARS database, the automatic control of the consistency of individual reports is implemented. The documentation/outcome of this control is also made available to the Supervision Department. The compilation of the central bank data is monitored on a quarterly basis by the BoA's Internal Audit Department.

In addition, source data are reviewed against those of previous periods to identify out-oftrend items. The identified data inconsistencies are investigated with the reporting units.

While commercial banks usually respect the deadline for reporting their balance sheets to the BoA, they frequently make errors in their reporting. Consequently, it takes several days for the OAR to check the returns, contact the banks with errors in their reporting, and correct the errors. Generally, the OMFS staff receives the checked and corrected balance sheet data in about 30-35 days after the month-end, which also contributes to the timeliness of about 40 days for the monetary statistics. As Albania aims to subscribe to the IMF's SDDS and, thus, to reduce the time lag of monetary statistics to one month, procedures are needed to improve the accuracy of data reporting by banks.

Recommendation: Implement measures to minimize errors in commercial banks' reporting and to speed up processes in addressing these errors. 


\subsection{Statistical techniques}

\subsubsection{Data compilation employs sound statistical techniques to deal with data sources}

The compilation of the other depository corporations survey does not use particular statistical techniques because source data are collected from the entire targeted population of ODCs.

The current procedure is to delay the compilation of monetary statistics until such time as all commercial banks' reports are received by the BoA. This practice affects the timeliness of monetary statistics.

Recommendation: When delayed reporting by commercial banks occurs, carry forward the balance sheet for the previous month of the late reporting bank and make users aware of this technique. The data should be denoted as provisional.

\subsubsection{Other statistical procedures (e.g., data adjustments and transformations, and} statistical analysis) employ sound statistical techniques

The conversion of foreign-currency accounts into domestic currency equivalents is checked in the process of the BoA's verification of compliance by depository corporations with accounting and reporting rules.

Monetary data are not seasonally adjusted.

\subsection{Assessment and validation of intermediate data and statistical outputs}

\subsubsection{Intermediate results are validated against other information where applicable}

The accuracy and reliability of the reported source data for the BoA and commercial banks are checked against other sources or information; for instance, data on government securities holdings and data for the government deposits are checked against the records of the Monetary Operation Department.

\subsubsection{Statistical discrepancies in intermediate data are assessed and investigated}

The BoA monetary data compilers identify statistical discrepancies (e.g., discrepancies in interbank [including central bank] positions) and, in collaboration with the APD and Supervision Department, investigate their causes.

\subsubsection{Statistical discrepancies and other potential indicators of problems in statistical outputs are investigated}

Procedures are in place to investigate large and unexplained movements in monetary and credit aggregates to detect possible classification and sectorization errors. Usually, this is done by contacting directly the reporting units and asking for explanations. 


\subsection{Revision studies}

\subsubsection{Studies and analyses of revisions are carried out routinely and used internally to inform statistical processes (see also 4.3.3)}

The BoA studies and analyzes revisions as part of its data quality control process. The OAR prepares a monthly document containing the errors found in the reporting systems by commercial banks and the SLAs. This document is made available to the Supervision Department, which takes it into account during on-site supervision. For errors found, commercial banks and the SLAs are required to revise past periods to incorporate changes in monetary statistics series. The SD regularly maintains relevant documentation on analyses of revisions.

\section{Serviceability}

\subsection{Periodicity and timeliness}

\subsubsection{Periodicity follows dissemination standards}

The periodicity for both the central bank and other depository corporations data is monthly, thus meeting the periodicity recommendation of the GDDS and requirement of the SDDS.

\subsubsection{Timeliness follows dissemination standards}

The broad money survey is disseminated about 40 calendar days after the end of the reference period. This timeliness is in compliance with the GDDS recommendation (twothree months) but does not meet the timeliness requirement of the SDDS (one month). Data on the analytical accounts of the central bank are disseminated within two weeks after the end of the reference month, which is in compliance with the SDDS requirement. Some selected (daily) indicators for the central bank are available to internal users only.

\subsection{Consistency}

\subsubsection{Statistics are consistent within the dataset}

The BoA's monetary statistics are internally consistent. No significant discrepancies exist between the central bank's and commercial banks' data on interbank positions as recorded in monetary statistics, because the check for consistency is one of the control criteria used by the OAR before monetary statistics are compiled.

A reconciliation of stock and flow data is not available, because the BoA does not yet compile flow data for monetary statistics. Also, the BoA does not yet compile flow of funds accounts. 


\subsubsection{Statistics are consistent or reconcilable over a reasonable period of time}

Monetary statistics series in accordance with the MFSM's methodology are available since December 2002. Given that constructing monetary series based on the new methodology for earlier periods is not possible, the BoA is creating detailed "bridge tables," which should enable the continuity of the indicators before and after changes in methodology. The time series, stored in the "Time Series" database accessible through the BoA's website, will provide users of monetary data with a possibility to analyze trends and patterns of changes in various aggregates.

\subsubsection{Statistics are consistent or reconcilable with those obtained through other data sources and/or statistical frameworks}

The monetary statistics compilers communicate with the balance of payments compilers and the MoF to check the consistency of the monetary statistics with flow data from the balance of payments and government finance statistics. The net foreign assets in monetary statistics are consistent with foreign assets and foreign liabilities of the banking sector in the corresponding measure of the balance of payments. Central government securities and deposits with the BoA in monetary statistics are reconciled with the MoF records. The definition of general government in the monetary statistics is the same as the definition for general government in GFS. As such, monetary data are broadly consistent with the GFS financing data and data on government financial assets and liabilities held by other sectors.

\subsection{Revision policy and practice}

\subsubsection{Revisions follow a regular and transparent schedule}

Monetary data disseminated on the BoA's website or in its publications may be revised any time a need for their revision occurs. Revisions of monetary data usually occur when changes arise in the balance sheets of commercial banks, owing to auditing outcomes or on-site inspection of the BoA. The BoA's revision policy is posted on its website.

\subsubsection{Preliminary and/or revised data are clearly identified}

The revised data are identified on the BoA's website.

\subsubsection{Studies and analyses of revisions are made public (see also 3.5.1)}

Studies and analysis of revisions are made available to the public. 


\section{Accessibility}

\subsection{Data accessibility}

\subsubsection{Statistics are presented in a way that facilitates proper interpretation and meaningful} comparisons (layout and clarity of text, tables, and charts)

Generally, the statistics published by the BoA are presented in a clear way and in different levels of aggregation to respond to different needs of users. The BoA's website provides users with opportunities for viewing the data, metadata, explanatory notes on the data, calendar for the dissemination of data, and other information. The website features userfriendly tables with key indicators of monetary statistics. Statistical bulletins, such as the Economic Bulletin and Monetary Policy Report, also include comments on the development of the current periods, accompanied by charts and tables to facilitate the analysis.

\subsubsection{Dissemination media and format are adequate}

Statistics produced by the BoA are disclosed through its website and publications. These are accessible without distinction to any interested user. Monetary statistics posted on the BoA's website have different levels of detail to satisfy the needs of different groups of users.

\subsubsection{Statistics are released on a preannounced schedule}

An advance release calendar for monetary statistics is posted on the BoA's website. Release of monetary statistics follows the dates announced.

\subsubsection{Statistics are made available to all users at the same time}

Data are released simultaneously to all users of monetary statistics when information is disseminated on the BoA's website.

\subsubsection{Statistics not routinely disseminated are made available upon request}

Statistics not regularly published are made available to interested users upon request.

\subsection{Metadata accessibility}

5.2.1 Documentation on concepts, scope, classifications, basis of recording, data sources, and statistical techniques is available, and differences from internationally accepted standards, guidelines, or good practices are annotated

A comprehensive document on sources and methods for monetary statistics compilation, "Methodology of Monetary and Financial Statistics, Bank of Albania, June 2003," is posted on the BoA's website. Moreover, the database "Time Series" contains not only monetary data but also metadata. 
The GDDS metadata for the financial sector are posted on the IMF's Dissemination Standards Bulletin Board website and regularly reviewed and updated.

\subsubsection{Levels of detail are adapted to the needs of the intended audience}

The metadata stored in the database "Time Series" provide various levels of detail for different needs of users.

\subsection{Assistance to users}

\subsubsection{Contact points for each subject field are publicized}

Contact information is posted on the BoA's website for users to send comments, queries, and requests concerning any category of monetary data published by the BoA. Users frequently request assistance in the form of clarification and explanation of data through email, telephone, or mail, and the assistance is promptly provided. Although no monitoring of assistance to users has been carried out through comprehensive user surveys, the BoA reviews closely comments, queries, and requests from external data users as well as from the internal users to obtain feedback.

\subsubsection{Catalogs of publications, documents, and other services, including information on any charges, are widely available}

The list of BoA's publications is available on its website. The BoA's Sector of Publications maintains and updates a list of regular recipients of its publications, and publications are sent to them regularly. The BoA publications are also provided to other users upon request free of charge. 


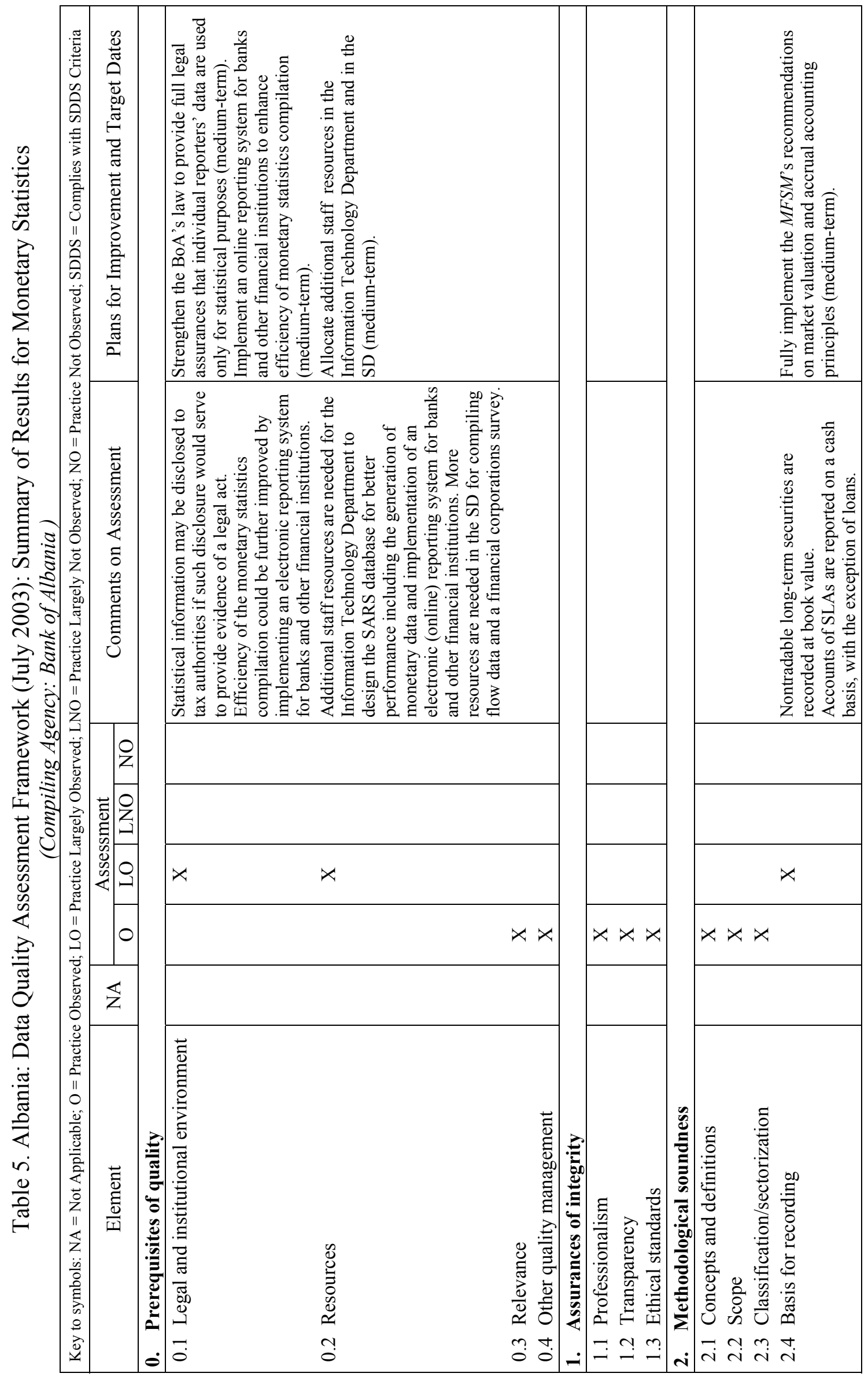




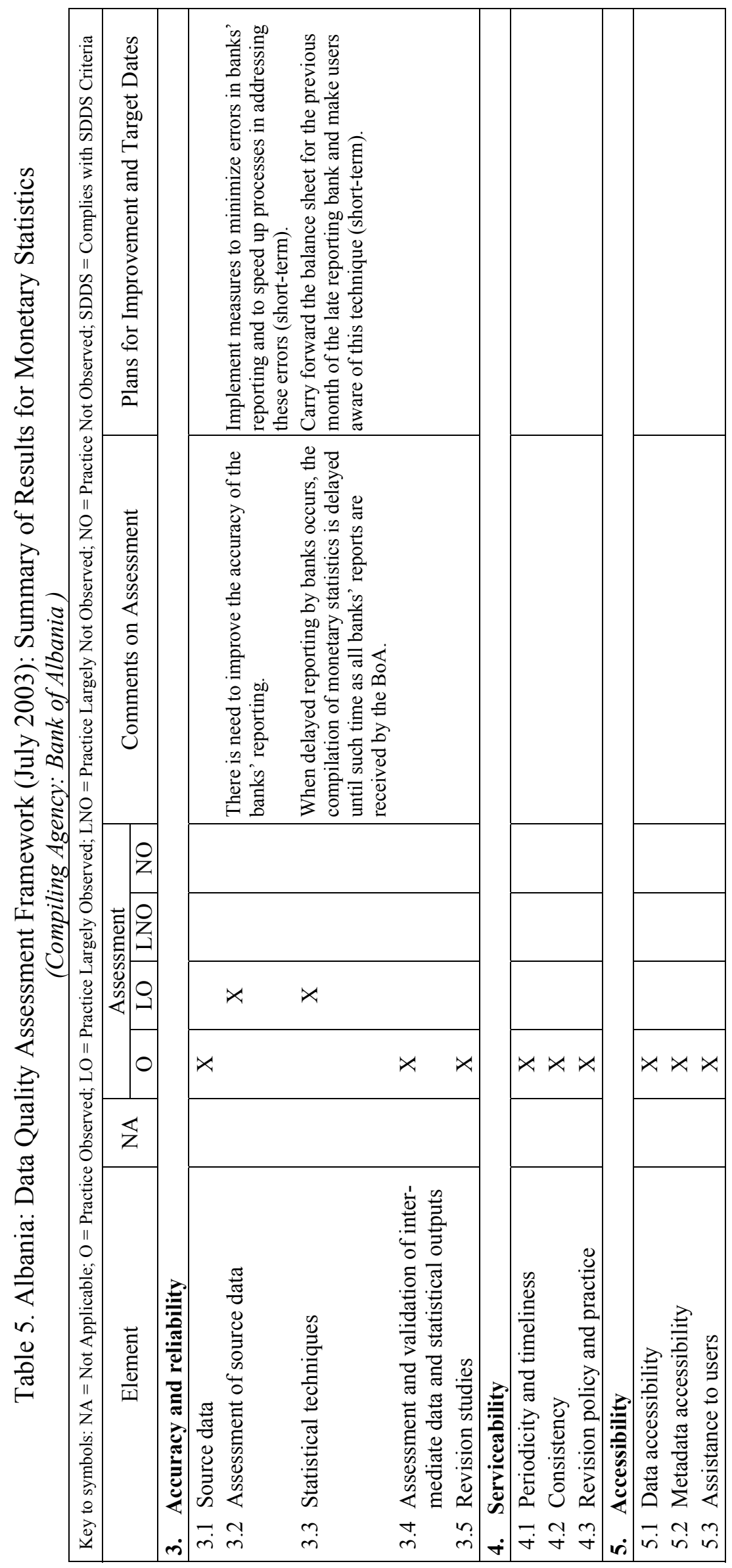




\section{Balance of Payments Statistics}

\section{Prerequisites of quality}

\section{$0.1 \quad$ Legal and institutional environment}

\subsubsection{The responsibility for collecting, processing, and disseminating the statistics is clearly specified}

The Bank of Albania (BoA) has statutory responsibility for producing balance of payments statistics. Article 27 of the statute On the Bank of Albania (Law, enacted in 1997) authorizes the BoA to "compile the balance of payments of the State of Albania as well as coordinate and direct the statistical system of this balance of payments." Article 27 also states that "banks, institutions, juridical and physical persons shall be required to deliver statistical data in accordance with reporting system approved by the Bank of Albania, employing appraisal standards, and indicating the designation and classification presented herewith."

The Balance of Payments and Surveys Section (BoPS), within the BoA's Statistics Department, has responsibility for compiling the balance of payments. The Statistics Department was established in November 2005, following a management decision to upgrade the capabilities of the BoA's statistical functions. ${ }^{32}$

\subsubsection{Data sharing and coordination among data-producing agencies are adequate}

Several government agencies provide data to the BoPS as input for balance of payments compilation in a timely and reasonably complete manner. The General Directorate of Customs (Customs) submits foreign trade data. The Ministry of Finance (MoF) provides the data on official external debt and government guaranteed debt and official foreign financing (formerly the responsibility of the Ministry of Economy, recently moved to MoF). The MoF also provides data on government expenditures abroad. The Ministry of Economy provides data on the privatization of the state-owned companies purchased by foreign direct investors. In addition, BoPS receives reports from the National Petroleum Agency on direct investment performed as drilling activity. The Ministry of Interior provides the benchmark of the arrivals and departures of travelers used as an input for tourism receipts and expenditures estimates.

Because the national statistics agency (INSTAT) has statutory authority to conduct surveys and because of INSTAT's experience with surveys, the BoA has provided INSTAT with the financial support needed to conduct all surveys to date for balance of payments purposes, such as foreign direct investment surveys, household surveys of remittances from abroad, and travel expenditure surveys. However, some of these surveys have suffered from being

\footnotetext{
${ }^{32}$ BoA Supervisory Council Resolution No. 79 of October 31, 2005.
} 
conducted long after the target time period, from incomplete geographical coverage, or from requesting only stock and not transactions data.

Recommendation: BoPS should strive to improve further coordination with INSTAT with respect to survey design, execution, and follow-up to nonresponse.

\subsubsection{Individual reporters' data are to be kept confidential and used for statistical purposes only}

The BoA ensures the confidentiality of individual data through the Law (Article 58), the "Code of Ethics of the Bank of Albania," and the "Regulation for Transparency and Confidentiality in the Bank of Albania" (all available on the BoA website, www.bankofalbania.org). In combination these forbid the BoA officials or staff from disclosing or transferring data reported by individual firms or persons to virtually all third parties for any purpose. However, as an exception, Article 58 also states, "Such persons [viz., officials or employees of the BoA] may disclose nonpublic material information to tax authorities of the Republic of Albania." While no BoA report ever disclosed individual reporter data to tax authorities, the existence of such a provision possibly deters reporting.

BoA regulations also address the "prevention of indirect disclosure of confidential information," for example, in the case when a bank or group of banks has a dominant position in a given instrument that would disclose individual reporter's information even when the data are aggregated. Such regulation also applies to individual nonbank firms and persons with regard to transactions. Besides protection by law and regulation, procedures are observed that prevent the dissemination of individual information by guaranteeing the security of databases and by limiting the number of personnel that have access to data of individual reporters.

Recommendation: The statute On the Bank of Albania should be revised and clarified to ensure that data collected for statistical purposes may not be disclosed to tax authorities.

\subsubsection{Statistical reporting is ensured through legal mandate and/or measures to encourage response}

While endowed with the statutory mandate to collect data for compiling and disseminating the balance of payments, the BoA has enforcement authority only over banks. Nonbank reporters of data are not subject to penalties or other enforcement sanctions by the BoA. Similarly, the BoA does not have authority to conduct surveys among nonbank entities engaging in international transactions. The response rate to the first survey of foreign direct investment conducted by INSTAT on behalf of the BoA was less than desired.

The BoPS has attempted to compensate for this lack of enforcement authority by contacting companies directly and informing them about the potential uses to them of balance of payments statistics, by emphasizing how the confidentiality of their data is ensured, and by explaining the importance of these statistics in national policymaking. In addition, the BoPS 
provided these companies with several published analyses of balance of payments and external economic developments, to generate interest among potential respondents. The BoPS attempted to conduct the surveys by using its own staff but failed to persuade more than a small percentage of firms to complete report forms accurately or to return the forms. Hence, the BoA relies upon INSTAT to conduct surveys for balance of payments purposes.

Recommendation: The statute On the Bank of Albania should be amended to give the BoA authority to survey firms, households, or individuals about transactions they may be conducting with nonresidents. The BoA should be given statutory authority to inspect - with absolute protection against disclosure of individual records to third parties - the financial accounts of firms that may be transacting with nonresidents, as well as authority to impose effective sanctions, including fines, on nonreporters. Such amendments should put the BoA on a par with other countries with advanced statistical systems in terms of the statutory powers they can employ in compiling the balance of payments.

\section{$0.2 \quad$ Resources}

\subsubsection{Staff, facilities, computing resources, and financing are commensurate with statistical programs}

The number and qualifications of the BoA staff collecting, compiling, and analyzing balance of payments statistics are inadequate for current responsibilities, even under existing statutory authority. While computing capacity for compilation is currently adequate, and all staff are equipped with computers, there is no unified compilation database. Although facilities for communications among specialists are sufficient, the physical working conditions are acknowledged to be inadequate regarding office space. The funding for balance of payments statistics is sufficient only for the limited current activities.

Within the BoPS, five specialists work in the balance of payments compilation and analysis unit, and three survey specialists work in the surveys unit. All of them have college degrees in finance or economics and statistics. Also two of them have master's degrees in economics. In addition to obtaining on-the-job training, three of them have participated in the IMF's balance of payments statistics course conducted in Washington or at the Joint Vienna Institute. Staff turnover is manageable, in part due to salaries for the specialists that are at a higher level than those in public administration generally.

The workload appears to be less than required for complete compilation of the balance of payments because of data unavailability. Prime examples are the lack of a quarterly household survey on remittances, failure of direct investment enterprises to report, and the absence of a periodic survey to check the estimate of trade credit derived from bank reports. As the economy grows and Albania's credit rating continues to strengthen, the Balance of Payments Manual, fifth edition (BPM5) classification will soon require collection of data on international portfolio investment by nonbanks. Staff capacity is not available to undertake the compilation of other external sector statistics, such as the international investment position (IIP) and external debt according to the External Debt Statistics: Guide for 
Compilers and Users (2003). These additional statistical compilations are included in the BoA's short-term plans for improvement. Moreover, BoPS staff have responsibilities in addition to compilation (e.g., drafting speeches for the BoA officials and writing analyses of external transactions, the composition of which is evolving rapidly).

Independent spreadsheets unlinked by formulae are used for compilation. Integrated, database-driven software that includes automatic cross-checks is needed to replace manual transfer of spreadsheet output, which is error-prone. A fully electronic system for data processing and the elimination of manual data entry would speed compilation and minimize the risk of errors. A database-driven compilation system could be written either by programmers in the BoA or purchased externally. Currently, the Information Technology Department has systems in place to protect computers and files against corruption and to maintain operations in the event of an emergency. However, data are backed up only on-site, rather than outside Tirana. Compiling balance of payments statistics under the full, effective statutory authority recommended above would overwhelm the capabilities of the current BoPS personnel and the software they employ.

Crowding hinders some staff from performing effectively their respective functions. Improved physical arrangements would enhance productivity and facilitate more complete data collection, more accurate classification by compilers, and more insightful analysis.

A higher level of financial support is needed to employ additional compilers, to introduce a database-driven compilation system incorporating linked files as well as an automatic secured backup, and to upgrade physical accommodations. To date, most surveys conducted with the assistance of INSTAT have not produced results usable for balance of payments compilation. The BoPS requires staff with more experience and expertise in survey design, so that cooperation with INSTAT may be productive; and funding should be increased for more frequent surveys incorporating larger numbers of respondents.

\section{Recommendation: Commensurate with successful, complete execution of current and announced compilation responsibilities, staff size, information technology support, and physical plants should all be expanded to facilitate the data collection required by the BPM5 and to derive optimal benefits from the information gathered. Realizing these improvements will require additional financial support from the BoA, including additional funding for surveys conducted with the assistance of INSTAT.}

\subsubsection{Measures to ensure efficient use of resources are implemented}

The Statistics Department promotes the efficient use of existing resources through monthly, semiannual, and annual staff performance reviews. Staff training in relevant areas to enhance their technical knowledge and skills, periodic reviews of work processes in the framework of the GDDS project, and the design of cost effective reporting requirements in relation to their purpose all enhance efficient resource use. By maintaining regular contacts with outside experts, such as from the IMF and other central banks, the implementation of balance of payments statistical methodology is reviewed and enhanced. There are clear budgeting 
procedures for allocating resources. Within the framework of the annual budget program of the BoA, the Department of Statistics reviews its resources and assesses its needs for additional funding in future years.

\subsection{Relevance}

\subsubsection{The relevance and practical utility of existing statistics in meeting users' needs are monitored}

Currently the Albanian public seems to perceive the relevance of balance of payments statistics as limited. The Statistics Department in the BoA actively seeks to meet the needs of internal users and the European Department of the IMF. In absence of active interest from the public, the BoPS strives to comply with international standards for compiling and disseminating data. In addition, the Statistics Department ensures that balance of payments statistics satisfy the concerns of management and other relevant departments within the BoA.

The Department organizes annual seminars with users (mainly the media, banks, and academicians) not only to obtain feedback from them but also to provide users with a better understanding of the data disseminated. Ad hoc meetings with the banks are arranged at any time these essential reporters raise questions about classifying specific transactions or request other clarifications. The BoA publications and its website (www.bankofalbania.org) provide contact information to data users for sending comments, queries, and requests, which are usually addressed promptly.

The staff of the Statistics Department participate in meetings and round tables organized by international institutions to exchange experiences with other countries about the characteristics of the statistics they compile and new requirements that arise. Also the Statistics Department staff participate in meetings with other Albanian data-producing and user agencies that clarify the specific needs for statistics in their respective programs.

\subsection{Other quality management}

\subsubsection{Processes are in place to focus on quality}

The BoA management gives importance to statistics. Being sensitive to data quality issues, the management initiates improved data flows between the BoA and other institutions by emphasizing this issue at interagency meetings. The establishment of the Statistics Department in November 2005 highlights the increased importance of statistics at the BoA. The BoA management has encouraged initiatives for analytical research and for use of appropriate methodologies.

The BoA has requested and received several IMF technical assistance missions in order to improve balance of payments compilation methodology and to assist with the adoption of international standards as the framework for quality improvement. Extensive plans for improvement are listed with Albania's GDDS metadata, posted on IMF's DSBB. 


\subsubsection{Processes are in place to monitor the quality of the statistical program}

The Statistics Department has internal processes to identify and resolve issues at various stages in the collection, compilation, and dissemination of balance of payments statistics. When errors are discovered, compilers also revise the statistics for earlier quarters within the current calendar year. There is frequent contact between the less experienced members of the compilation staff and others who have attended more external instruction courses. Contacts with experts from international agencies and balance of payments compilation staff from other countries necessarily are less frequent.

\subsubsection{Processes are in place to deal with quality considerations in planning the statistical program}

Comments and requests from data users provide important feedback for monitoring the quality of balance of payments statistics. Frequent contacts with internal users, such as the Research Department and Monetary Policy Department, as well as outsiders interested in using balance of payments data for their own purposes, are essential inputs for planning quality improvements. The BoA management and staff recognize the trade-offs among the dimensions of data quality. Increased attention has been given to improving the timeliness of dissemination of balance of payments data.

\section{Assurances of integrity}

\subsection{Professionalism}

\subsubsection{Statistics are produced on an impartial basis}

The independence of the BoA in its function of compiling the balance of payments is established in the general provisions of Article 1 and in Article 27 of the Law. The BoA is governed by the Supervisory Council, consisting of the Governor, two Vice-Governors, and six other members, who may be academicians or professional or business persons. The Governor of the BoA is appointed for a seven-year term by the President of the Republic on the basis of the recommendation of the Prime Minister (Article 44). The Governor can only be removed by Parliament. The Governor and Board members are not permitted to belong to a political party.

The Code of Ethics of the BoA includes the "Principle of Integrity," "Principle of Objectivity," and "Principle of Independence" of the staff from the "activities of the political parties."

Professional competence plays a key role in recruitment and promotion policies.

The BoA's Human Resources Department establishes requirements for potential recruits, including educational background and written professional and English language tests. At a later stage, relevant department heads interview candidates before finalizing recruitment decisions. Most of the balance of payments staff have professional qualifications in relevant 
fields such as economics, banking, and accounting, and some of them have postgraduate degrees. Most of the balance of payments specialists also have received training from the IMF, as well as attended seminars organized by the BoA. Continuous collaboration with statisticians of the IMF has made possible the availability of the most recent literature regarding contemporary statistical standards.

\subsubsection{Choices of sources and statistical techniques as well as decisions about dissemination are informed solely by statistical considerations}

The balance of payments data are derived from sources selected solely on the basis of statistical considerations. The data sources are similar to those used by other countries in the region. The dissemination of quarterly balance of payments data is made according to a regular schedule decided by the BoA and preannounced prior to the next calendar year through the BoA's Department of European Integration and Public Relations. The modes of dissemination are determined by the Statistics Department and are based solely on statistical considerations.

\subsubsection{The appropriate statistical entity is entitled to comment on erroneous interpretation and misuse of statistics}

The BoA continuously monitors the use of its publications in the media. The Statistics Department participates in seminars and debates on statistics issues. In response to public articles, if misinterpretations or other problems occur, the Department has prepared explanatory notes on its activities. It also seeks to clarify issues and prepares explanations to correct misinterpretations. If needed, the BoPS contacts newspaper reporters or other users to correct erroneous interpretations.

\subsection{Transparency}

\subsubsection{The terms and conditions under which statistics are collected, processed, and disseminated are available to the public}

The laws and regulations under which statistics are collected, processed, and disseminated by the BoA are available to the public. The statutes On the Bank of Albania and On Banks in the Republic of Albania and the regulations issued by the central bank are available on the BoA website. The BoA publications always indicate contact telephone and fax numbers, as well as the address of its website, where more information about the BoA, other data series for balance of payments and related statistics, and relevant working papers are disseminated.

The BoPS maintains personal contact with the main data suppliers. Manuals, report forms, and detailed instructions and background on balance of payments data collection systems are available on the BoA website in the Albanian language. 


\subsubsection{Internal governmental access to statistics prior to their release is publicly identified}

There is no internal government access to balance of payments data prior to their publication.

\subsubsection{Products of statistical agencies/units are clearly identified as such}

The publications of balance of payments data are clearly identified as BoA's products with its name and logo. The data are specifically attributed to the BoPS. All BoPS statistical publications contain a contact address and phone number.

\subsubsection{Advance notice is given of major changes in methodology, source data, and statistical techniques}

In recent years no major changes have occurred in balance of payments methodology, source data, or statistical techniques. However, detailed changes in sources and compilation techniques have occurred. Notice of detailed changes has not been provided in advance. Instead, the changes are identified and explained in the publications of BoPS when the data are published.

\subsection{Ethical standards}

\subsubsection{Guidelines for staff behavior are in place and are well known to the staff}

"The Code of Ethics" establishes the principles and rules for BoA staff integrity, objectivity, professional competence, professional independence, and maintaining confidentiality of data. New staff are made aware of the ethical standards of the BoA when they join the organization. Staff are reminded periodically of the standards by means of announcements and by periodic assessments of their conduct, including performance reviews.

\section{Methodological soundness}

\subsection{Concepts and definitions}

\subsubsection{The overall structure in terms of concepts and definitions follows internationally} accepted standards, guidelines, or good practices

The framework for balance of payments statistics follows the BPM5. The results are produced according to the IMF's standard presentation. A national presentation is also produced and is used in the BoA's balance of payments publications. The concepts and definitions used conform to those recommended in the BPM5.

Current, capital, and financial accounts of the balance of payments statement are defined according to the guidelines of $B P M 5$, and the current account balance in principle is equal (with sign reversed) to the net capital and financial account balance. The financial account provides for a separate recording of transactions in assets and transactions in liabilities. In 
constructing the balance of payments statement, a double-entry system is applied as a basic principle, and the remaining net residual (after estimation of remittances as a primary residual) is reflected in the errors and omissions item.

Resident institutional units are defined in conformity with the BPM5 and relate to those that have a center of economic interest in the country. For example, companies, including branches with foreign capital, are considered to be residents of Albania if they operate in the territory of Republic of Albania. Foreign direct investment transactions are defined by applying the 10 percent ownership rule. All units of foreign general governments in the territory of Albania (e.g., embassies, military bases, etc.) are not considered residents.

\subsection{Scope}

2.2.1 The scope is broadly consistent with internationally accepted standards, guidelines, or good practices

The scope of data collection by the BoPS in principle is consistent with the BPM5 recommendations.

The BoPS compiles the data on the basis of import and export declaration forms provided by the Customs Office. Transit trade is excluded properly from merchandise trade. An estimate for smuggling and shuttle trade is included in the trade balance.

Data on services and most income items are reported by banks. The information from banks is supplemented by reports submitted by communications and insurance firms. A data model developed by the BoPS provides estimates of compensation of employees and workers' remittances. The MoF supplies information on official grants from abroad.

Currently the banks report the direct investment transactions they are able to identify. In 2004, the BoPS, in cooperation with INSTAT, initiated annual surveys of foreign direct investment. Data have been collected, but the response rate and data accuracy were less than desired. The survey results have not been incorporated in balance of payments compilation. It is planned to introduce the results of the second survey, conducted in December 2005, and incorporate them in the balance of payments. The banks also report their portfolio investment transactions.

\subsection{Classification/sectorization}

\subsubsection{Classification/sectorization systems used are broadly consistent with internationally accepted standards, guidelines, or good practices}

Transactions are classified according to the standard components of the BPM5.

Construction services are identified through the balance of payments reports submitted by the banking system. Generally banks do not have the capability to identify construction services 
supplied by nonresident firms for projects completed in less than a year. The types of construction services that the banks report include (a) services between nonresident parent construction firms and Albanian resident direct investment subsidiaries, and (b) exports of construction services by firms of Albanian origin.

External debt transactions by the government are attributed to the general government sector. Public enterprise debt transactions are attributed to other sectors; loan transactions of the banking sector are classified separately from currency and deposit transactions of this sector. There is currently no separate item for financial derivatives, as these instruments have not been yet introduced in the banking system.

\subsection{Basis for recording}

\subsubsection{Market prices are used to value flows and stocks}

Valuation principles follow the BPM5 methodology:

- Market valuations are used for goods. A Customs Office unit monitors market prices to assess market-equivalent prices for goods to ensure that transactions are reported at arm's length market prices.

- Services are recorded at transaction prices.

- Financial asset and liability transactions are in nominal value.

Exports are valued f.o.b. Imports are collected on a c.i.f. basis and converted to f.o.b. using ratios derived from information contained in customs documents. These ratios are reestimated whenever the Customs office makes the revisions in its forms that yield more detailed or accurate information. The most recent revision was in 2003, when with the introduction of ASYCUDA, detailed data by product category on freight and insurance charges initially became available for large Customs posts. The new estimates for freight are fairly high by international standards, but there may be factors related to road and other conditions in Albania that contribute to relatively high costs. If these costs decline as infrastructure improves and freight volume grows, the next re-estimation, planned in 2006, may indicate lower freight costs.

In 1993, the BoPS began compiling the balance of payments statistics in U.S. dollars. Starting in 2004, the balance of payments is being compiled and published in euros as well. As recommended by the last IMF technical assistance mission, the BoPS is now compiling the monthly balance of payments statement in euros and converting it into U.S. dollars using the average monthly exchange rate, or the average quarterly rate for the few types of transactions reported only quarterly. For commercial banks' deposits, cash, own portfolio investment abroad, and changes in banks' capital due to reinvestment of dividends, transactions estimates are based on changes in stock positions. When this procedure is used, an exchange rate valuation adjustment is incorporated in estimating transactions. 


\subsubsection{Recording is done on an accrual basis}

The majority of individual transactions are recorded on an accrual basis, the exception being some interest income and payments, recorded when due for payment:

- The data source for goods reflects the time of customs declarations, reported monthly to BoPS. The change of the ownership of goods is considered to be the month in which they are cleared by Customs.

- Drawdowns of loans are recorded at the time of actual disbursement.

- The data on services and other remaining items in the balance of payments are largely based on banking system reports, which use the time of payment as their basis.

With monthly reporting by banks, bank interest receipts and payments closely approximate accrual accounting. The mission learned that the MoF has prepared a public debt service schedule. Public debt comprises the bulk of Albania's external debt. Use of the service schedule by the BoPS would permit public debt semiannual or annual interest payments to be recorded on an accrual basis.

Recommendation: The BoPS should obtain the public debt service schedule from MoF and record interest payments on an accrual basis.

\subsubsection{Grossing/netting procedures are broadly consistent with internationally accepted standards, guidelines, or good practices}

In line with the recommendations of $B P M 5$, current and capital account transactions are recorded and published on gross terms, and financial account transactions are recorded on a net basis, separately for the individual asset and liability components

\section{Accuracy and reliability}

\subsection{Source data}

\subsubsection{Source data are obtained from comprehensive data collection programs that take into account country-specific conditions}

With the creation of the Statistics Department in November 2005, the BoA undertook to improve the coverage, detail, and accuracy of balance of payments (and monetary) source data. This effort to improve specific aspects of data quality is constrained by a banking system that is only partially computerized, inhibiting review of significant individual transactions, and by the absence of a publicly recognized tradition that data reported for statistical purposes will be used for statistical purposes only. Attempts to use surveys to estimate directly compensation of employees and workers' remittances have been unsuccessful. Likewise, direct reporting by nonbank firms or individuals of direct or portfolio investment transactions does not exist. The economy has evolved rapidly and continues to do 
so. New types of international transactions place demands upon the BoA to expand the breadth and detail of its data collection efforts.

Data are provided to the BoPS from various sources, including BoA's own account (reserve assets and transactions with banks), government agencies (MoF for public debt and grants from abroad, Ministry of Interior for tourist arrivals and departures, National Petroleum Agency for direct investment drilling activity, and Ministry of Economy for purchases of former state enterprises by foreign direct investors), INSTAT (for survey responses, including direct investment enterprises), the General Directory of Customs (for goods exports and imports), commercial banks, other administrative sources, and private entities, including foreign firms providing mobile telephone services.

Travel receipts and expenditures are estimated from quarterly entry and exit reports covering border points serving in-bound or out-bound travelers. Estimates of average expenditure are applied to numbers of arrivals and departures, as supplied by the Ministry of Interior.

The report form currently used by the BoPS to collect data on insurance services deviates from the BPM5 standard. The last IMF technical assistance mission in balance of payments statistics (February 2006) helped develop a new reporting form for insurance companies that will be applied in data collection and compilation.

MoF staff have indicated that their accounts of general government revenue include less than half of the value of grants reported by donors. Officials felt that the underreporting seemed to originate with grants received directly by regional and local governments. The MoF expressed interest in cooperating with the BoA to improve data on government revenue from grants.

On behalf of the BoPS, INSTAT conducted recently a household survey to collect data on remittances - a significant net credit item in the external accounts. The survey was designed to cover a full calendar year. The survey covered 1,033 households, whose responses were extrapolated using the latest Living Standards Measurement Survey. This survey was carried out a year after the reporting period. Consequently, to report accurately, the respondents had to remember the detail of their receipts over two full years. Additionally, some respondents may have been apprehensive about a potential tax liability. Being unsatisfactory to BoPS staff, the survey results are not applied to balance of payments compilation. The plan is to conduct quarterly household surveys. When quarterly responses are available, the BoPS will decide whether the results are sufficiently accurate and credible to use in compilation.

The current estimates for direct investment are limited to what is obtained from the bank reporting system. Direct investment is not split between debt and equity. In the quarterly data, the whole amount is classified as "other capital." Reinvested earnings of direct investment enterprises are not reported by the banks. The BoPS checks that major transactions are included, such as large privatizations. While surveys of direct investment enterprises have been initiated, the data coverage and accuracy have not met expectations and are not used in compilation. 
The BoPS has concluded its second annual survey (carried out by INSTAT) of direct investment enterprises. The first survey, conducted in 2004 to cover data through 2003 , started with a total initial population of 2,600 companies and found that about 1,000 active and relevant companies could be identified. The survey response was approximately 80 percent, but the overall quality of data was poor, and important information was not provided by a large number of respondents. In the view of BoPS compilers, the missing and inaccurate data were due in part to the complicated survey form with inadequate definition of data requested. A second survey will be used as a base for building up a business register for the enterprises with direct investment. The sample is based on the INSTAT business register of companies operating in Albania. Survey questionnaires will be constructed according to the accounting principles of the companies contacted in order to ensure effectiveness.

The present system for compiling the balance of payments is based on a banking system report and a set of forms and surveys designed to cover most economic entities participating in transactions with nonresidents. The banking system report is based on the foreign exchange record, in which transactions settled through the banking system are recorded. The report form used by banks permits them to classify external transactions in accordance with the standard components of the BPM5. Banks aggregate each class of transaction monthly and report totals for each classification to the BoPS.

The data for portfolio investment by banks, bank lending and borrowing, and reserves are all from the bank reporting system or from the BoA's transactions.

The BoPS administers the banking system reports and controls them for the accuracy of statistics and new issues appearing in the recording process. The source data are kept under continuous review to ensure that the data collection system remains comprehensive, reflects recent developments, and meets new data demands. The reporting system is reviewed at the end of each year to identify required changes in reporting requirements, while supplementary data are required from banks and other reporters in their monthly submissions prior to the annual evaluation of the reporting system. The reviews take into account ongoing revisions that may be required to the classification instructions, as well as issues raised by data users.

The BoPS organizes annual and ad hoc meetings, as required, with the banking system and firms engaged in transactions with nonresidents (e.g., insurance, telecommunications, travel and tourism, etc.) to identify new developments that need to be taken into account in the balance of payments compilation system.

Recommendation: The BoPS should improve the coverage, detail, and accuracy of source data to produce a balance of payments statement that better serves policymakers and the public. The more important aspects to improve include the following: If complete coverage of trade transactions by ASYCUDA does not permit direct summation of freight and insurance charges, reestimate the c.i.f. to f.o.b. adjustment of imports every other year; likewise periodically reestimate the smuggling adjustment, in part through comparative surveys in domestic markets of the prices and places of origin of goods known to have cleared customs with other similar imports that apparently have not; survey average expenditures per 
traveler biannually; cooperate with the MoF to improve coverage of grants from abroad to regional and local governments; survey households quarterly for remittance receipts to check the remittances estimate; require direct quarterly reporting by the larger direct investment enterprises; survey real estate investment for financing outside the banking system, that is, for direct investment by Albanian citizens or others resident abroad-direct investment that would otherwise be unreported; survey brokers and banks for portfolio investment by nonbanks; and survey larger international trading firms for trade credit. As indicated by BoPS to be its intention, the corrected reporting form for insurance companies should be introduced at the earliest possible date.

3.1.2 Source data reasonably approximate the definitions, scope, classifications, valuation, and time of recording required

For most items, the source data requested by the BoPS for reporting by banks, government agencies, or other public and private enterprises, reasonably approximate the definitions, scope, classification, and time of recording required by BPM5. Report and survey forms are field-tested before use. The BoPS provides banks, government agencies, and enterprises with guidance via detailed reporting instructions and adhoc assistance in completing the report forms.

\subsubsection{Source data are timely}

Source data support the timely compilation of balance of payments. Customs data are available in an electronic version within one month of the end of the reference month. Banking system reports and other reports from official and private agencies are usually provided either in hard copy or in an electronic version 20 days after the end of the reference month. Data on travel services are provided through surveys conducted on a quarterly basis, and the results are provided with sufficient time for balance of payments compilation.

\subsection{Assessment of source data}

3.2.1 Source data-including censuses, sample surveys and administrative records-are routinely assessed, e.g., for coverage, sample error, response error, and nonsampling error; the results of the assessments are monitored and made available to guide statistical processes

The BoPS regularly reviews banking system data-entry procedures to avoid miscoding and misreporting. Data sources are checked with available related indicators. Data are checked for temporal consistency. The inclusion and accuracy of high-value transactions are confirmed.

As a consequence of the missing data and poor data quality received in the first survey of foreign direct investment, the survey form was revised to reflect the accounting codes that company owners and financial managers are familiar with. Source data have been analyzed in the context of refining and targeting the sample of companies surveyed. 
The survey of households used to estimate remittances will be conducted quarterly, rather than annually, and shortly after the end of each quarter to improve reporting accuracy. Based on surveys of Customs documents by BoPS, the freight and insurance adjustments of imports from c.i.f. to f.o.b. have been revised, and revision of the smuggling adjustment is in process.

\subsection{Statistical techniques}

\subsubsection{Data compilation employs sound statistical techniques to deal with data sources}

While the BoPS compilation procedures are generally sound, additional IT support would enhance accuracy and timeliness.

For the compilation of balance of payments data, MS Excel spreadsheet applications are used. Separate sections of the balance of payments fall under the responsibility of different individual staff. Since the computers and spreadsheets are not linked, no complete database exists showing all the balance of payments data. This system is prone to mistakes when reentering intermediate data and cumbersome when making revisions. An automated database system that utilized electronic reporting by banks would avoid the current practices of manually entering data and combining separate spreadsheets. The support of programmers and other IT technicians is required to introduce such a system.

Recommendation: IT support should be provided to the BoPS to set up an automated database system that will preclude the need for manual data entry and could accommodate fully electronic reporting by banks, including an ITRS if this option is selected.

\subsubsection{Other statistical procedures (e.g., data adjustments and transformations, and statistical analysis) employ sound statistical techniques}

With the use of periodic reviews and re-estimations of the various parameters employed, the BoPS adjustment procedures are sound.

Several adjustments are made to data received from Customs, relating to temporary imports and exports, imports to bonded warehouses and for duty-free sales, and diplomatic and personal goods.

A fixed coefficient of 10 percent is added to imports reported by Customs as an estimate of smuggling and under-invoicing of imports. A survey was carried out to estimate the extent of smuggling (including shuttle trade). The BoPS is working on the recommendation of the most recent IMF technical assistance mission for the further adjustment on applying the smuggling rate to each product category separately, to account for the effect that a change in the composition of imports would have on smuggling. Separate data on trade with Albania are not available from any partner country, because of the small volume of transactions.

Freight and insurance charged on goods imports are estimated by the BoPS, based on surveys of imports at Customs entry points. Currently, imports and exports of goods for repair are not 
identified separately by the Customs Office and so are included with other goods. The value of goods for repair is believed to be small.

A data model is employed to estimate the primary residual - unidentified inflows of foreign exchange, or "remittances," as measured by imports of goods and services not financed by exports or payments through the banking system. Of these total apparent unidentified inflows of foreign exchange, 10 percent is classified as compensation of employees, an income item. The remaining 90 percent of apparent receipts is classified as workers' remittances, a transfer item. The split between 10 and 90 percent is based on a survey of banking system clients conducted by the BoPS in 1999. Financial account investment transactions, such as direct investment by Albanian citizens resident abroad in land and structures, are not taken into account in estimating unidentified foreign exchange inflows.

Given the estimation of a significant intermediate residual such as unidentified inflows of foreign exchange, which potentially could include direct investment in real estate transactions, the usual net errors and omissions item might be minimized. Instead, net errors and omissions have grown modestly as a percentage of total trade. Taking a conservative approach, BoPS compilers have limited the debits in the estimation model to current account items (i.e., to imports of goods and services). The structure of the estimation model was specified in 2000; since then, detailed changes in its components have been limited.

Recommendation: Because "remittances" are an important item in the Albanian balance of payments, a new survey should be conducted to reestimate the division of unidentified inflows of foreign exchange between compensation of employees and workers' remittances. This survey could be either among banks and foreign exchange bureaus or among households, whichever the BoPS considers to be more feasible and cost-effective.

\subsection{Assessment and validation of intermediate data and statistical outputs}

\subsubsection{Intermediate results are validated against other information where applicable}

Intermediate data are validated using other sources whenever possible. Newspapers and other information agencies are monitored for news about large international transactions, such as privatization of state-owned enterprises. Survey data are checked against banking system records.

\subsubsection{Statistical discrepancies in intermediate data are assessed and investigated}

While discrepancies in intermediate data are often addressed satisfactorily, given the independent, unlinked spreadsheets used for compilation, and the manual entry of intermediate results, the current procedures are error prone. Compilation errors have occurred in the form of incorrect algebraic signs and omitted items. The linkage of spreadsheets via formulas or the introduction of a database-driven compilation system would virtually eliminate the possibility of such errors. 
Data on freight earnings are regularly assessed in relation to the value of the trade flows based on the BoPS estimation methodology.

Data on travel-related transactions are based on two data sources. A quarterly survey of 1,000 travelers is carried out by INSTAT on behalf of the BoA. This survey covers both residents and nonresident (i.e., credits and debits). The survey is used to estimate daily spending by travelers as well as their average duration of travel. However, the survey may be inadequate as a benchmark, since it covered only the busiest border crossings and omitted others. The survey expenditure data are then multiplied by the number of travelers reported by immigration authorities, the other input source.

Recommendation: During the interim before a database-driven compilation system can be introduced, the spreadsheets currently in use for intermediate compilation of different portions of the balance of payments should be linked by introduction of relevant formulas.

\subsubsection{Statistical discrepancies and other potential indicators of problems in statistical outputs are investigated}

Taking into account the estimate of "remittances," a primary residual, BoPS monitors the development in the usual errors and omissions item, which consequently relates to unrecorded or unidentified transactions arising from the income, official transfers, capital and/or financial accounts.

The BoPS has been trying to reconcile trade data with that of other trading partners, but trade with Albania is insignificant to partner countries; hence it is not shown separately in their data.

\subsection{Revision studies}

\subsubsection{Studies and analyses of revisions are carried out routinely and used internally to inform statistical processes (see also 4.3.3)}

The BoPS carefully monitors revisions of individual records. Revisions are documented as to the cause, identified by the staff member making the amendment, and signed off by a supervisor. The BoPS checks data to ensure that the revisions flow through to aggregate results. The aggregates are also compared with data for the same month as reported in the previous quarter's publication. Changes are checked to ensure they can be explained.

Staff study revision patterns with a view to improving methods. For example, the estimation of trade credit and of the freight coefficients of imports was subject to review because of the large revisions in these items.

With the near completion of the ASYCUDA, trade data revisions are becoming infrequent. In other instances, persistent errors or implausible estimates have prompted the BoPS to revise data collection or estimation procedures. 


\section{Serviceability}

\subsection{Periodicity and timeliness}

\subsubsection{Periodicity follows dissemination standards}

Balance of payments data are compiled and disseminated quarterly and annuallyperformance that meets GDDS recommendations and SDDS requirements.

\subsubsection{Timeliness follows dissemination standards}

Quarterly balance of payments data are released 65-70 days after the end of the reference quarter, meeting the SDDS requirement of 90 days. Data are delayed only in exceptional cases. For example, delays occur in data released for the concluding quarter of the calendar year, because following the end of the year, the banking system reports later than for the first three quarters.

Annual balance of payments statistics are disseminated within three-four months after the reference period, well within the GDDS recommendation of six months.

\subsection{Consistency}

\subsubsection{Statistics are consistent within the dataset}

Balance of payments statistics are internally consistent. Checks ensure that subitems are consistent with aggregate data. Annual statistics are the sum of quarterly data. The IIP is not prepared. As part of internal validation procedures, transactions are reconciled with position data that are available for particular components, such as external debt and reserve assets. The development of methods (but not the resources) to be used in compiling the IIP is included in the short-term plan for improvement.

Since 1996, the net errors and omissions item has been consistently positive (even after estimation of the remittances inflow) and occasionally large, as it apparently is again for 2005. 


\subsubsection{Statistics are consistent or reconcilable over a reasonable period of time}

Time series data are available back to 1993 (monthly and quarterly). Major changes in methodology are implemented infrequently. Revised or new methodologies are not used to revise data back beyond the current calendar year, but at the time a change in compilation practice is introduced, explanations for users are provided in the quarterly public releases and in the metadata disseminated in Albanian.

\subsubsection{Statistics are consistent or reconcilable with those obtained through other data sources and/or statistical frameworks}

Balance of payments data on trade in goods are reconciled with international merchandise trade data. The balance of payments publications show the differences of the methodology used by the balance of payments from the International Trade Statistics methodology. The adjustments are mainly for imports in transforming c.i.f. to f.o.b. valuation and allowing for smuggling.

National accounts data are produced by INSTAT; the international transactions components are based on the balance of payments data supplied by the BoPS.

Banking sector transactions in the balance of payments are reconciled with the balance sheet data used in the compilation of monetary and financial statistics.

The balance of payments components for debt are fully consistent with the corresponding external debt data because the data collection processes are coordinated.

\subsection{Revision policy and practice}

\subsubsection{Revisions follow a regular and transparent schedule}

The revisions policy for balance of payments statistics is that revisions are made to data for the current calendar year only. Errors detected are corrected for the quarter in which they occurred, within the current calendar year. Revisions are discussed with the users on request, and major revisions may be explained in table footnotes and analytical articles. The revision policy is posted on the BoA website in Albanian and English.

\subsubsection{Preliminary and/or revised data are clearly identified}

No balance of payments data are identified as preliminary. Published data are subject to revision within the current calendar year only. Revised data are noted as such.

\subsubsection{Studies and analyses of revisions are made public (see also 3.5.1)}

Brief statements explaining important revisions are provided in the annual publications of the BoA and shown in the annexes. 


\section{Accessibility}

\subsection{Data accessibility}

5.1.1 Statistics are presented in a way that facilitates proper interpretation and meaningful comparisons (layout and clarity of text, tables, and charts)

Albanian balance of payments statistics are disseminated according to the standard components of the BPM5, and with the time series published on the BoA website. The statistics are disseminated clearly, with charts and tables to facilitate analysis. Press releases and different descriptive analyses are included for the current period.

\subsubsection{Dissemination media and format are adequate}

Balance of payments statistics are available on the BoA website on a monthly basis and are also disseminated through quarterly press releases and annually in the Balance of Payments Bulletin on paper and in electronic format.

\subsubsection{Statistics are released on a preannounced schedule}

In December each year, the Public Relations Department posts on the BoA website the release schedule of balance of payments statistics for the next five calendar quarters.

\subsubsection{Statistics are made available to all users at the same time}

Quarterly balance of payments data are sent initially by e-mail and hard copy in a press release to the media and to all users who have registered on the BoA website. About a week later, the same press release and data are posted on the BoA website.

\subsubsection{Statistics not routinely disseminated are made available upon request}

The BoPS meets requests for additional information without a fee. For example, additional data or more disaggregated data on trade or other balance of payments transactions are supplied to the users to calculate their market share for particular categories.

\subsection{Metadata accessibility}

5.2.1 Documentation on concepts, scope, classifications, basis of recording, data sources, and statistical techniques is available, and differences from internationally accepted standards, guidelines, or good practices are annotated

Metadata in both Albanian and English are provided annually in the Balance of Payments Bulletin (yearbook) and in Albanian on the BoA website. The metadata also are available from the IMF's DSBB. Considering that relatively few users are interested in the details of 
statistical methodology, the BoPS considers that the level of information available is quite high.

A comprehensive document of sources and methods is published yearly in the annexes of the Balance of Payments Bulletin (yearbook). This document includes information on concepts, definitions, classifications, data sources, compilation methods, and information on surveys, including descriptive analysis and survey characteristics (response rates, survey monitoring and studies of nonsampling errors), and other survey features such as method, sample frame, and sample design and selection.

The GDDS metadata and other related descriptions are reviewed and updated annually.

\subsubsection{Levels of detail are adapted to the needs of the intended audience}

Besides publishing the short analyses, bulletins, and survey analyses, the BoPS has published a short brochure with the general information about the balance of payments. This brochure, intended for the general public, is illustrated with short examples of balance of payments transactions. The brochure is published in Albanian language only and is available in hard copy and on the BoA website.

More specialized information, such as working papers on balance of payments developments or analyses of specific items, is published on the BoA website.

\subsection{Assistance to users}

\subsubsection{Contact points for each subject field are publicized}

Prompt and knowledgeable assistance is provided. The BoPS has provided assistance with papers and theses to students studying in Albania or abroad, providing them with balance of payments data according to the administrative regulation approved by the Supervisory Council of Bank of Albania and published in the official bulletin of 2002. As intended, this regulation has facilitated and expanded understanding of the balance of payments.

All publications and the BoA website provide telephone and fax numbers and the e-mail address (public@bankofalbania.org) for the Department of European Integration and Public Relations. While the names of individuals are not supplied as contact points, the department or section that produced each document or publication is identified.

BoA personnel usually respond to e-mail enquiries within 48 hours.

Recommendation: A larger, faster server would substantially facilitate downloads from the $B o A$ website, which at times are slow. 
5.3.2 Catalogs of publications, documents, and other services, including information on any charges, are widely available

A complete list of BoA's balance of payments hard-copy publications and of similar or related information available via the Internet is included on the BoA website in Albanian and English. All publications are available free of charge in hard copy or on the Internet. 
166

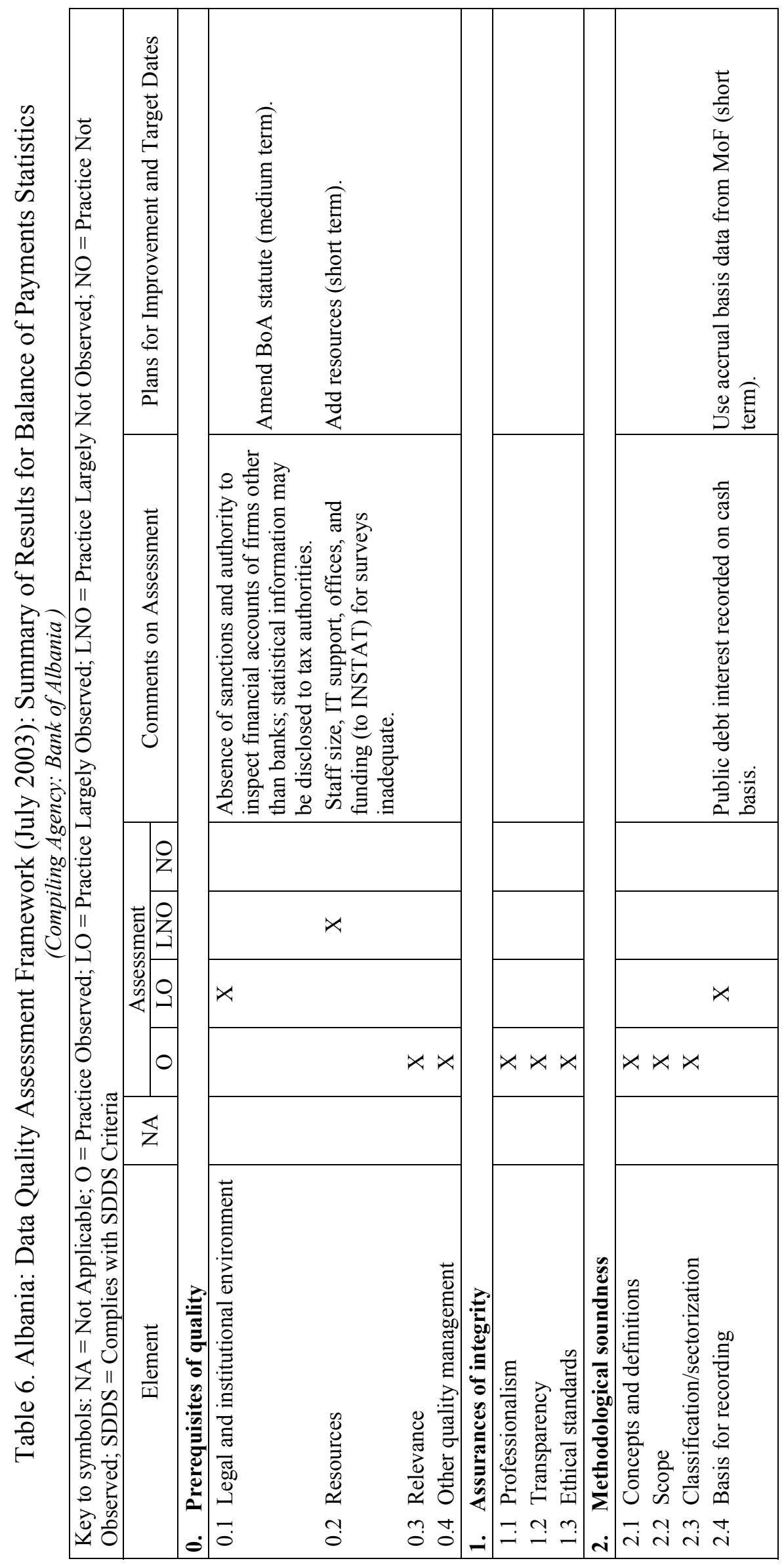


167

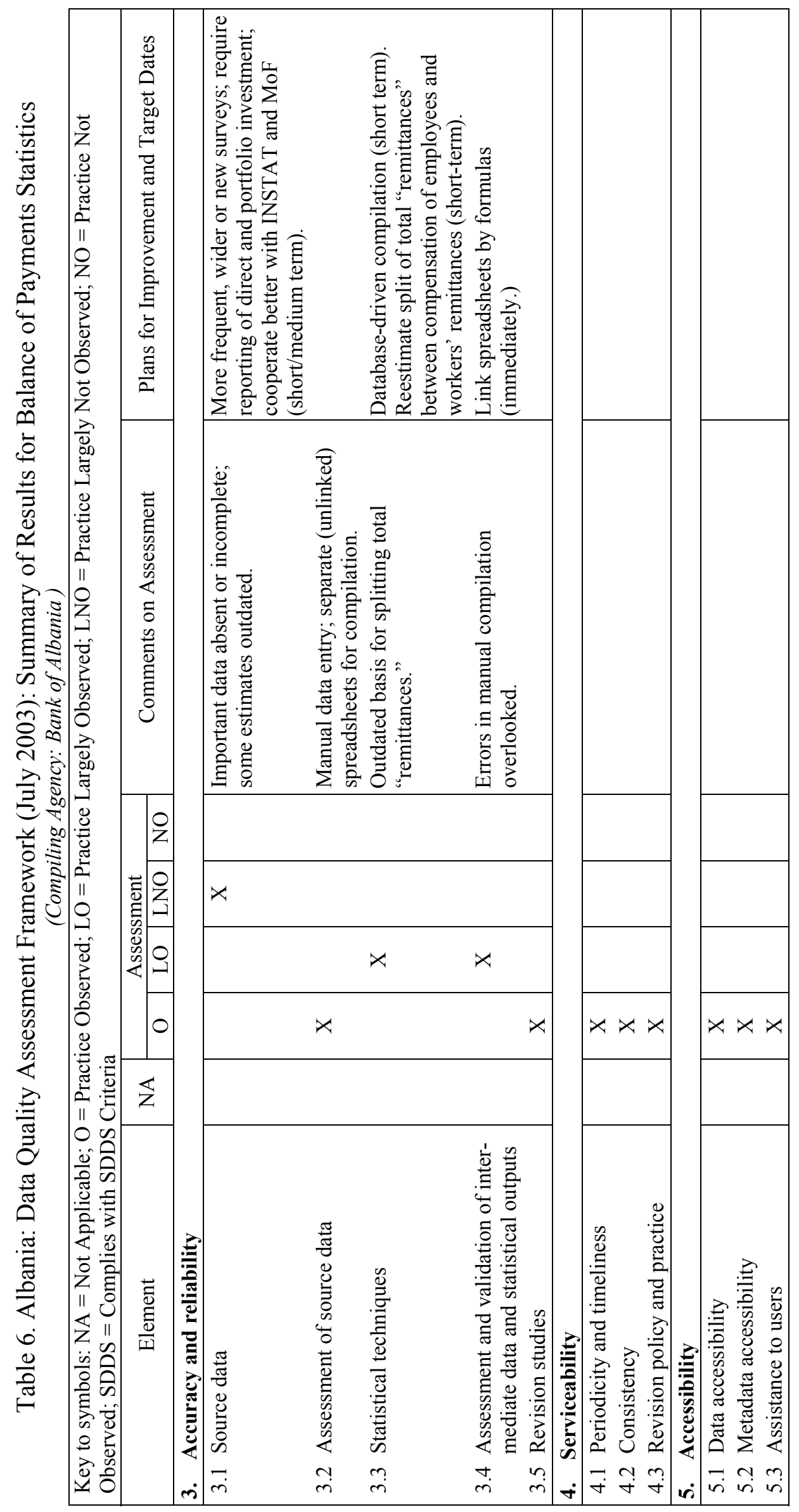




\section{Summary of the General Data Dissemination System (GDDS)}

\section{Data coverage, periodicity, and timeliness}

Dissemination of reliable, comprehensive, and timely economic, financial, and sociodemographic data is essential to the transparency of macroeconomic performance and policy. The GDDS contains specific recommendations concerning coverage, periodicity, and timeliness for comprehensive frameworks as well as for data categories and indicators.

\section{Quality}

Data quality must have a high priority. Data users must be provided with information to assess quality and quality improvements. The GDDS recommends:

- dissemination of documentation on methodology and sources used in preparing statistics; and

- $\quad$ dissemination of component detail, reconciliations with related data, and statistical frameworks that support statistical cross-checks and provide assurance of reasonableness.

\section{Integrity}

To fulfill the purpose of providing the public with information, official statistics must have the confidence of their users. In turn, confidence in the statistics ultimately becomes a matter of confidence in the objectivity and professionalism of the agency producing the statistics. Transparency of practices and procedures is a key factor in creating this confidence. The GDDS, therefore, recommends:

- dissemination of the terms and conditions under which official statistics are produced, including those relating to the confidentiality of individually identifiable information;

- $\quad$ identification of internal government access to data before release;

- $\quad$ identification of ministerial commentary on the occasion of statistical releases; and

- $\quad$ provision of information about revision and advance notice of major changes in methodology.

\section{Access to the public}

Dissemination of official statistics is an essential feature of statistics as a public good. Ready and equal access by the public are principal requirements. The GDDS recommends:

- $\quad$ dissemination of advance release calendars; and 
- $\quad$ simultaneous release to all interested parties.

\section{Plans for improvement}

The GDDS recommends that plans for improvement be developed for all areas in which shortcomings exist and that these plans be disseminated.

The GDDS also recommends that any needs for assistance be identified in the metadata. This may also be helpful for donors and technical assistance providers to prioritize their activities.

For each participating member country, the GDDS metadata provide descriptions of the dimensions listed above, together with plans for improvement and needs for assistance. This information is posted on the DSBB; participating countries are encouraged to also post the metadata on their national websites.

Source: Guide to the GDDS, March 2002: http://dsbb.imf.org 


\section{DATA QUALITY ASSESSMENT FRAMEWORK-GENERIC FRAMEWORK (JULY 2003 FRAMEWORK)}

\begin{tabular}{|c|c|c|}
\hline Quality Dimensions & Elements & Indicators \\
\hline \multirow[t]{4}{*}{$\begin{array}{l}\text { 0. Prerequisites of } \\
\text { quality }\end{array}$} & $\begin{array}{l}\text { 0.1 Legal and institutional } \\
\text { environment-The environment } \\
\text { is supportive of statistics }\end{array}$ & $\begin{array}{l}\text { 0.1.1 The responsibility for collecting, processing, } \\
\text { and disseminating the statistics is clearly specified. } \\
\text { 0.1.2 Data sharing and coordination among data- } \\
\text { producing agencies are adequate. } \\
\text { 0.1.3 Individual reporters' data are to be kept } \\
\text { confidential and used for statistical purposes only. } \\
\text { 0.1.4 Statistical reporting is ensured through legal } \\
\text { mandate and/or measures to encourage response. }\end{array}$ \\
\hline & $\begin{array}{l}\text { 0.2 Resources-Resources are } \\
\text { commensurate with needs of } \\
\text { statistical programs. }\end{array}$ & $\begin{array}{l}\text { 0.2.1 Staff, facilities, computing resources, and } \\
\text { financing are commensurate with statistical } \\
\text { programs. } \\
0.2 .2 \text { Measures to ensure efficient use of resources } \\
\text { are implemented. }\end{array}$ \\
\hline & $\begin{array}{l}\mathbf{0 . 3} \text { Relevance-Statistics cover } \\
\text { relevant information on the } \\
\text { subject field. }\end{array}$ & $\begin{array}{l}\text { 0.3.1 The relevance and practical utility of existing } \\
\text { statistics in meeting users' needs are monitored. }\end{array}$ \\
\hline & $\begin{array}{l}\text { 0.4 Other quality } \\
\text { management-Quality is a } \\
\text { cornerstone of statistical work. }\end{array}$ & $\begin{array}{l}\text { 0.4.1 Processes are in place to focus on quality. } \\
0.4 .2 \text { Processes are in place to monitor the quality of } \\
\text { the statistical program. } \\
\text { 0.4.3 Processes are in place to deal with quality } \\
\text { considerations in planning the statistical program. }\end{array}$ \\
\hline \multirow{3}{*}{$\begin{array}{l}\text { 1. Assurances of } \\
\text { integrity } \\
\text { The principle of } \\
\text { objectivity in the } \\
\text { collection, } \\
\text { processing, and } \\
\text { dissemination of } \\
\text { statistics is firmly } \\
\text { adhered to. }\end{array}$} & $\begin{array}{l}\text { 1.1 Professionalism-Statistical } \\
\text { policies and practices are } \\
\text { guided by professional } \\
\text { principles. }\end{array}$ & $\begin{array}{l}\text { 1.1.1 Statistics are produced on an impartial basis. } \\
\text { 1.1.2 Choices of sources and statistical techniques } \\
\text { as well as decisions about dissemination are } \\
\text { informed solely by statistical considerations. } \\
\text { 1.1.3 The appropriate statistical entity is entitled to } \\
\text { comment on erroneous interpretation and misuse of } \\
\text { statistics. }\end{array}$ \\
\hline & $\begin{array}{l}1.2 \text { Transparency_Statistical } \\
\text { policies and practices are } \\
\text { transparent. }\end{array}$ & $\begin{array}{l}\text { 1.2.1 The terms and conditions under which } \\
\text { statistics are collected, processed, and disseminated } \\
\text { are available to the public. } \\
\text { 1.2.2 Internal governmental access to statistics prior } \\
\text { to their release is publicly identified. } \\
\text { 1.2.3 Products of statistical agencies/units are } \\
\text { clearly identified as such. } \\
\text { 1.2.4 Advance notice is given of major changes in } \\
\text { methodology, source data, and statistical techniques. }\end{array}$ \\
\hline & $\begin{array}{l}\text { 1.3 Ethical standards-Policies } \\
\text { and practices are guided by } \\
\text { ethical standards. }\end{array}$ & $\begin{array}{l}\text { 1.3.1 Guidelines for staff behavior are in place and } \\
\text { are well known to the staff. }\end{array}$ \\
\hline
\end{tabular}




\begin{tabular}{|c|c|c|}
\hline Quality Dimensions & Elements & Indicators \\
\hline $\begin{array}{l}\text { 2. Methodological } \\
\text { soundness } \\
\text { The methodological } \\
\text { basis for the } \\
\text { statistics follows } \\
\text { internationally } \\
\text { accepted standards, } \\
\text { guidelines, or good } \\
\text { practices. }\end{array}$ & $\begin{array}{l}\text { 2.1 Concepts and definitions-- } \\
\text { Concepts and definitions used } \\
\text { are in accord with } \\
\text { internationally accepted } \\
\text { statistical frameworks. } \\
\mathbf{2 . 2} \text { Scope-The scope is in } \\
\text { accord with internationally } \\
\text { accepted standards, guidelines, } \\
\text { or good practices. } \\
\mathbf{2 . 3} \text { Classification/ } \\
\text { sectorization-Classification } \\
\text { and sectorization systems are in } \\
\text { accord with internationally } \\
\text { accepted standards, guidelines, } \\
\text { or good practices. } \\
\mathbf{2 . 4} \text { Basis for recording-Flows } \\
\text { and stocks are valued and } \\
\text { recorded according to } \\
\text { internationally accepted } \\
\text { standards, guidelines, or good } \\
\text { practices }\end{array}$ & $\begin{array}{l}\text { 2.2.1 The scope is broadly consistent with } \\
\text { internationally accepted standards, guidelines, or } \\
\text { good practices. } \\
\text { 2.3.1 Classification/sectorization systems used are } \\
\text { broadly consistent with internationally accepted } \\
\text { standards, guidelines, or good practices. }\end{array}$ \\
\hline $\begin{array}{l}\text { 3. Accuracy and } \\
\text { reliability } \\
\text { Source data and } \\
\text { statistical techniques } \\
\text { are sound and } \\
\text { statistical outputs } \\
\text { sufficiently portray } \\
\text { reality }\end{array}$ & $\begin{array}{l}\text { 3.3 Statistical techniques-- } \\
\text { Statistical techniques employed } \\
\text { conform to sound statistical } \\
\text { procedures } \\
\text { 3.4 Assessment and validation } \\
\text { of intermediate data and } \\
\text { statistical outputs- } \\
\text { Intermediate results and } \\
\text { statistical outputs are regularly } \\
\text { assessed and validated. } \\
\text { 3.5 Revision studies- } \\
\text { Revisions, as a gauge of } \\
\text { reliability, are tracked and } \\
\text { mined for the information they } \\
\text { may provide. }\end{array}$ & $\begin{array}{l}\text { 3.1.1 Source data are obtained from comprehensive } \\
\text { data collection programs that take into account } \\
\text { country-specific conditions. } \\
\text { 3.1.2 Source data reasonably approximate the } \\
\text { definitions, scope, classifications, valuation, and } \\
\text { time of recording required. } \\
\text { 3.1.3 Source data are timely. } \\
\text { 3.2.1 Source data-including censuses, sample } \\
\text { surveys, and administrative records-are routinely } \\
\text { assessed, e.g., for coverage, sample error, response } \\
\text { error, and nonsampling error; the results of the } \\
\text { assessments are monitored and made available to } \\
\text { guide statistical processes. } \\
\text { 3.3.1 Data compilation employs sound statistical } \\
\text { techniques to deal with data sources. } \\
\text { 3.3.2 Other statistical procedures (e.g., data } \\
\text { adjustments and transformations, and statistical } \\
\text { analysis) employ sound statistical techniques. } \\
\text { 3.4.1 Intermediate results are validated against other } \\
\text { information where applicable. } \\
\text { 3.4.2 Statistical discrepancies in intermediate data } \\
\text { are assessed and investigated. } \\
\text { 3.4.3 Statistical discrepancies and other potential } \\
\text { indicators or problems in statistical outputs are } \\
\text { investigated. } \\
\text { 3.5.1 Studies and analyses of revisions are carried } \\
\text { out routinely and used internally to inform statistical } \\
\text { processes (see also } 4.3 .3 \text { ). }\end{array}$ \\
\hline
\end{tabular}




\begin{tabular}{|c|c|c|}
\hline Quality Dimensions & Elements & Indicators \\
\hline $\begin{array}{l}\text { 4. Serviceability } \\
\text { Statistics, with } \\
\text { adequate periodicity } \\
\text { and timeliness, are } \\
\text { consistent and } \\
\text { follow a predictable } \\
\text { revisions policy. }\end{array}$ & $\begin{array}{l}\text { 4.1 Periodicity and } \\
\text { timeliness-Periodicity and } \\
\text { timeliness follow internationally } \\
\text { accepted dissemination } \\
\text { standards. } \\
4.2 \text { Consistency_-Statistics are } \\
\text { consistent within the dataset, } \\
\text { over time, and with major } \\
\text { datasets. } \\
\text { 4.3 Revision policy and } \\
\text { practice-Data revisions follow } \\
\text { a regular and publicized } \\
\text { procedure. }\end{array}$ & $\begin{array}{l}\text { 4.2.1 Statistics are consistent within the dataset. } \\
\text { 4.2.2 Statistics are consistent or reconcilable over a } \\
\text { reasonable period of time. } \\
\text { 4.2.3 Statistics are consistent or reconcilable with } \\
\text { those obtained through other data sources and/or } \\
\text { statistical frameworks. } \\
\text { 4.3.1 Revisions follow a regular and transparent } \\
\text { schedule. } \\
\text { 4.3.2 Preliminary and/or revised data are clearly } \\
\text { identified. } \\
\text { 4.3.3 Studies and analyses of revisions are made } \\
\text { public (see also 3.5.1). }\end{array}$ \\
\hline $\begin{array}{l}\text { 5. Accessibility } \\
\text { Data and metadata } \\
\text { are easily available } \\
\text { and assistance to } \\
\text { users is adequate. }\end{array}$ & $\begin{array}{l}\text { 5.1 Data accessibility- } \\
\text { Statistics are presented in a } \\
\text { clear and understandable } \\
\text { manner, forms of dissemination } \\
\text { are adequate, and statistics are } \\
\text { made available on an impartial } \\
\text { basis. } \\
\\
\text { 5.2 Metadata accessibility- } \\
\text { Up-to-date and pertinent } \\
\text { metadata are made available. }\end{array}$ & $\begin{array}{l}\text { 5.1.1 Statistics are presented in a way that facilitates } \\
\text { proper interpretation and meaningful comparisons } \\
\text { (layout and clarity of text, tables, and charts). } \\
\text { 5.1.2 Dissemination media and format are adequate. } \\
\text { 5.1.3 Statistics are released on a preannounced } \\
\text { schedule. } \\
\text { 5.1.4 Statistics are made available to all users at the } \\
\text { same time. } \\
\text { 5.1.5 Statistics not routinely disseminated are made } \\
\text { available upon request. } \\
\text { 5.2.1 Documentation on concepts, scope, } \\
\text { classifications, basis of recording, data sources, and } \\
\text { statistical techniques is available, and differences } \\
\text { from internationally accepted standards, guidelines, } \\
\text { or good practices are annotated. } \\
\text { 5.2.2 Levels of detail are adapted to the needs of the } \\
\text { intended audience. } \\
\text { 5.3.1 Contact points for each subject field are } \\
\text { publicized. } \\
\text { 5.3.2 Catalogs of publications, documents, and other } \\
\text { services, including information on any charges, are } \\
\text { widely available. }\end{array}$ \\
\hline
\end{tabular}




\section{Users' Survey}

\section{Summary of results of survey of data users}

With the assistance of the authorities and as a complement to the IMF staff's own assessment of the quality of Albania's macroeconomic statistics, the mission that visited Tirana during March 8-22, 2006 conducted an informal survey of users of macroeconomic statistics. ${ }^{33}$ The survey questionnaire was sent to ministries and state agencies, banks, embassies and international organizations, and the private sector (universities, researchers, media, and enterprises). The questionnaire was completed by 24 out of a sample of more than 100 users to whom it was sent. The survey asked users to evaluate six specific aspects of national accounts, prices, government finance, monetary, and balance of payments statistics - namely (1) coverage and detail; (2) periodicity and timeliness; (3) data release and revisions; and (4) accessibility. In addition, the users were asked to provide an overall assessment. A follow-up meeting was conducted and was attended by eight users.

The following is a summary of the survey results and additional comments provided by users at the follow-up meeting.

\section{Coverage and detail}

Users were broadly satisfied with the coverage of monetary, prices, and balance of payments statistics. Users were least satisfied with national accounts statistics, assigning those the lowest relative rating and monetary statistics the highest. As for the level of detail provided, the national accounts statistics again received the lowest relative rating, and monetary statistics the highest.

\section{Periodicity and timeliness}

Users were somewhat satisfied with the periodicity of the price indices and monetary and balance of payments statistics, and less satisfied with national accounts statistics. Users were dissatisfied with the timeliness of national accounts and balance of payments statistics.

\section{Data release and revisions}

A significant proportion of users were not aware that advance release calendars are produced by all the agencies. There was also a strong feeling that statistics are not always released on the dates specified in the advance release calendars. This was particularly so for the national accounts, and only for the price indices did more than 50 percent of users feel that release dates were met. At the meeting with users, concern was expressed about inconsistent values for GDP being published by different agencies. It was not known if this was due to timing

${ }^{33}$ The survey questionnaires were sent through the IMF Resident Representative in Tirana. 
differences in picking up revisions or if there was confusion between actual values and forecasts.

\section{Accessibility}

Users were most satisfied with the accessibility of the monetary statistics, and least satisfied for the national accounts. For price indices and monetary statistics, a significant majority of users were satisfied with the information pertaining to official statistics, such as explanatory notes, methodological descriptions, references concerning concepts, classifications, and statistical practices. At the meeting with users, it was suggested that the INSTAT, MoF, and BoA be more active in promoting users' awareness of the availability of statistics. Users felt that seminars for users were a very good idea but that some of these seminars that have taken place in the past were not perceived to have been successful. Users at the meeting praised the BoA's website and were generally satisfied with the assistance provided to them by all three data-producing agencies.

\section{Overall assessment of data quality}

Users were asked to rank the overall quality of official statistics on a scale of one to five, with one rated as poor and five as excellent. On this scale, monetary statistics was rated the highest, followed by prices, balance of payments statistics, and government finance statistics. National accounts was rated the lowest. 